\title{
Movement Through the Marginalised: \\ An Urban Landscape Investigation
}

By

Frederick Jackson Bensemann

A 120-point thesis

submitted to the Victoria University of Wellington

in partial fulfiilment of the requirements for the

degree of Masters of Landscape Architecture(Professional)

Victoria University of Wellington

School of Architecture

2021 


\section{Movement Through the Marginalised: An Urban Landscape Investigation}

By

Frederick Jackson Bensemann

A 120-point thesis

submitted to the Victoria University of Wellington

in partial fulfiilment of the requirements for the

degree of Masters of Landscape Architecture(Professional)

Victoria University of Wellington

School of Architecture

2019 


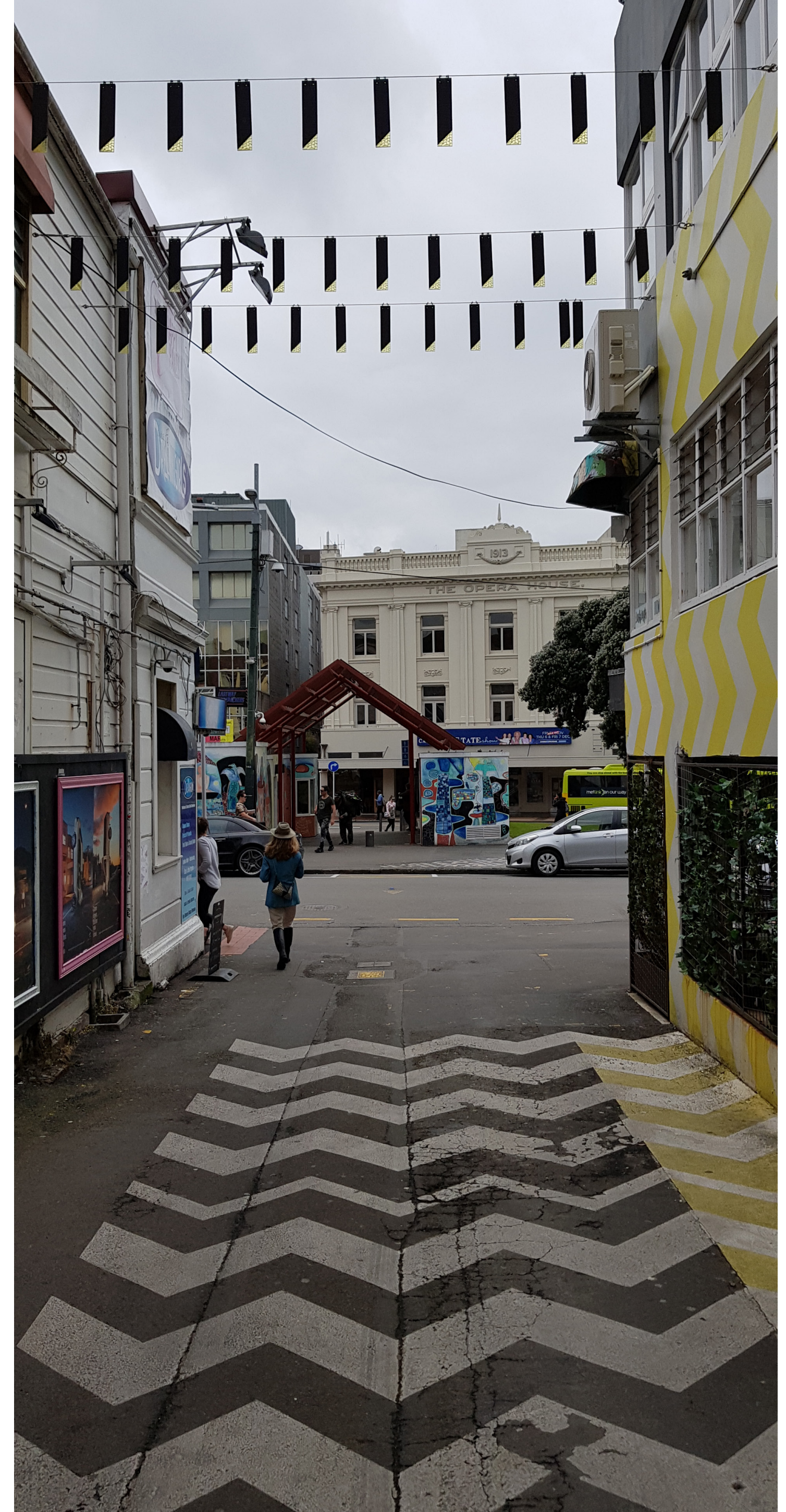




\section{Abstract}

In Western democratic society, urban public space has always been dominated by the Mainstream user. The Marginalised, to being periodically shifted from one area to another through prevailing processes that gentrify and regulate space. These habitual processes directly and indirectly manage civic space eroding particular character evolved from Marginalised occupation and expression, and in doing so, urban space caters to the needs and wants of the Mainstream.

This project investigates such a situation yet with such habits reversed. Through the landscape design of urban space the project asks can we design urban space to accommodate the socio-spatial needs of the Marginalised whilst at the same time, support Mainstream users?

The investigation situates its research in Te Aro Park, a public urban space in Wellington City occupied predominantly by the Marginalised. From the homeless to the eccentric, the drug addict to the gang member, the space is often a considered a black spot avoided or uncomfortably and rapidly moved through by the Mainstream user. With a social hierarchy that has been flipped on its head the space exudes the diverse nature of Wellington with murals and public artwork that represent the Marginalised groups including local Iwi.

This project aims to use landscape architecture design to critically assess, seek and develop potentials for harmony of urban spaces exhibiting spatial and social conflicts between Marginalised and Mainstream citizens. It is an attempt through landscape architecture technique, to destabilize the binary between Mainstream and marginal, and therefore engender conditions for truly diverse urban spaces. In doing so the research discovers how designers can approach public space design problems while opposing the forces of displacement. The research additionally contributes an understanding of the underpinnings of trying to introduce new actors without displacement of the existing and more vulnerable actors. 


\section{Dedication}

To my Mum, Dad and Sister 


\section{Acknowledgments}

I would like to acknowledge Hannah Hopewell for her unwaivering support over the years and especially as my supervisor for the final year 


\section{Contents}

Abstract IV

Dedication $\quad \mathrm{VI}$

Acknowledgments $\quad$ VIII

$\begin{array}{lll}\text { Chapter } 1 \text { Introduction } & 1\end{array}$

1.1 Background 2

1.2 Scope 4

$\begin{array}{lll}1.3 & \text { Research Question } & 7\end{array}$

1.4 Research Proposition 8

$\begin{array}{lll}1.5 & \text { Aims and Objectives } & 11\end{array}$

1.6 Research Methodology 12

$\begin{array}{ll}\text { Chapter } 2 \text { Literature Review } & 21\end{array}$

2.1 Introduction 23

2.2 The city as a Commons 25

2.3 Emancipation with Public Convenience \& Public 27 Convenience Precedents

2.4 Tracing Occupation 29

$\begin{array}{ll}\text { Chapter } 3 \text { Site } & 30\end{array}$

3.1 Introduction 32

3.2 Social and Cultural Environment 34

3.3 Physical Environment 38

Chapter 4 Public Convenience Lead Design Research 40

4.1 Introduction 42

4.2 Placement and Form of Public Convenience 44

4.3 Replacing the Wall 48

4.4 Initial Topography Investigation in Section 50

4.5 Diluting The Threshold 52

4.6 Concept and Reflection 54 
$\begin{array}{lll}5.1 & 59\end{array}$

$\begin{array}{lll}\text { 5.2 Topography in Abstract } & 60\end{array}$

5.3 Modeling Topographic Combinations 62

5.4 Re Introducing the Public Convenience 66

$\begin{array}{lll}\text { 5.5 The Wall and affect } & 68\end{array}$

5.6 Aesthetic Continuity Testing 72

$\begin{array}{lll}\text { 5.7 Discovery Through Concept } & 76\end{array}$

$\begin{array}{ll}\text { 5.8 Concept and Reflection } & 80\end{array}$

Chapter 6 Critical Reflection and Conclusion 83

6.1 Critical Reflection $\quad 85$

$\begin{array}{lll}6.2 & \text { Conclusion } & 89\end{array}$

$\begin{array}{ll}\text { Works Cited } & 91\end{array}$

$\begin{array}{ll}\text { Figure List } & 93\end{array}$

Bibliography 95 


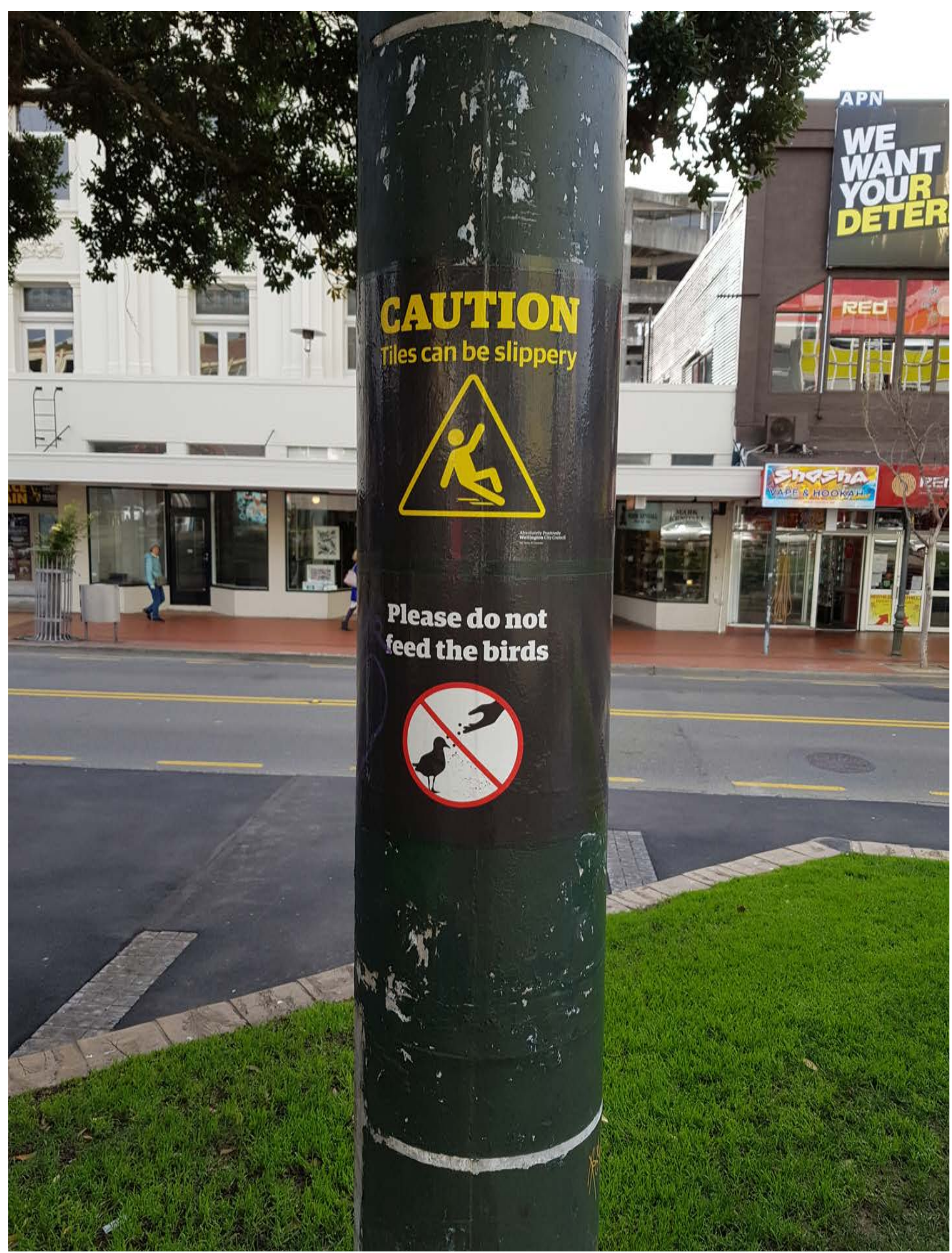

Chapter 1

\section{Introduction}




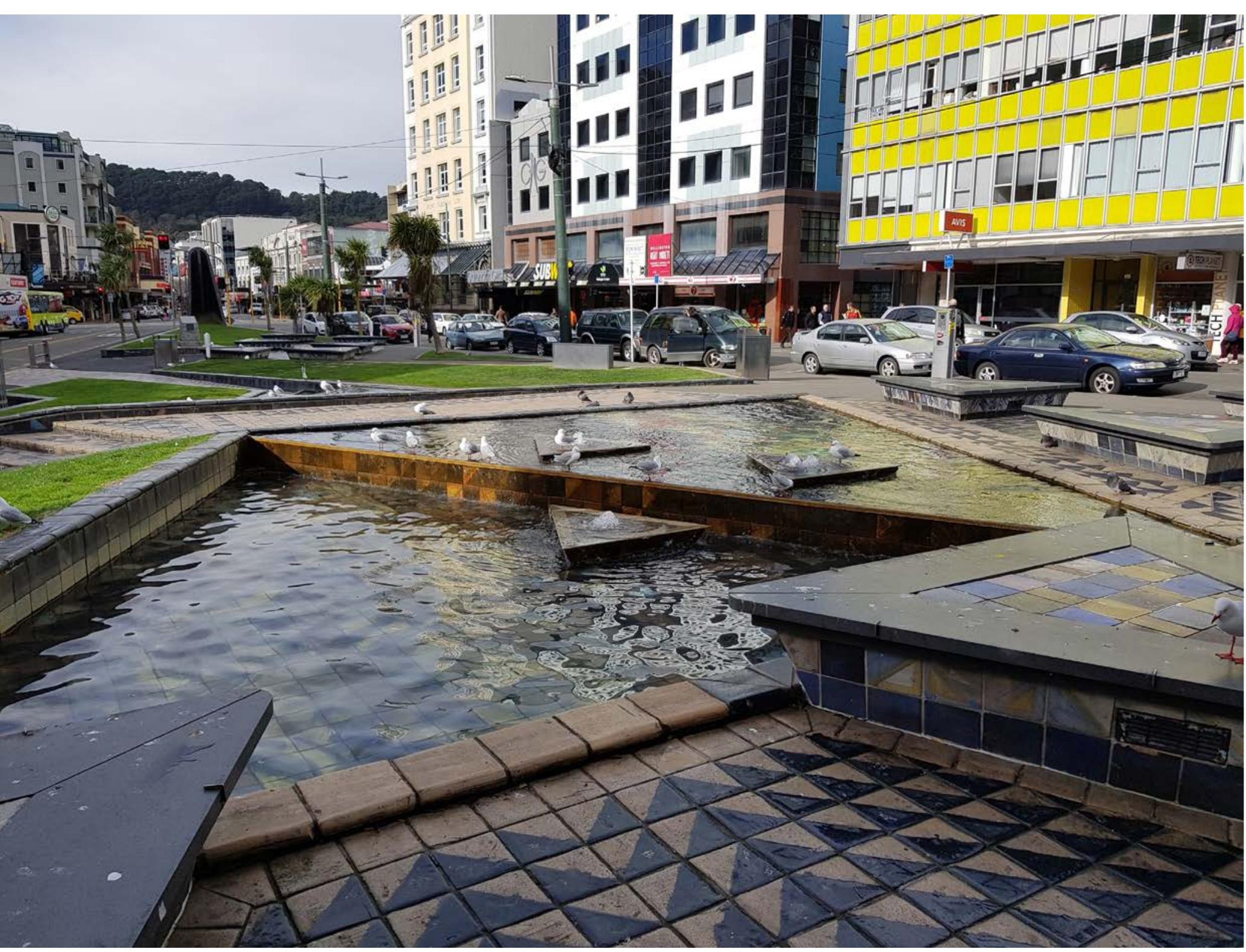

Fig. 1.02. Te Aro Park. Shona Ripira Davies Tiled Artwork. Courtney Place in the background. 


\subsection{Background}

By their very definitions, people of the Mainstream dominate the city environments while people of the Marginalised are constantly dispersed from public space and public view. The current mechanism for dealing with congregations of the Marginalised is to indirectly enact the process of gentrification or directly through authoritative means or via authoritative regulation of activity. This project explores whether we can design to introduce the Mainstream to a public urban space of Marginalised occupation without dictating, explicitly or implicitly how either cohort may use the space. For this research by design we are using Te Aro Park in Wellington as a case-study site. In this way the research is an attempt, through public space design and landscape architecture technique, to destabilize the binary between Mainstream and marginal, and therefore engender conditions for truly diverse urban spaces.

Stavros Stavrides (2016) describes the urban environment as an archipelago of enclaves, each with its own local character defined by users who occupy the space most regularly. With this sense of occupation comes certain expectations of behavior that add colour and character to a city that is singular, unique and irreplaceable. However, varying degrees of spatially enacted conflict inevitably arise between the Mainstream and the Marginalised cohorts of society. Whilst the character of any space within an urban environment is constantly in flux, there is often an imbalance between these two generalized cohorts. This imbalance represents a subtle segregation of societies cohorts and over time, and at a larger scale in society this imbalance can be a catalyst for less empathy, social divide and disparate establishment of the insiders and the outsiders. I question whether landscape architecture techniques of mapping paired with iterative testing of design components of significance may act as a catalyst for re-balance and subsequent harmony in the space of Aro Park.

Within the public space of Te Aro, Wellington, Marginalised groups evidence their continuous process of staking on space with behaviors under the umbrella of defacement and loitering. These behaviors if regularly practiced can re-purpose the specific area of the park, making " outsiders" less likely to participate in other behavior. Te Aro Park has become known to locals as a hot-spots of uncomfortableness or perceived lack of safety due to these gatherings. In responding to these concerns city authorities and their designers normally incite processes of gentrification and/or and wholesale redesign that inevitably normatively result in the Marginalised moving on to another location. Cities also frequently enforce restrictions on certain activities with the aim of standardizing the publics behavior. These approaches, this research asserts, leads to a reduction of diversity, homogeneity of experience and a loss of local character in cities. While on the other hand, a lack of action by authorities can stall inclusive transformation and perpetuate 'black spots' in a cities urban fabric. These black spots catalyze further segregation and it is the catalyzing agents that I wish to use in order to reaffirm the potential of diversity in public space. 
Fig. 1.03. Te Aro Park. Shona Ripira Davies Tiled Artwork With the 'Bow' Prominent. Taken from Courtney Place.

Manners Street splitting to the right.

Dixon Street Splitting to the left.

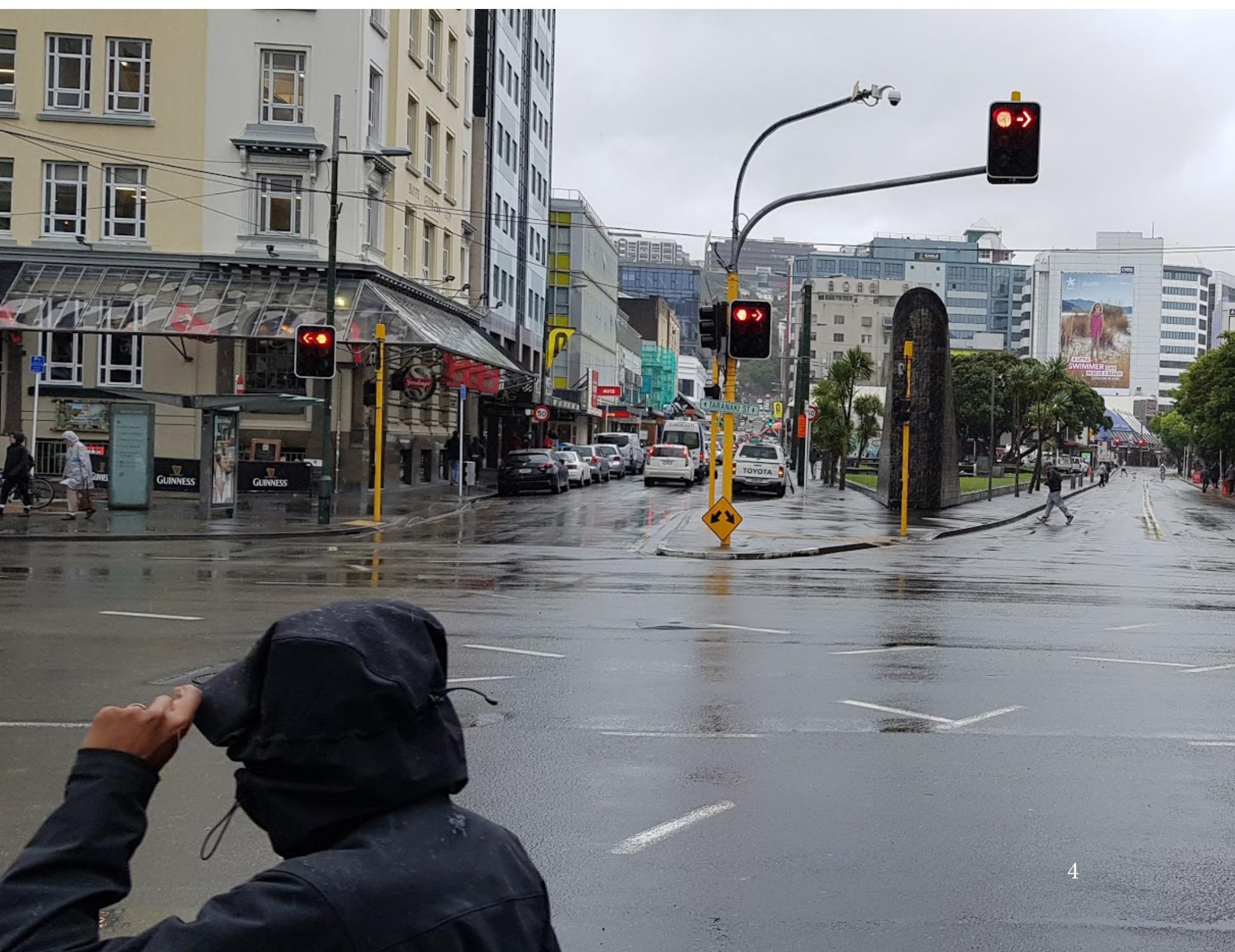




\subsection{Scope}

This design-led research suggests that subtle and restrained landscape design augmentations may offer a catalytic solution to this described tension in public space. It investigates how design can support public spaces to issue a sense of freedom and ownership for both the Marginalised and the Mainstream. It aims to create safe and coherent spaces that support the prevailing character the Marginalised exert on public space.

Using mapping and photographic studies as research tools, the project identified core components and their effects at work in Te Aro Park. Public Convenience design, subtle topographic shifts, aesthetic continuity, clear sight-lines and wall systems are explored through iterative design research and contributed collectively to creating spatial diversity, exposure between cohorts and inclusivity. The project undertakes a series of design tests critically assessed against prescribed criteria. This resulted in restrained design outcomes that maintained features that allowed for Marginalised occupation whilst also accommodating for the everyday walker, or who I most generally deem as the Mainstream. It was found throughout the iterative design process that subtle augmentation of existing urban elements can re-balance a site, installing freedoms for all users without exclusion or loss of original character. In this way these design techniques demonstrate how landscape architecture can participate in a restructuring and thus assertion of the commons in the urban landscape of cities.

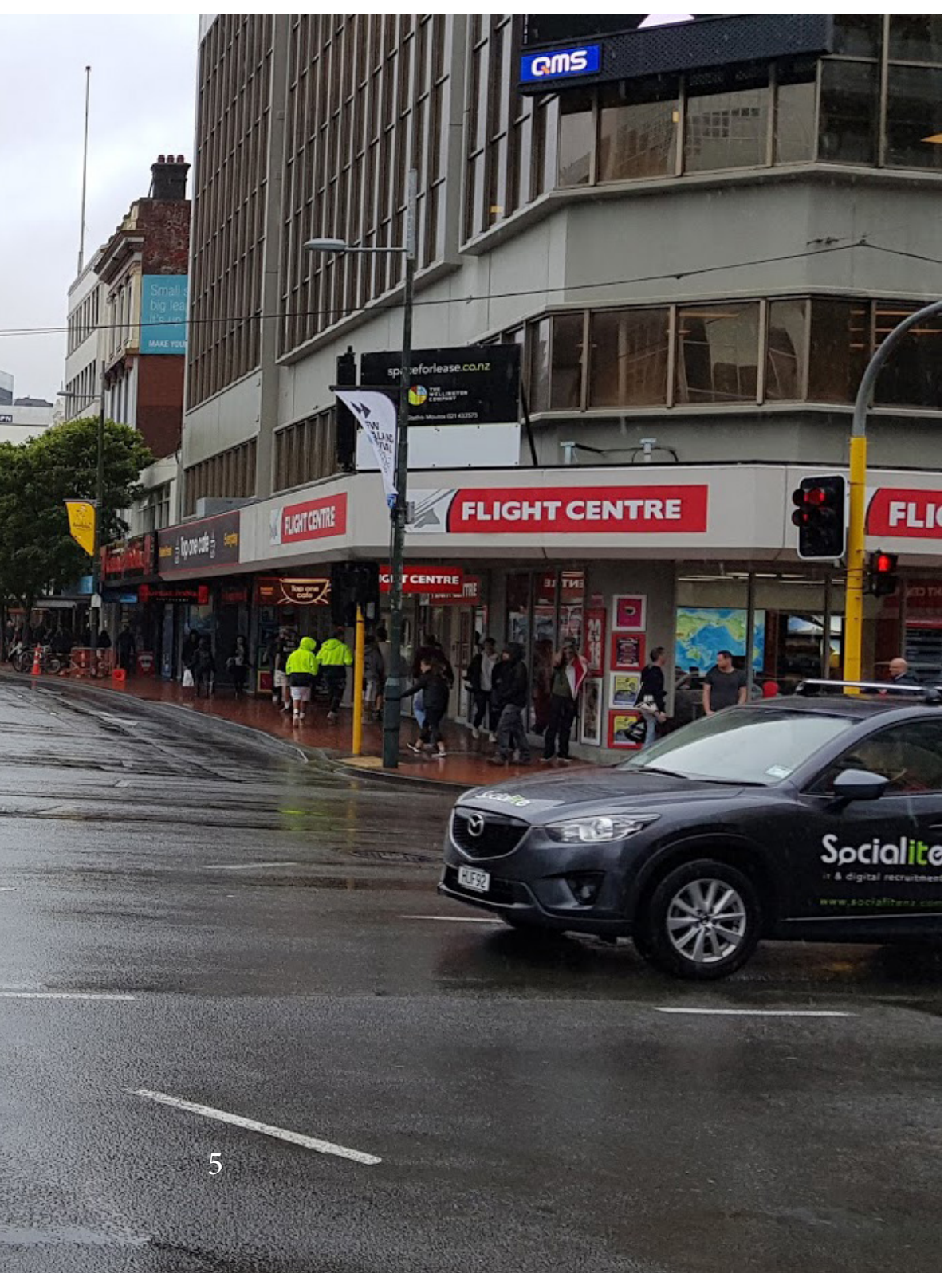




\subsection{Research Question}

How can landscape architecture techniques be used to design public urban Space to accommodate the socio-spatial needs of the Marginalised, whilst at the same time, support Mainstream users? 


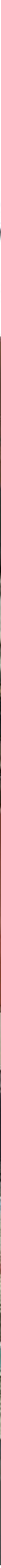




\subsection{Research Proposition}

This design-led research suggests that subtle and restrained landscape design augmentations may alleviate this tension in public space. This is in contrast to a complete redesign, or reinvention of a space. I want to resist wholesale redesign as I believe that would dictate too firmly what activities could take place on site and lose the potential for commoning*1. Restrained augmentation relies on using what is available on site physically, as well as acknowledging the intricacies of the social constructs and behaviors that exist on site. It investigates how design can support public spaces to issue a sense of freedom and ownership for both the Marginalised and the Mainstream. The research aims to create safe and coherent spaces that support the prevailing character the Marginalised exert on public space. This research is therefore an attempt to destabilize the binary of Mainstream and Marginalised through the space of the city.

Fig. 1.04. The Oaks Building Adorned with DIY decoration. An Example of the act of Defacement in the Commons.

*1 Commoning, Verb/ Gerund.

I will be using the word commoning throughout this work to describe the action of local users of a site in creating a shared spatial resource(The Commons). This includes unique and ever changing social hierarchies not dictated by the state or local council (public space) or by private enterprise (private space) 


\subsection{Aims and Objectives}

This project aims to use landscape architecture design to critically assess, seek and develop potentials for harmony of urban spaces exhibiting spatial and social conflicts between Marginalised and Mainstream citizens.

It sets these aims out with the following objectives:

1. To investigate slope and topography as means to create spatial transition and congregation space.

2. Investigate the role and the risks of public conveniences and seek alternative relationships in public landscapes.

3. To use design to develop visual and textural highly legible pathways through public landscape that improve walk-ability. 
Petrescu Mapping

Phase 1

Mapping

Over Scales

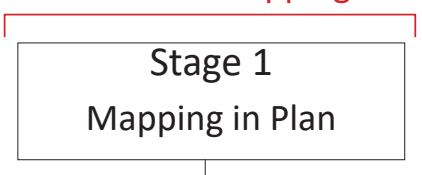

\section{Stage 2 \\ Perspective Study}

Petrescu Mapping Adaptation
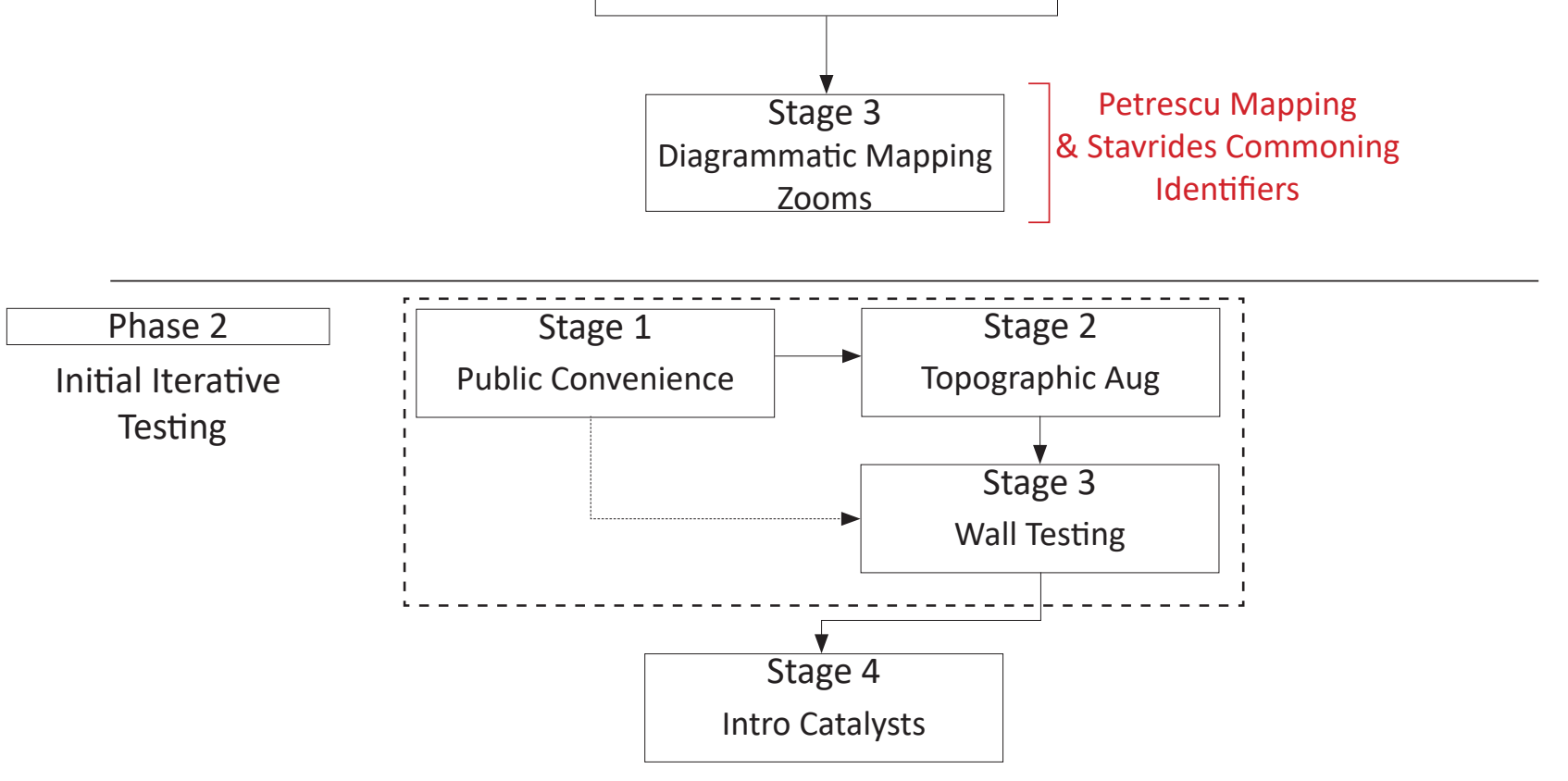

Phase 3

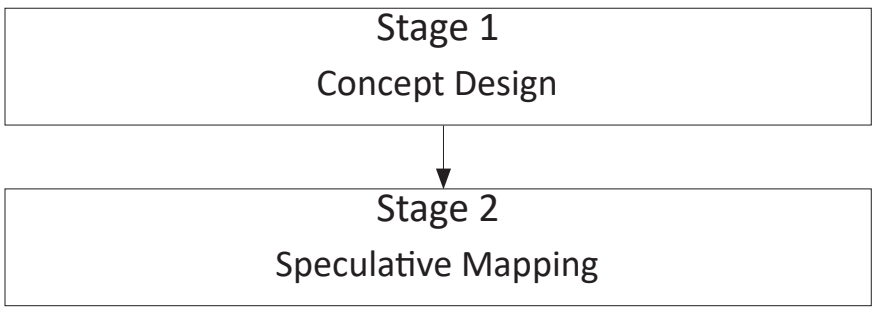

Petrescu Mapping

Initial Component Combination Testing

Speculative Mapping

\section{Phase 4}

Physical Modelling

\& Testing

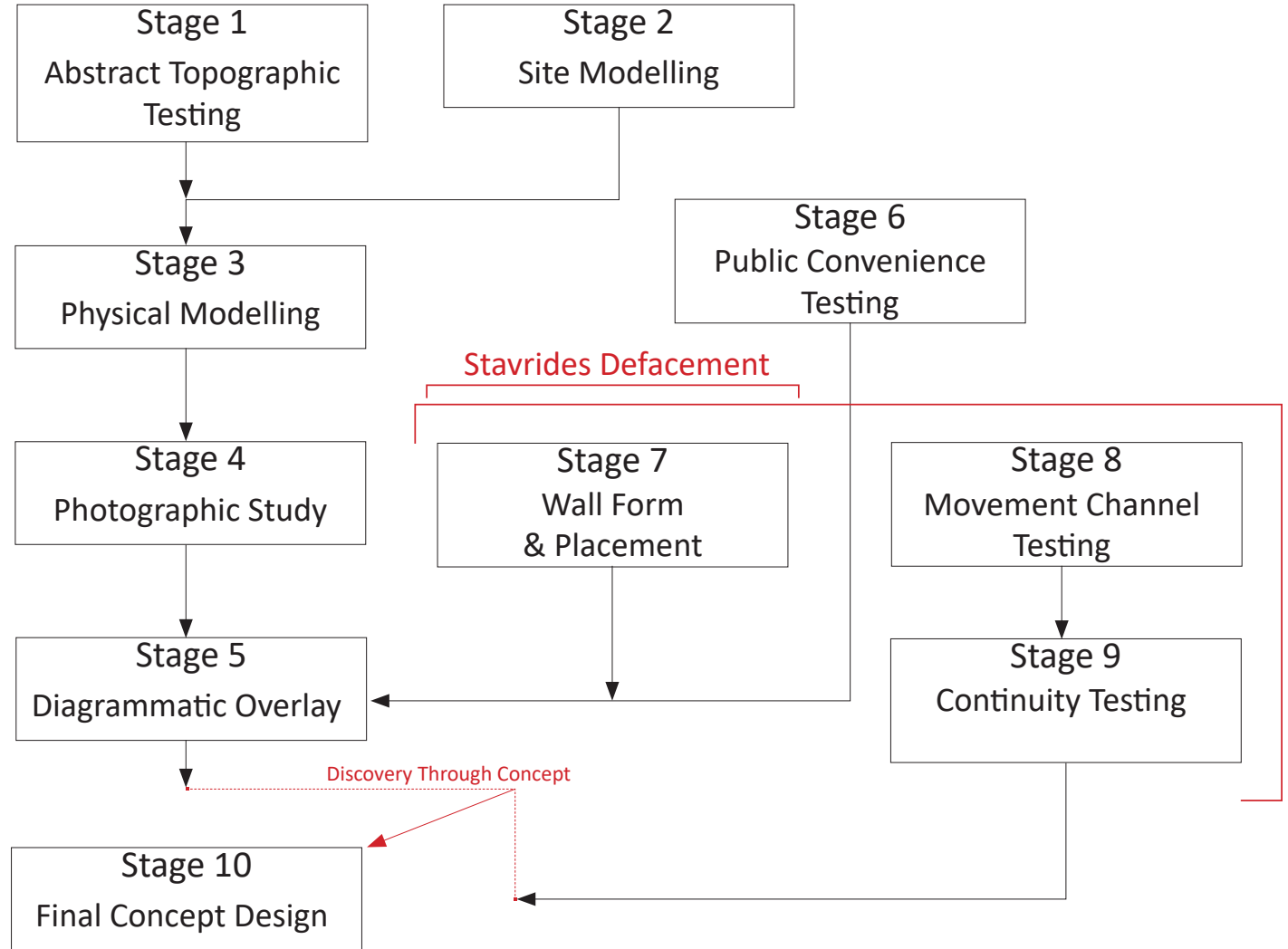




\subsection{Research Methodology}

To approach the research question the study in the first instance grounded its exploration within the site itself. The fieldwork involved significant observation across different times of the day and night of the behaviors of various Marginalised groups, along with the habits of walkers of the Mainstream; historical analysis of the change in the sites land use and form was thus placed on the periphery of the investigation. This motivation was centered around attending to what people did in the space, how they moved, congregated and dispersed either singularly or as a group.

This moved the design testing away from traditional urban form based methods and opened the space for me to innovate a method to suit the problem. Here I developed a method of mapping across different scales coupled with photographic and perspective studies. These techniques informed a restrained design approach by way of iterative testing and proposed subtle shifts to the core components existing on site. This method was initiated by frequent and intimate observation of prevailing site movements and activities. Mapping at scales coupled with perspective studies were used to inform restrained iterative testing of identified core components existing on site to establish design outcomes.

To support this approach my exploration into urban discourse focused upon the commons and approaches to being in urban space to help me build an understanding and rationale for the kinds of interactions I was observing in fieldwork. This will be explored in the Literature Review section below.

I also identified design precedents to expand my understanding in what spatial ways does public space offer the kinds of binaristic breakdown I was looking to enact. It was difficult to locate examples however my learnings are discussed below. 


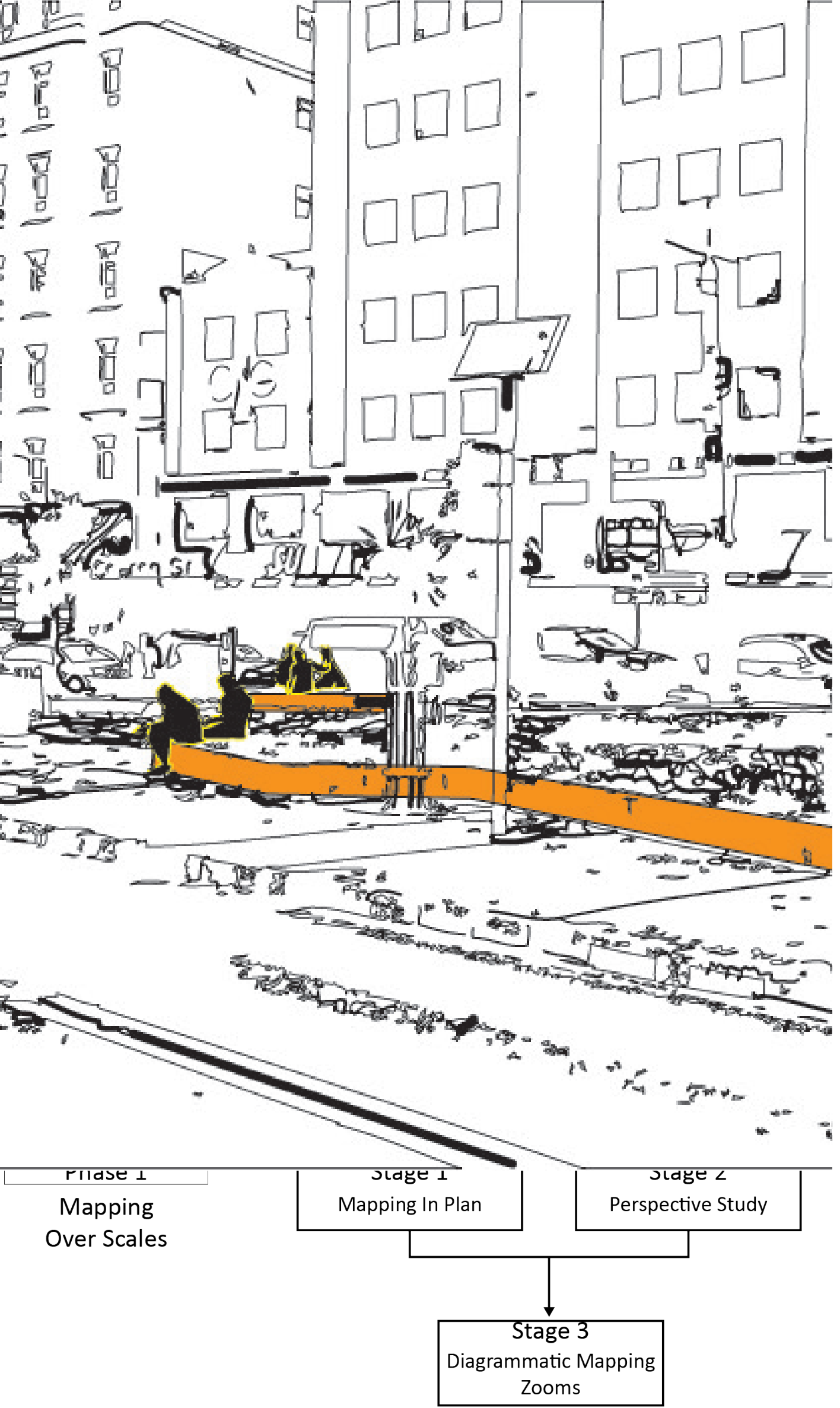

Fig. 1.06. (Left) An Example of the Perspective Study. Irrelevant Details Stripped back and affordances highlighted

Fig. 1.07. (Below) Phase 1 of Method Diagram

\section{Phase 2}

Initial Iterative

Testing
Stage 1

Public Convenience

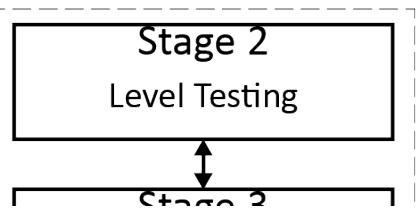


What follows is a diagrammatic representation illustrating how this research evolved a design process. Following the diagram I explain the different stages and the task undertaken therein.

Phase 1: Attempting to Map the macro and micro movements through the urban public realm.

Stage 1: Mapping over scales in plan.

Using Doina Petrescu's "Walkscapes" (2007) to map over time traces of movement and behaviors related to the site.

Using the highest quality GIS satellite images at scales A city Scale, A Local Area Scale (Suburb), A Site Scale and tracing paper.

City Scale tracing, maps the macro flows of people as well as the congregation of the Marginalised around the city. This mapping includes public transport and road function related to the site. I was interested in how people were introduced to the site and what their vectors were. This mapping also takes note of the simple hierarchies existing at different points around the city.

Local Area tracing, maps the intermediate flows of pedestrian traffic, congregation and hierarchies within upper Courtney Place, Cuba Street and Lane segments (Eva Street, Opera House Lane, Egmont Street and Lukes lane). This was an investigation into when and how users move through site, their vectors and the effect of major roads (Dixon, Manners and Taranaki) have on the area, and whether the road being dominated by private or public transport makes a difference.

Site Scale tracing maps the accumulation of different people in different areas. Here I am Interested in what physical features can be identified that may attract certain types of user and what features can be highlighted to have an encouraging effect for either remaining stationary or moving through the site. Identification of obstacles to movement are also key here.

Stage 2: Perspective Study and Bridge to Zoom Investigations of site Influenced by and made to compliment Petrescu (2007) mapping techniques this Photo-study is identifying simple movements and accumulation of users related to physical features of the site. These techniques are used to bridge the mapping gap between Site scale mapping and Phase 3 mapping at component scale.

Tracing a photograph of interest in illustrator and stripping back layers to look at combinations of features. E.g. Ground Plane materiality vs vertical structures vs movement of users. This technique strips back an image to the bare components of interest and produces a primarily diagrammatic/symbolic output for analysis.

Using similar black and white photographs within site to identify details, layered onto the physical objects. This study will maintain the original photograph

Stage 3: Mapping components in Plan and Section (Diagrammatic) The components identified in stage 1 and 2 can be further broken down in terms of their influence and potentials on user behavior within site. Stavros Stavrides (2016) the City as a Commons can guide some of this mapping to establish moments and locations where defacement or threshold creation signal entry into an enclave. In regards to Public Convenience assemblage as a thoroughfare as a well for protection of proximal commoning assemblage. Removing components features/separating them/moving them to speculate as to what might happen to movement and congregation patterns. Mapping subtle level changes on the site and what they currently afford/how they relate to movement, congregation and hierarchy In the interest of introduction to site. Mapping the bus stop positioning and relationship to the site. Main routes and their relation to site. Secondary lane-ways and the effect site has on their connection/disconnect. 
Phase 2: Initial Iterative Testing

Stage 1: Breaking apart functions of Public Convenience.

Iterative testing of placement of Public Convenience on site with similar core functions including capacity.

Iterative testing of form of Public Convenience while maintaining capacity

Perspective overlay of proposed form and placement for speculation and diagrammatic analysis

Speculate function for improved movement and ergonomics of position and form

Stage 2: Testing the connection over levels in section across the space (2D Elevation)

Section tests using the 1 meter drop using only fill.

Section tests using the 1 meter drop using only cut.

Exaggerated tests using a 2 meter variance using only fill.

Exaggerated tests using a 2 meter variance using only cut.

Speculate on connections between users at different levels highlighting which part of the section share the greatest connection.

Stage 3: Testing the affect of different wall combinations integrated into level testing and Public Convenience placement/form. These are to be used for separation and defacement on the site (this is a remnant from the peripheral functions of the now relocated Public Convenience) Subtle wall placement adjustment in plan (for now we want to explore the affect of the wall remaining where the Public Convenience once stood)

Height changes in section related to views across park, Public Convenience and channeling through the site.

Stage 4: in plan mapping road networks and pedestrian networks at Neighborhood scale to see what can be adjusted around the site to better connect the site to the surrounding streams of movement as well as discovering how the site can better accommodate these streams of movement through it between key points.

Phase 3: Initial Concept combination testing

Combine appropriate component iterations that fit overall criteria as well as criteria for individual component testing.

Stage 1: Perspective mapping in the fashion of stage 1: Phase 2. Layering of perspective and diagrammatic analysis of elements related to intended function

\{Review and FeedBack\}

Stage 2

Speculative Mapping

\section{Phase 4 \\ 'hsyical Modelling \& Testing}

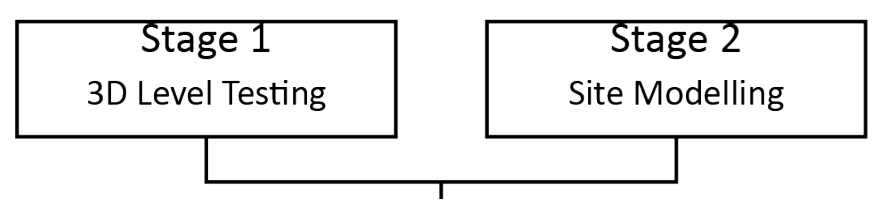

Fig. 1.10.(Above) Phase 3 of Method Diagram. 


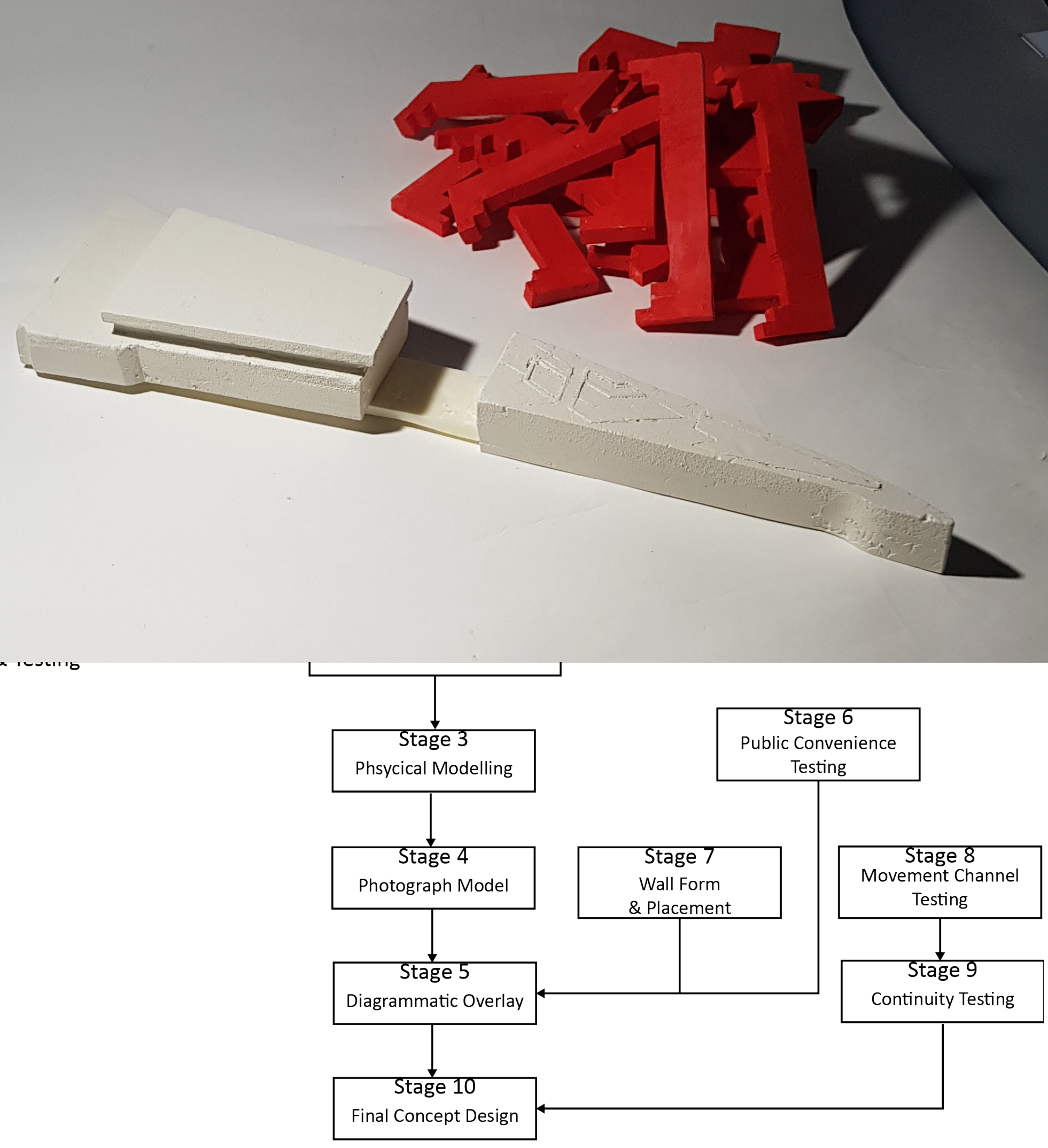


Phase 4: Physical Modeling.

Stage 1: Revisiting level iterations in 3 dimensions. How can the 2 dimensional level testing in section be brought into 3 dimensions and how can they be combined on site to compliment each other to match overall criteria for the site.

Create perspectives from the 2 dimensional level iterations in the abstract (outside of site context) examining how these 3D sections function in the abstract.

Stage 2: Create 1:1 Scale Rhino model of site.

Stage 3: Bring 3D sections into site model, Scale and CNC router components.

Using a physical model of the site section testing can be inspected from several angles at once. A fluid and natural inspection into combinations of section testing.

Cutting down sanding and painting scale model provided time to appreciate the subtle differences in each iteration.

Stage 4: Photograph Model

The flexibility of photographing a model.

Stage 5: Overlay diagrammatically speculation as to how various level iterations may affect behavior and then choosing one level iteration to test.

Stage 6: Public Convenience Testing in plan.

Tests in plan of placement of Public Convenience within defined regions of congregation With the development of one Public Convenience in section, plan and perspective.

Stage 7: Multiple tests of wall placement and form Multiple tests in plan according a theme (Split, create and audience, Segregate from the Mainstream of filter). A select few to be tested in section elevation and perspective, challenging the original grouping of plan iterations.

Stage 8: Movement Channel testing

Test several augmentations of traffic flow obstructing connections to site

Stage 9: Continuity Testing

Ground plane materiality and aesthetic study of surrounding street scape and lane ways used to inform appropriate materiality and aesthetic to improve path-finding and continuity through site and between connecting spaces on periphery of site.

Stage 10: Create Final Concept Design

Select appropriate combinations from testing results, review and repeat.

Re-asses continuity of materiality.

Fig. 1.11. A Scale Model of Te Aro Park in white.

In red the 17 pieces of section iteration used in combination

testing.

Fig. 1.12. Third and Final method Phase. 


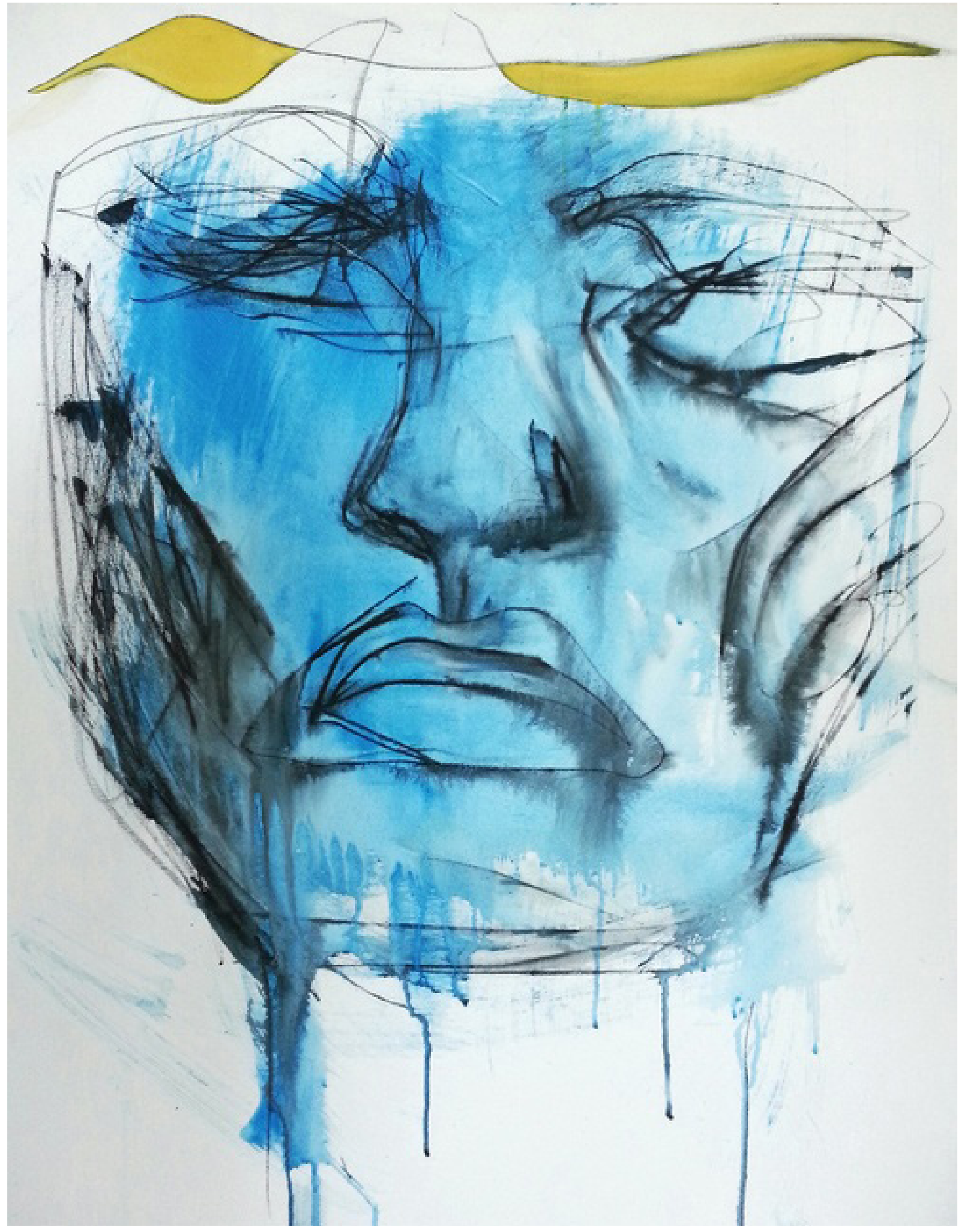

Chapter 2

Fig. 2.01. Photograph of defacement found down Opera House Lane

\section{Literature Review}




\subsection{Introduction}

There were three key texts that helped me both understand the marginal in relation to urban space, whilst supporting positioning my research within existing literature. Stavros Stavrides 2016, The City as a Commons; D. Petrescu, 2007 The indeterminate mapping of the common, and P Greenaway's 2009 Ladies and Gents: Public Toilets and Gender.

Stavros Stavrides research helped me understand the unique social hierarchies created within a space by the users of that space that dictate how space is divided up, shared and cared for within a city. This to me seemed like an interesting place to start forming a position looking at creating harmony between the Mainstream and the Marginalised users of a space through design of space itself. My logic here being that the results of commoning are a direct, localised democratic representation of the social cohort that uses the space.

Here my speculation grew from if I could locate identifiers of commoning on a site of Marginalised occupation based on Stavrides, then through testing of significant components of the site, I might be able to create the right conditions to A) Allow a new group (Mainstream walkers) to enter the social hierarchy/commons of the selected study site, and B) allow the two groups to slowly form their own social space through commoning. It gave me some criteria for recognising commoning practices within Wellington that were exhibited by the Marginalised members of society. Observed commoning practices of the Marginalised included but were not limited to, Placing themselves in locations were there were existing thresholds between the space and the Mainstream dominated world outside, these included pocket parks, alcoves and spaces hidden from direct view of the main thoroughfare.

Defacement was another observed commoning practice, not always explicitly undertaken by the Marginalised. The Marginalised though would occupy areas where the aesthetic of facades and paths were informal and altered in some way. Whether this was the grind marks or tags left by skaters, or the large locally commissioned murals.

It also motivated me to attempt to recreate initial conditions in which commoning flourishes for the Marginalised. Stavrides work primarily focuses on defining commoning in cities and describing how to identify urban commoning using real world examples. My research was directed at using Stavrides observations in combination with my own to specifically design for the tension between changing urban spaces where the Mainstream and the Marginalised were situated.

In order to identify and analyse these commoning precursors i needed to figure out how to map them. I found Doina Petrescu (2007): The indeterminate mapping of the common touched on the issues $i$ had with mapping social movements, occurrences and assemblages that happened over time, in a static format for analyse and representation.

Because I was looking to re-balance/introduce more Mainstream users to the site without displacing the existing Marginalised users, I needed to find an anchor/important spatial components that would cater to both cohorts. This is where the importance of public amenities came in. In particular public bathrooms formally known as Public Conveniences. Ladies and gents (2009) offered me an insight into the importance of Public Conveniences for creating equality among the many cohorts of society.

Within these three texts I found conditions for describing commoning, that I wanted to turn into tools for creating commoning. Much of this research is preoccupied with this shift from the description of commoning, to knowing how to create the optimum spatial form to support the process of commoning to unfold. This shift I discovered needed new tools of engagement for design. I therefore sought to learn techniques from the above mentioned literature that I wanted to combine with techniques I developed intuitively. This combination of techniques led to the tracing of behavior in relation to the physical site of Te Aro Park over time. 


\subsection{The City as Commons}

\section{People creating space through behavior, Insiders and Outsiders,}

Stavrides, S. (2016). Common space : The city as commons / Stavros Stavrides. (In common (London, England)).

Stavrides' writing on common space describes ways in which a city functions as an urban archipelago of enclaves. An individual moves through a threshold into a new enclave with a new identity and place within the enclave. The movement of the Mainstream user into, through and out of, the enclave of the occupying Marginalised. Each enclave, he argues, has a layer beyond the public/private dichotomy, this layer is called the commons and is produced by the local users of the space.

Within my research this would be the Marginalised occupier of the space primarily. Hierarchies and unwritten rules for using the space are developed and are ever changing as the hierarchy is broken down and rebuilt. Commoning is a gerund used to describe the constant restructuring of the commons and therefore commoning is not a thing, not an object, but something that takes place, and thus is temporal. This description of the commons and commoning helps to understand the chosen site of study (Te Aro Park), and many sites where the Marginalised dominate and traditional public/private space hierarchy is flipped on its head. Defacement of the space is a key action that Stavrides argues makes commoning take form. In the instance of Te Aro park, street art, tagging and modification of both public and private structures has occurred again and again to reflect informal local character and behavior. The ability to transform or at least leave a mark on the space enforces the ownership of the local Marginalised occupying the space day and night. This tool for commoning and a sense of informal ownership may be a key anchor for enabling safe dignified movement through the park, while maintaining the space as a place for the Marginalised.

Stavrides work mainly centres around the observation and description of patterns occurring in the urban setting. Although he has many examples of how space is claimed, restructured socially and physically acted upon informally, his writing does not make it clear how one would intentionally replicate or emulate the conditions required for a self structuring public space. I believe that there are allowances that we can make when designing a space that would allow to a greater or lesser degree the act of commoning as observed by Stavros Stavrides. Through testing component adjustments of a site we find a way to jump start a re-balancing/harmonising of a space without dictating the rules of the space. In this way Stavrides observations could serve as a loose guide to the conditions required in a space that would allow the users of the space (in this case the Marginalised) to have maximum influence over the assemblage while still re-balancing the use of the space (in this case making it more Mainstream walker centric than it previously was).

I believe there is an opportunity to use Stavros Stavrides observations to guide test conditions resulting in a catalysing effect that will re-balance a space through the physical design in combination with user actions on the space overtime. In other words the final concept will be a canvas for the occupants/users to act upon and create harmony through commoning practices that are ever changing and ever adaptable to the changing hierarchies within the space. 


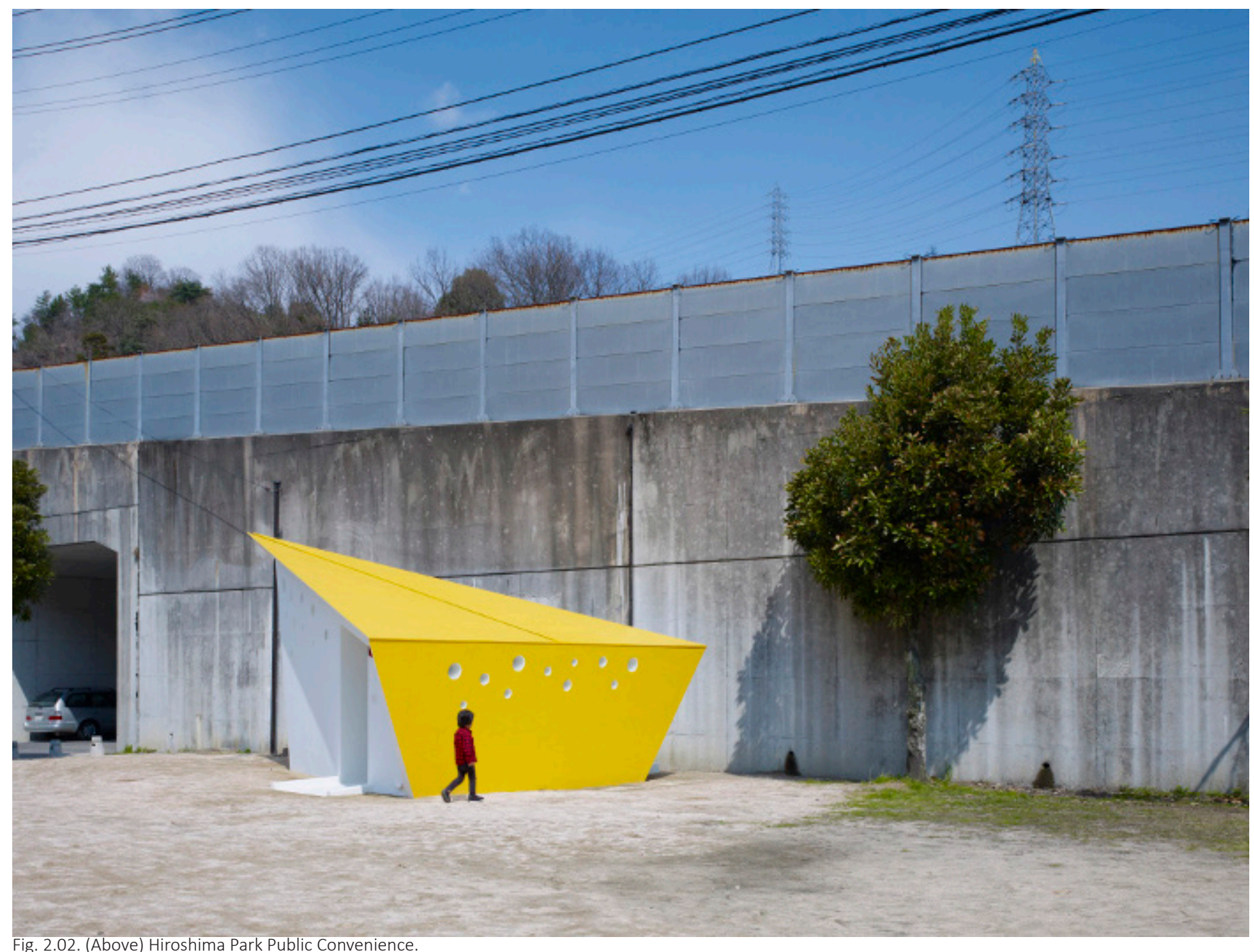

Fig. 2.02. (Above) Hiroshima Park Public Convenience.

Fig. 2.03. (Below) Oriental Bay Changing Sheds.

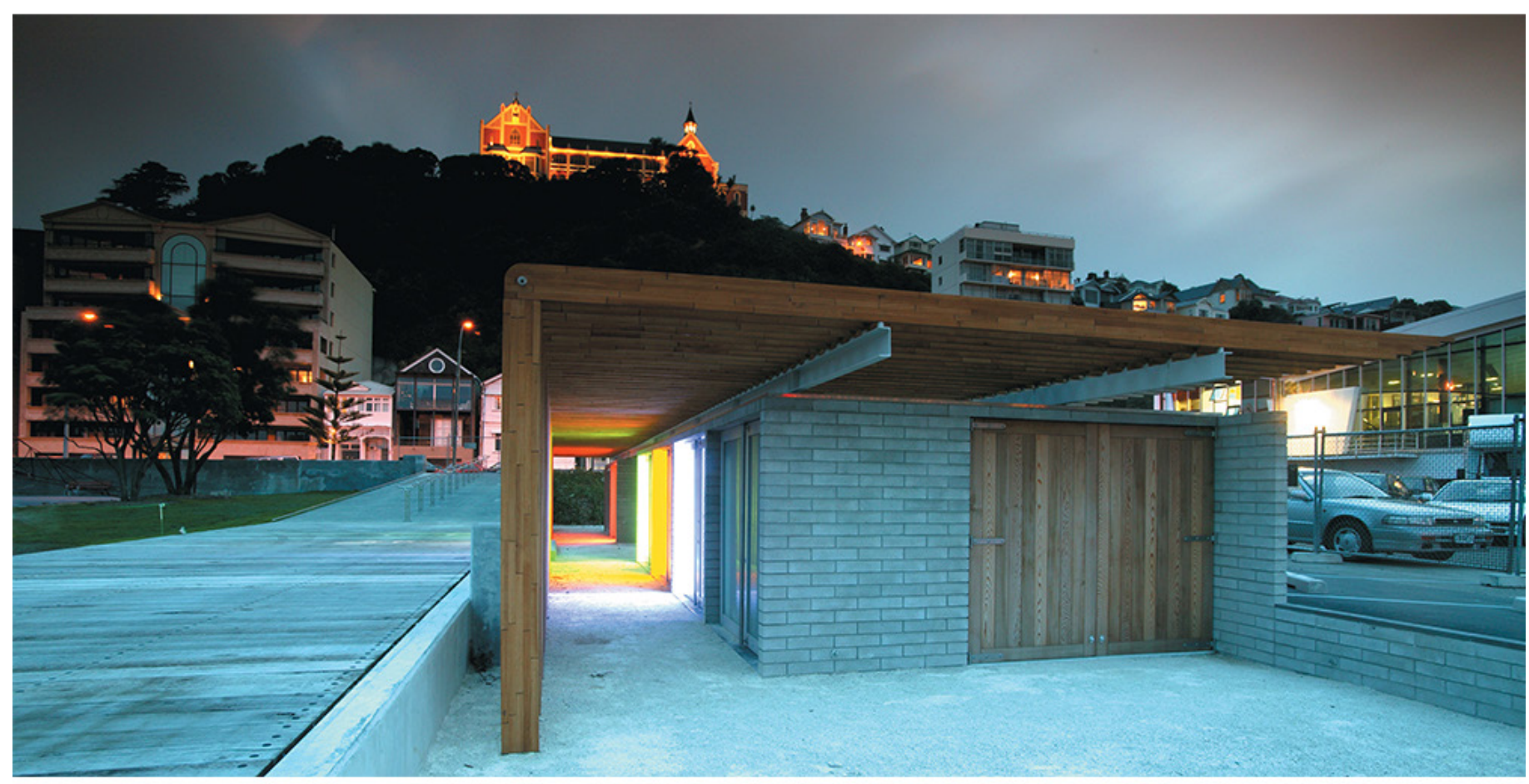




\subsection{Emancipation with Public Convenience}

\section{How universal dignified access to public bathrooms can move towards basic social equality}

Greenaway, P. (2009). Ladies and Gents: Public Toilets and Gender (Gershenson O. \& Penner B., Eds.). PHILADELPHIA: Temple University Press. Retrieved from http://www.jstor.org/stable/j.ctt14btdn9

Ladies and Gents explores the great equalizer that is the public bathroom through three historical time periods where the public bathroom allowed greater freedom and dignity to Marginalised members of society. The first was Public Conveniences enabling woman to leave the house in the Victorian Era where an otherwise inability to relieve themselves in a dignified way constricted their ability to stray far from home. The second was the desegregation of otherwise black and white bathrooms in America where the two races were forced to respectfully share the same quality of public amenity. The third and still currently debated, is the unisex bathroom that allows gender-fluid individuals to relieve themselves without judgment on which bathroom/ sex they align with. The importance of appropriate access to public bathroom facilities is highlighted here and extended beyond the simple need to relieve oneself away from home. In particular i am interested in how Public Conveniences can empower the Marginalised, attract them and function as a drop pin for the activity of the Marginalised. In order to test designs that encourage movement through the site while still maintaining the presence of the Marginalised, the public bathroom must be understood in all its capacities.

With an new found appreciation and understanding of the role and importance of universal availability and access to Public Convenience I began to collect international examples of Public Convenience design as well as local Public Convenience design. As this research was not focused on individual components design as a measure of success, I was more interested in finding forms and features of Public Convenience that could assist the integration of the structure into sight as well as keeping it discreet, avoiding visual obstruction.

The were two examples I found, each lending features of their design to my research.

The first was the triangular bathrooms designed by Future Studios, Hiroshima (see fig 2.02). The Public Convenience were designed for Hiroshima Park, Japan. The triangular structure was simple and elegant but what i was interested in was its geometry in matching with the triangular geometry and existing pathway arrangement in my sight. This Geometry, I would find through testing in site, also lent itself to a limiting visual occlusion through site depending on its orientation. It was possible to alter in a way that would let foot traffic slip into the bathrooms and back out the other side to re join foot traffic. This geometry would be the winning form in plan for the entirety of this thesis.

The second example was the Oriental Bay Changing sheds, designed by Architecture Workshop, Isthmus \& Tonkin and Taylor in 2006 (see fig 2.03). Here i was Interested Primarily in the way the changing sheds were lowered $.5 \mathrm{mtres}$ below the boardwalk. This was an intentional design move intended to limit visual occlusion over Wellington harbour for the walker. An important technique that would be used through out my evolving Public Convenience testing. Secondly the wooden facade that obscured by did not completely occlude users entering and exit the changing sheds presented a powerful tool for dignified entry and exit of the amenity. 


\subsection{Tracing Occupation}

\section{The Indeterminate Mapping of the Common}

Petrescu, D. (2007). The indeterminate mapping of the common. Field: A Free Journal of Architecture, 1(1), 88.

The impossibility of mapping walking statically. Embracing the becoming of repetitive traces becoming a movement through space in itself. An apt technique introduced to the site of mixing between the Marginalised and Mainstream on separate but similar vectors.

Petrescu highlights the problems associated with using a static representation (2 dimensional mapping in plan) to represent a process or a temporal based observation. Repetitive mapping and overlays representing a period of time can close the discrepancy between occurrence and representation. I wanted to use this theory as a tool for mapping but also as a challenge in attempting to capture assemblages of social happenings in photography that could be representative of a few of the key happenings that could be picked apart and associated with the physical environment.

Mapping the behavior and happenings of the Marginalised and Mainstream over time was an important activity in determining the physical qualities of the site in relation to the sociocultural (and more temporal) qualities.

Petrescu mapping over time was part of the solution I needed to approach the same issues he faced when attempting to map 4th dimensional qualities in 3 dimensional space.

To identify Stavrides commoning practices, the 4th dimension needed to be represented at least to some degree. This is because as mentioned commoning is an ever changing activity. It is in a constant state of becoming something else. What occurs in the social commons is then represented in the physical and visa versa.

The need to capture the 4th dimension statically combined with Petrescu theory, propelled me into taking photographs. I believed that with the combination of tracing in plan over time in combination with photographs of social happenings I could garner a richer understanding of what was happening moments before and predict what might be happening moments after the photograph was taken while maintaining the ability to represent my observations in a static image.

The writing of Stavros Stavrides in identifying factors that are at once a catalyst as well as a product of commoning lead me to wonder if there could be physical and spatial adjustments that could be made to the city that could initialise commoning. It is important to note here that it is the initialisation of commoning and the slight redirection of commoning that are the intent here. Set the ball rolling in a direction using features identified by Stavrides and let the ball take its course. This indirect approach lead me to my initial identification of important spatial components on site. Again both catalysts as well as products of existing commoning. 


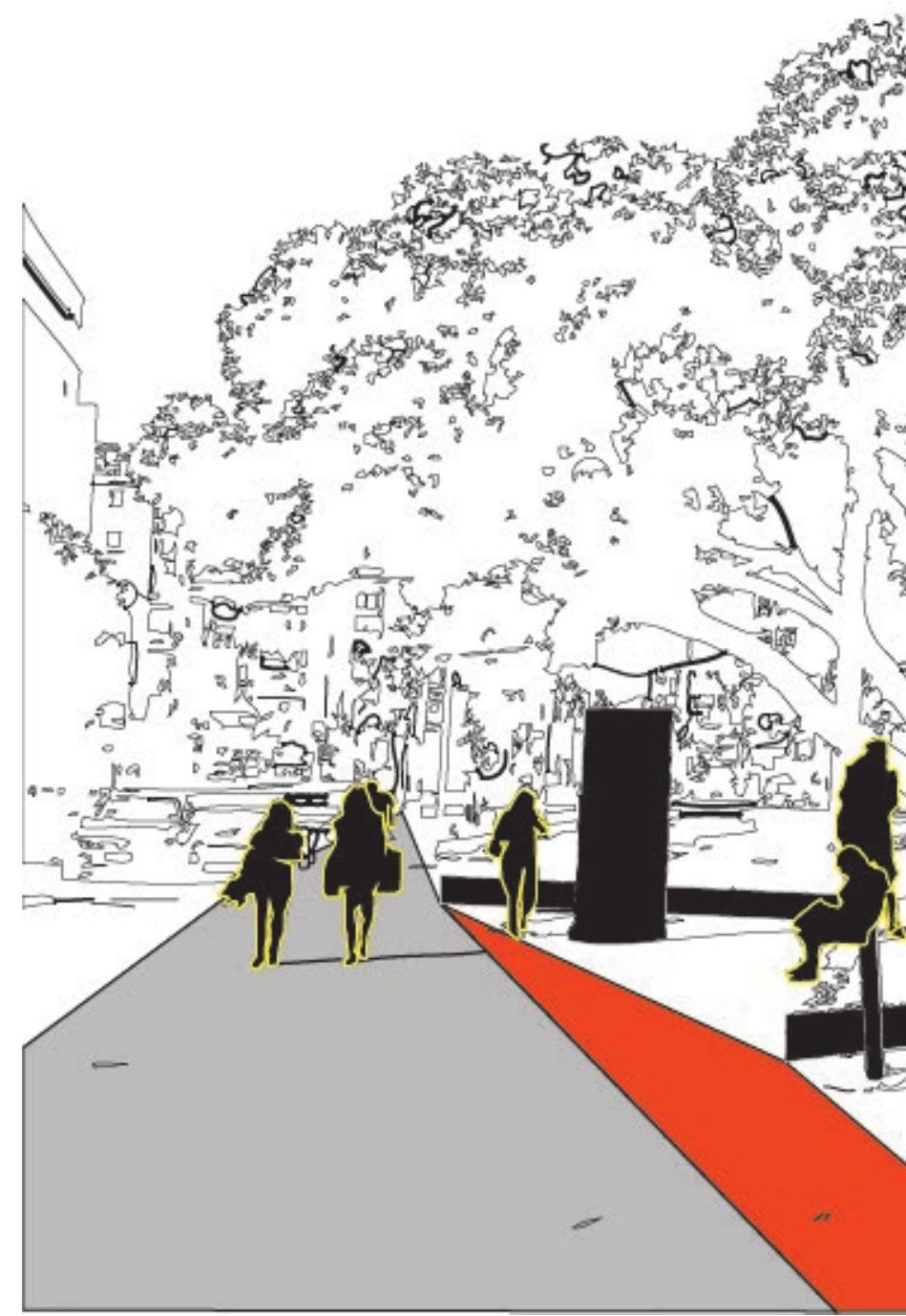

Fig. 3.01. Perspective Study.

Stripping back details and

highlighting Paths, Zones and

Vertical elements. 


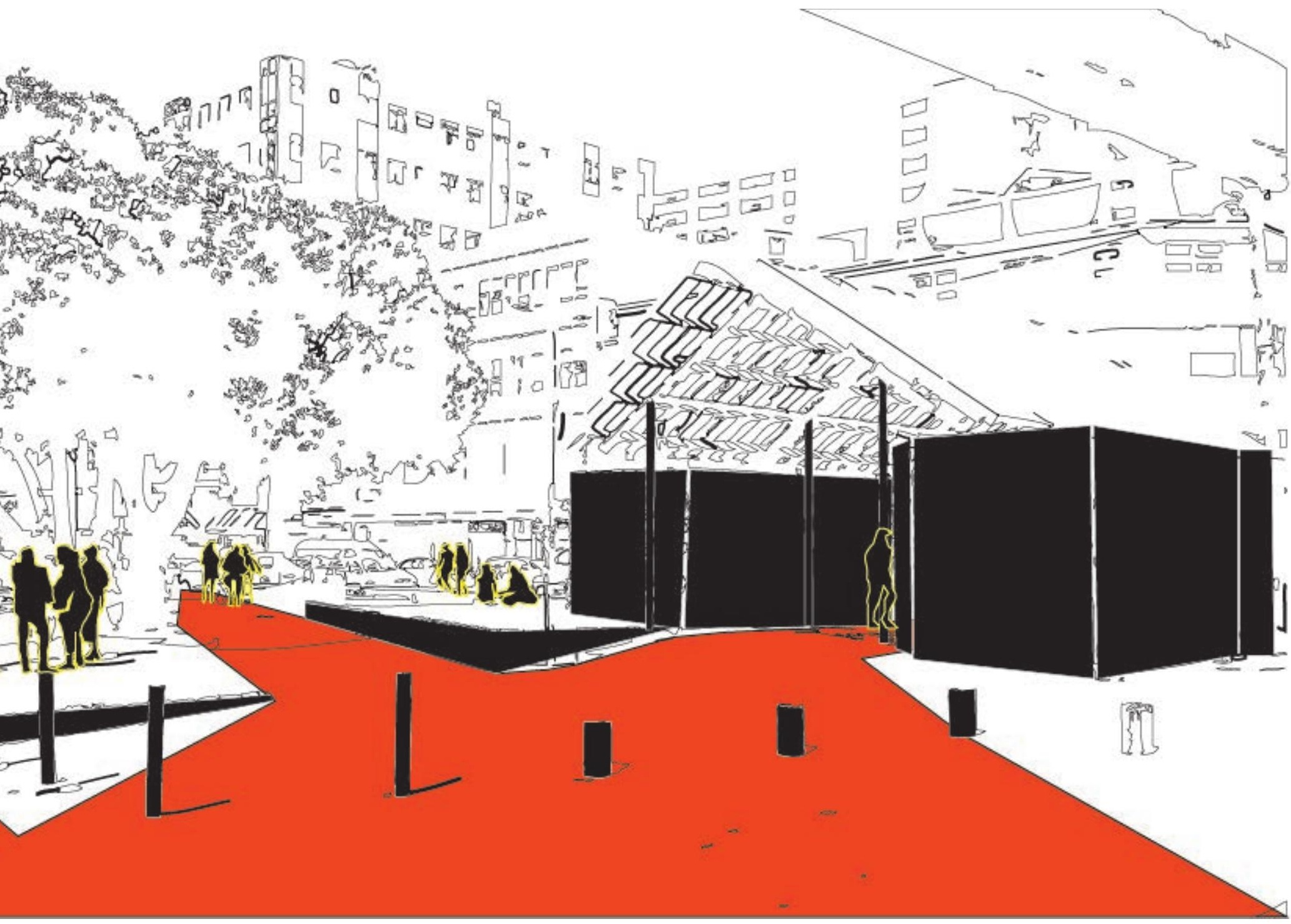

Chapter 3

\section{Site}




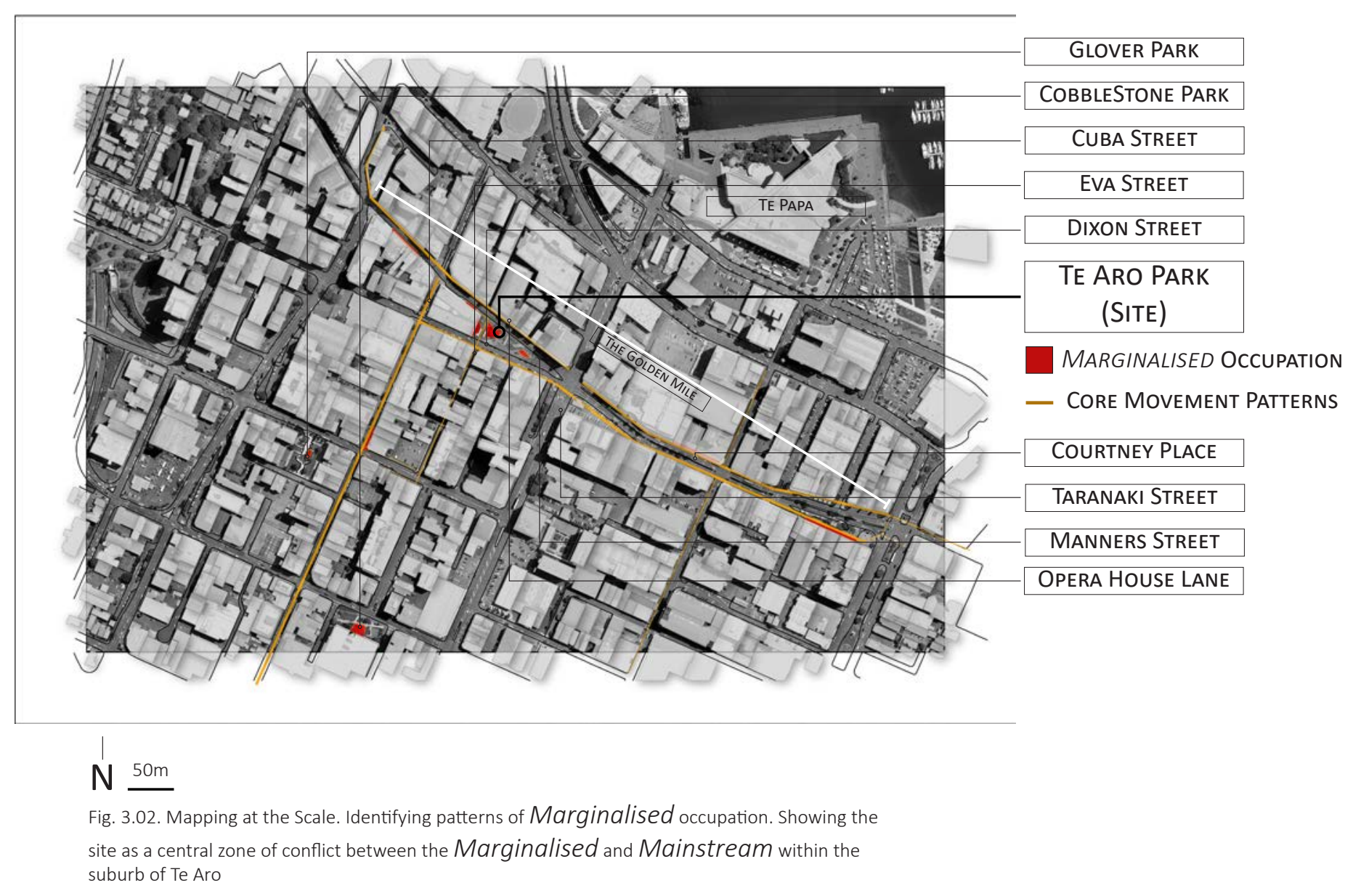




\subsection{Introduction}

Designated as a public park, the site acts as a focal Point between several major destinations and arterial pathways for pedestrian movement within Wellington. With the bus stop connecting the region, the Public Convenience facilities, central and key location, the site is a hub for the

Marginalised. As a key thoroughfare, the site is essential for the Mainstream user moving through the city and accessing public transport.

Through an inquiry into the physical and Socio/Cultural Environment a relationship of occupation and movement became apparent within Wellington City. Te Aro park was found to be a key site for the study of conflict between the Marginalised and the Mainstream. This revelation was the product of mapping at a city scale, a suburb scale and a site scale. To tie this to a component inquiry, a photographic studied was also actioned.

Te Aro Park accommodates an increasingly broad array of functions, behaviors and public necessities. As the lane ways develop either side of the park, the park as a thoroughfare grows as one of its core functions. Where it was once a detour or a secondary, rarely used route alternative to Cuba street, it is increasingly becoming a main thoroughfare connecting Courtney Place, Cuba Street and Lambton Quay.

This slide towards a thoroughfare lies in conflict with the popularity of the park for Marginalised members of society to congregate and rest. There are several components within the park that entice the congregation of the Marginalised. These physical components include the Public Conveniences, The bus stop, multiple opportunities for seating, a central location within the city, shelter, as well as the light but consistent flow of foot traffic in the case of begging and interaction with the Mainstream.

It is these components that, through critical assessment, may be considered and augmented to create harmony between the growing use by the Mainstream as a thoroughfare and the claim to space the Marginalised have enjoyed up until this point in time. 


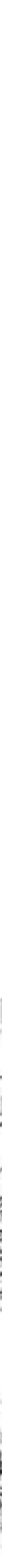

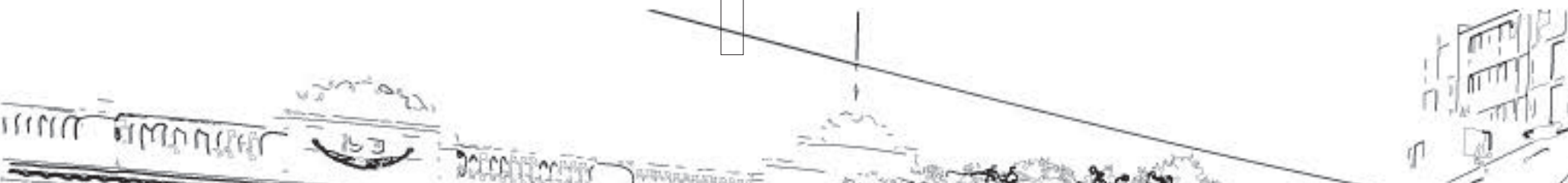

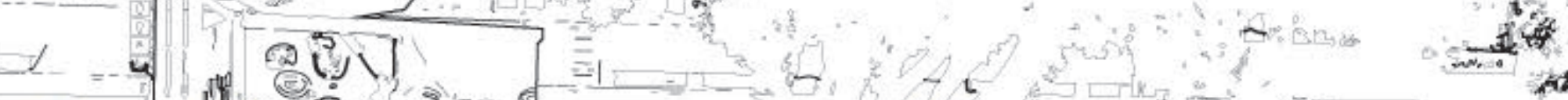

at.

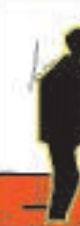

R 1,8

$5-\frac{\cos }{\mathrm{xm}}$

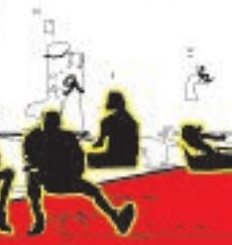

Fig. 3.04. Perspective Study. Breaking down congregation and movement focusing User Movement. 


\subsection{Social and Cultural Environment}

The site sits next to the remains of Te Aro Pa. A Pa that held its ground as Wellington as we know it intensified with European development and occupation. It was a site shared by the Iwi of the west and east. The Maori tile artist Shona Rapira Davies honored the arrival and spiritual ownership of the area with her tiled artwork that represents the canoe that brought the first Maori to the area. Vertical components represent the oarsmen while the horizontal tiles tell a story of the female within the space. A large pounamu is buried on the site and has been blessed by elders.

This physical dedication brings a spiritual sense of importance to the site for harboring those who do not quite fit into the Eurocentric Mainstream of today's society.

When entering the site as a Mainstream user there is a sense of a hierarchy that has been flipped on its head. The Marginalised have now taken the place of the Mainstream. The former Mainstream user is the outsider who must quickly learn and accept the social rules dictated implicitly by the former Marginalised. The main rule/expectation implicitly laid down is recognition and acknowledgment. This is a difficult circumstance for many Mainstream users to accept through my observation. I have observed many people move through the site, head down and visibly uncomfortable. I have witnessed confrontations that end in the Mainstream user shying away and even avoiding the direct route through the site altogether.

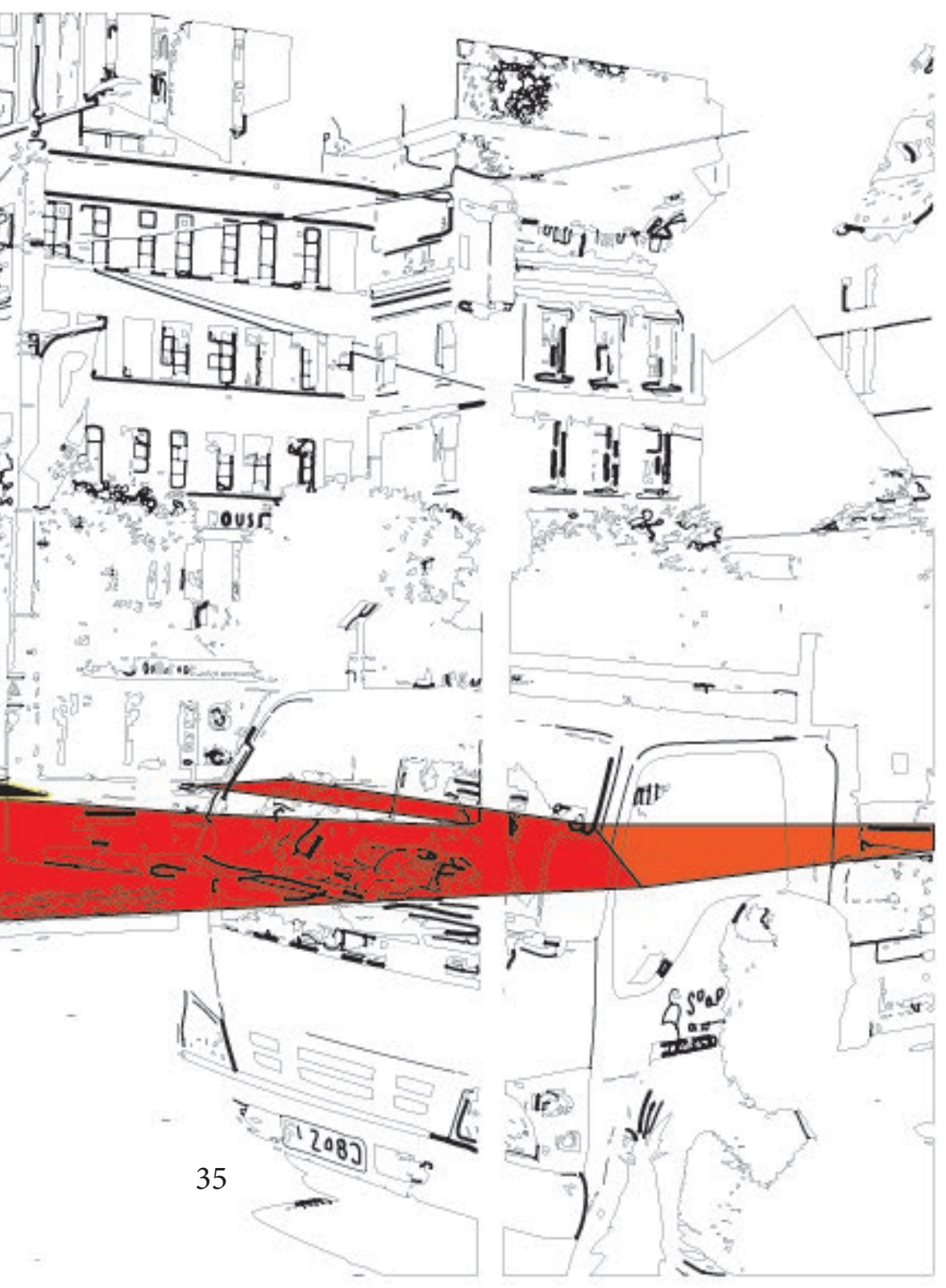


Fig. 3.05. Perspective Study. Highlighting the dense social congregation of Marginalised and the initiated Mainstream outside Memphis Belle protected by the Public Convenience

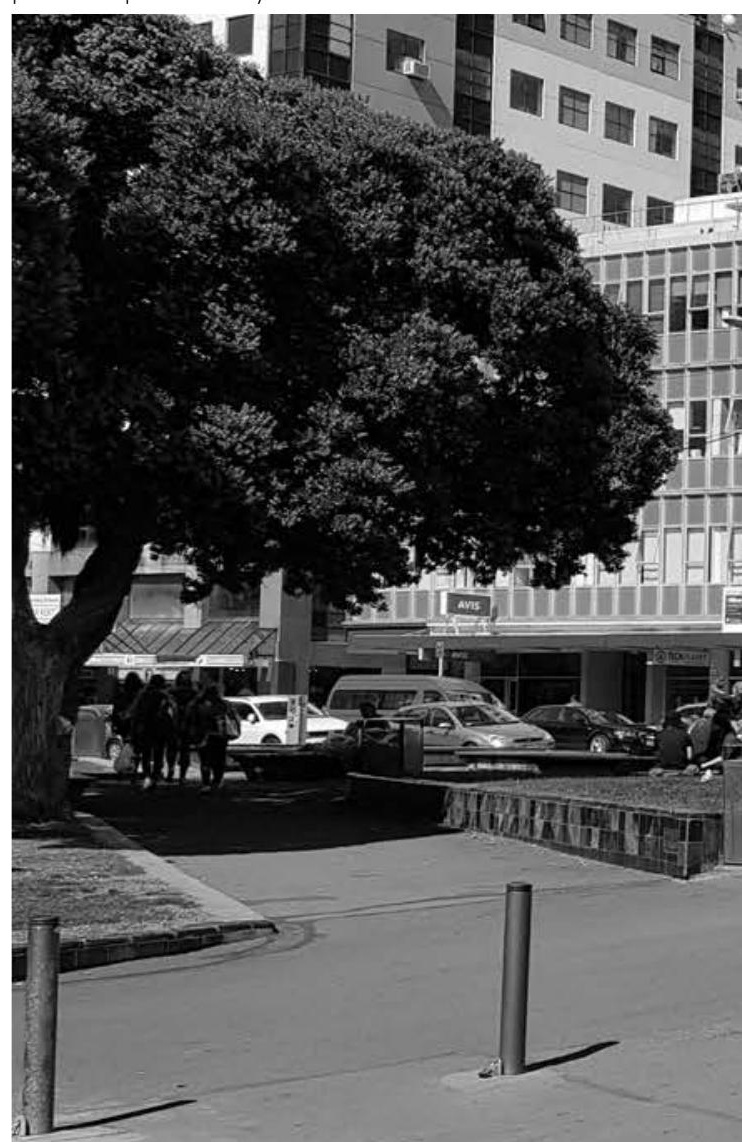


There is a business proximal to site that has clearly been aware and progressive enough to accept this flipped hierarchy and in many instances promotes it, accepting it into its character. Memphis Belle is a cafe that borders the site. Sitting in The Oaks building serving Wellington's creative crowd with coffee and cabinet food in a nonchalant way. The cafe also runs tabs for several of the Marginalised regulars. These tabs, as far as I have observed, are rarely paid off but garner report with the Marginalised that occupy the site. This informal charity operation sees a respect for the Marginalised of the site. It gives the Marginalised a more formalised confidence on the site and to the uninitiated Mainstream customer, it seems confusing and times uncomfortable. For the initiated user however, the exposure has brought a sense of respect, assertive consideration and harmony that is not often witnessed in other spaces throughout the city. The culture of acceptance here has taken time and has come about, through my observations, through gentle and ongoing exposure. This social construct has not been forced but rather willingly adopted by both cohorts. This unforced exposure is a key element that I wanted to preserve and promote through my research.

It is important to note here that exposing the Mainstream to the Marginalised in a flipped hierarchy has been observed to be successful in creating harmony. In contrast to this type of social space, within the wider context of a city, the Marginalised are constantly confronted with their atypical constructs within Mainstream society. Outside of spaces like this the Mainstream will rarely be put in a situation where they have no choice but to be exposed to the Marginalised.

Exposure rather than integration. I aim to cherish the Marginalised rather than attempt to directly and forcibly integrate them.

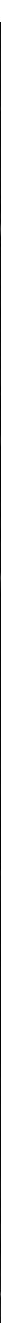




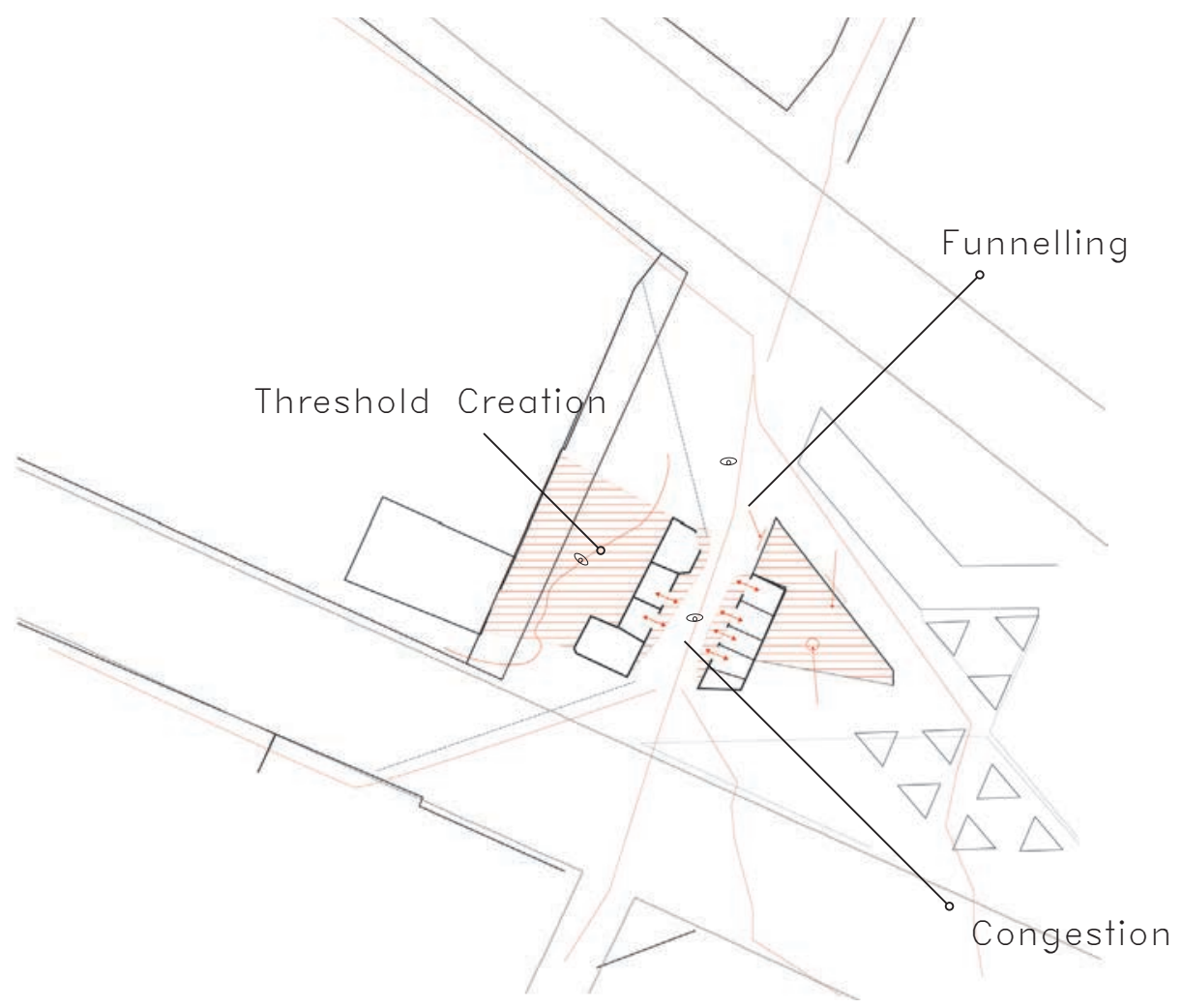

I

Fig. 3.06. Petrescu Mapping the Commons. Highlighting the congregation and movement the public convenience affords as well as the obstruction and congestion it causes.

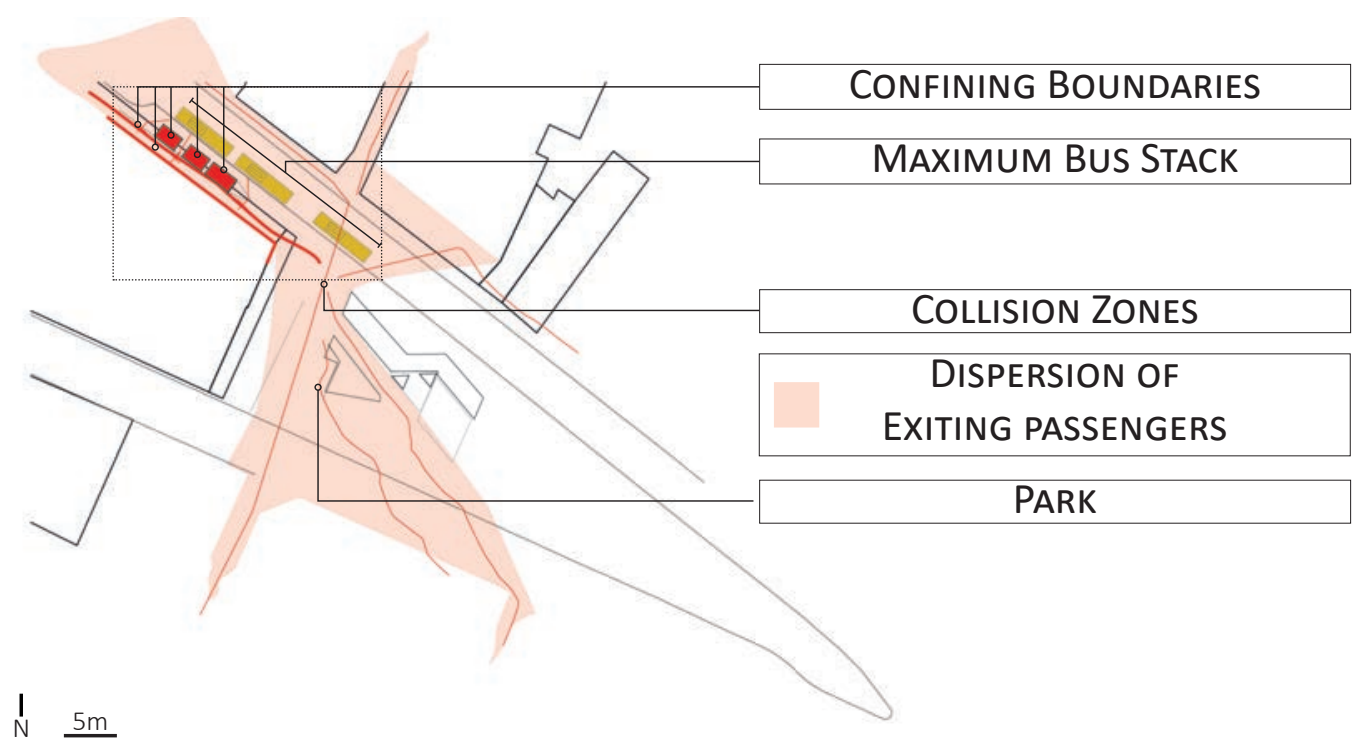

Fig. 3.07. (Above) Observational mapping of the collision zones on manners street and the importance of the site for bus passengers dispersing on separate vectors.

Fig. 3.08.(Right) Perspective Study highlighting the channeling effect the current Public Convenience has on the site as well as its visual and physical domination of the thoroughfare. 


\subsection{Physical Environment}

The site in its physical form does not cater to the Mainstream user moving through. Neither does it adequately cater to the Marginalised user who congregates there. The site is made up of several physical amenities that have the potential to provide an effective walking space as well as a congregation space. Disconnection between these components as well as flaws in their form and placement see the parts all their but the machine not running as it should.

The Public Conveniences are essential for the Marginalised, who often do not have a home, at least not within walking distance and rely on the Bathrooms to not only relieve themselves but also at times clean themselves. As these Public Conveniences sit in the middle of what has become a thoroughfare, the ability for the Marginalised to use them with dignity is deteriorating.

Te Aro Park is set between the primary Wellington bus channel running through Manners Street (part of The Golden Mile) and the busy thoroughfare of Dixon Street which connects traffic from Courtney Place to The Terrace. Both key arterial routes in the city.

Parking along Dixon Street caters to private users who are usually, through my observation heading to Cuba Street to shop or eat. Despite the parking spaces being unrelated to the Mainstream users moving through or the Marginalised occupying the park, they create a significant physical boundary for those crossing the road to enter the park.

The site sits between the gentrified Eva Street and the neglected Opera House Lane. Both streets are becoming increasingly popular as alternative routes that run parallel to the bustling Cuba Street. Lane way pop up culture is increasing in popularity meaning these lanes will become busier as time goes on. Specifically the occupation of the side streets/lanes will move from Marginalised occupation to Mainstream occupation.

A Historic Pa Site, Location of tile artwork by Famous Maori tiler, Shona Ripira Davies. This tiled artwork presents a surface that is slippery underfoot, but affords a variety of seating opportunities.

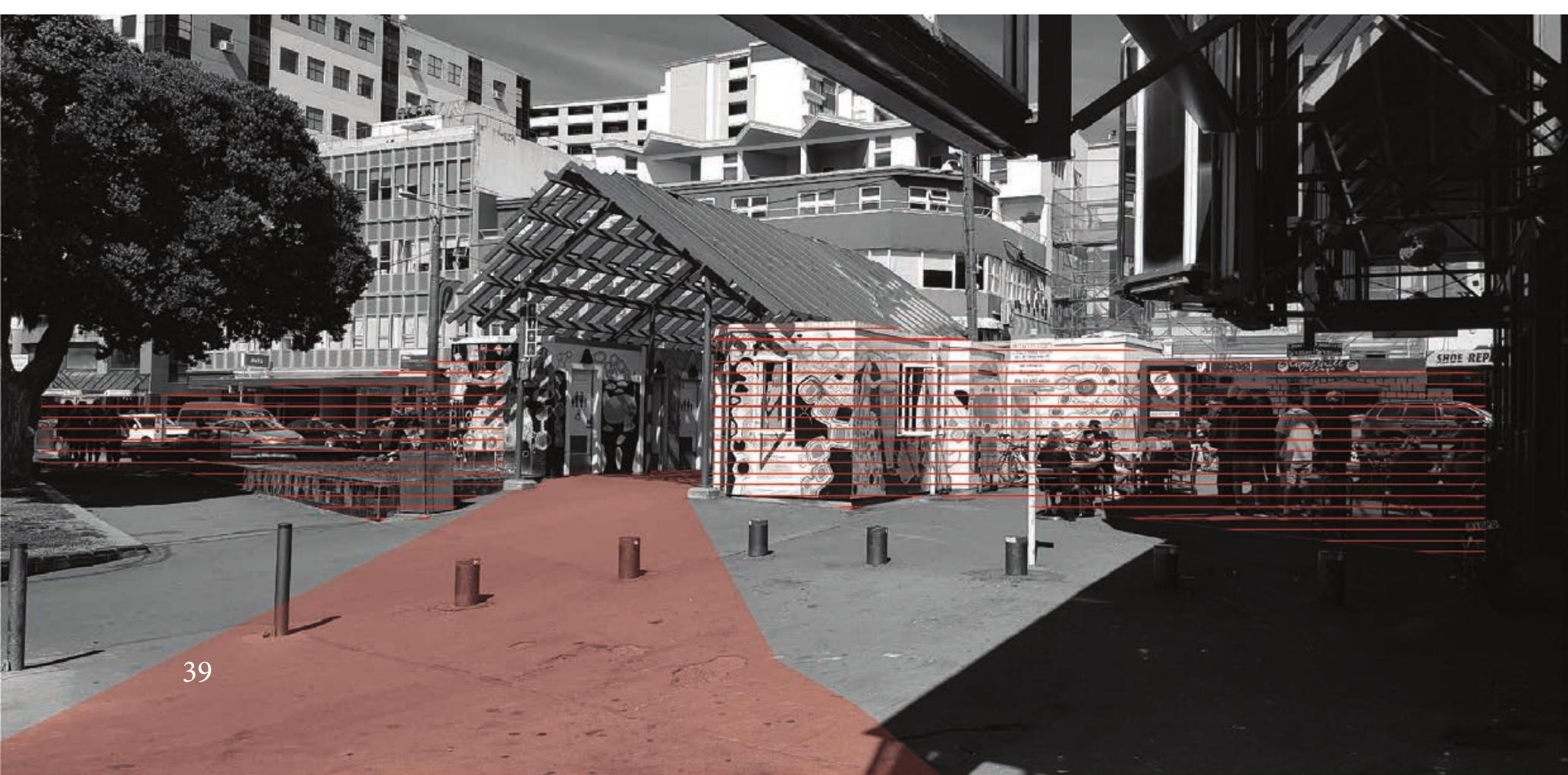




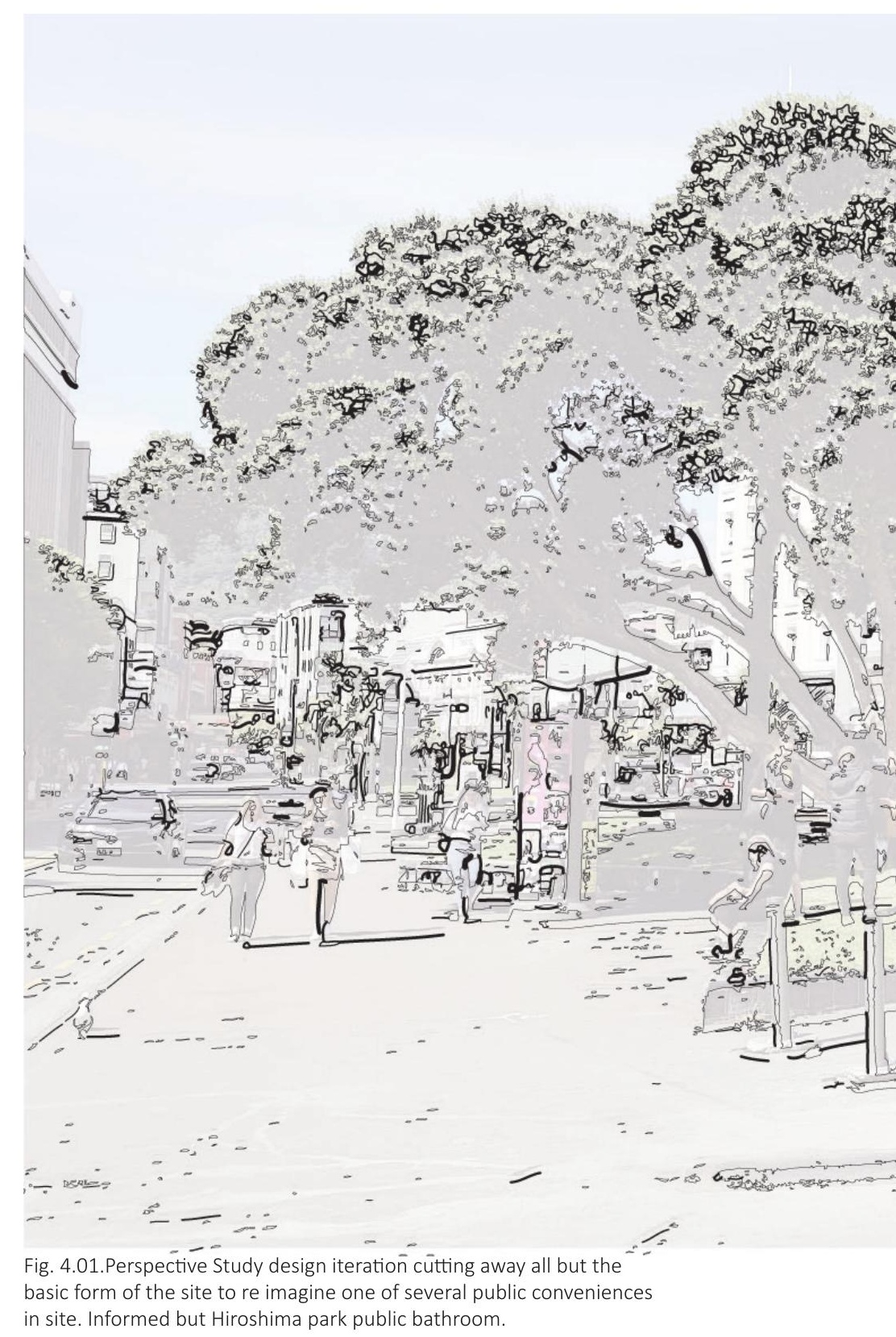




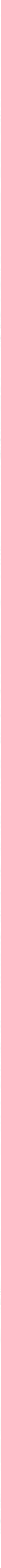

Chapter 4

Public Convenience Lead Design Research 


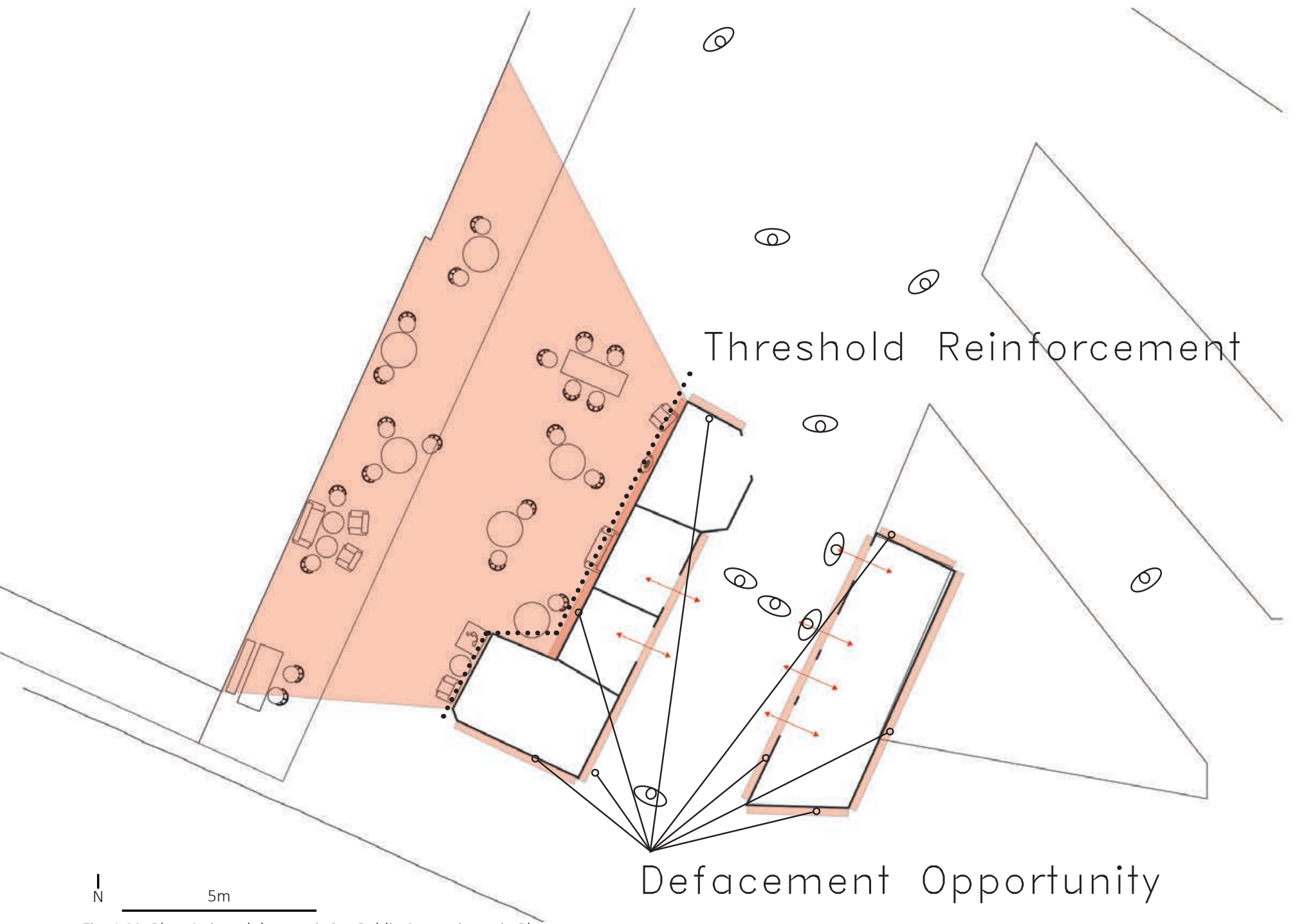

Fig. 4.02. Plan. Stripped down existing Public Convenience in Plan

breaking down the peripheral functions of the structure as a threshold

reinforcer for the Memphis Belle assemblage and as a wall for formal and

informal defacement.

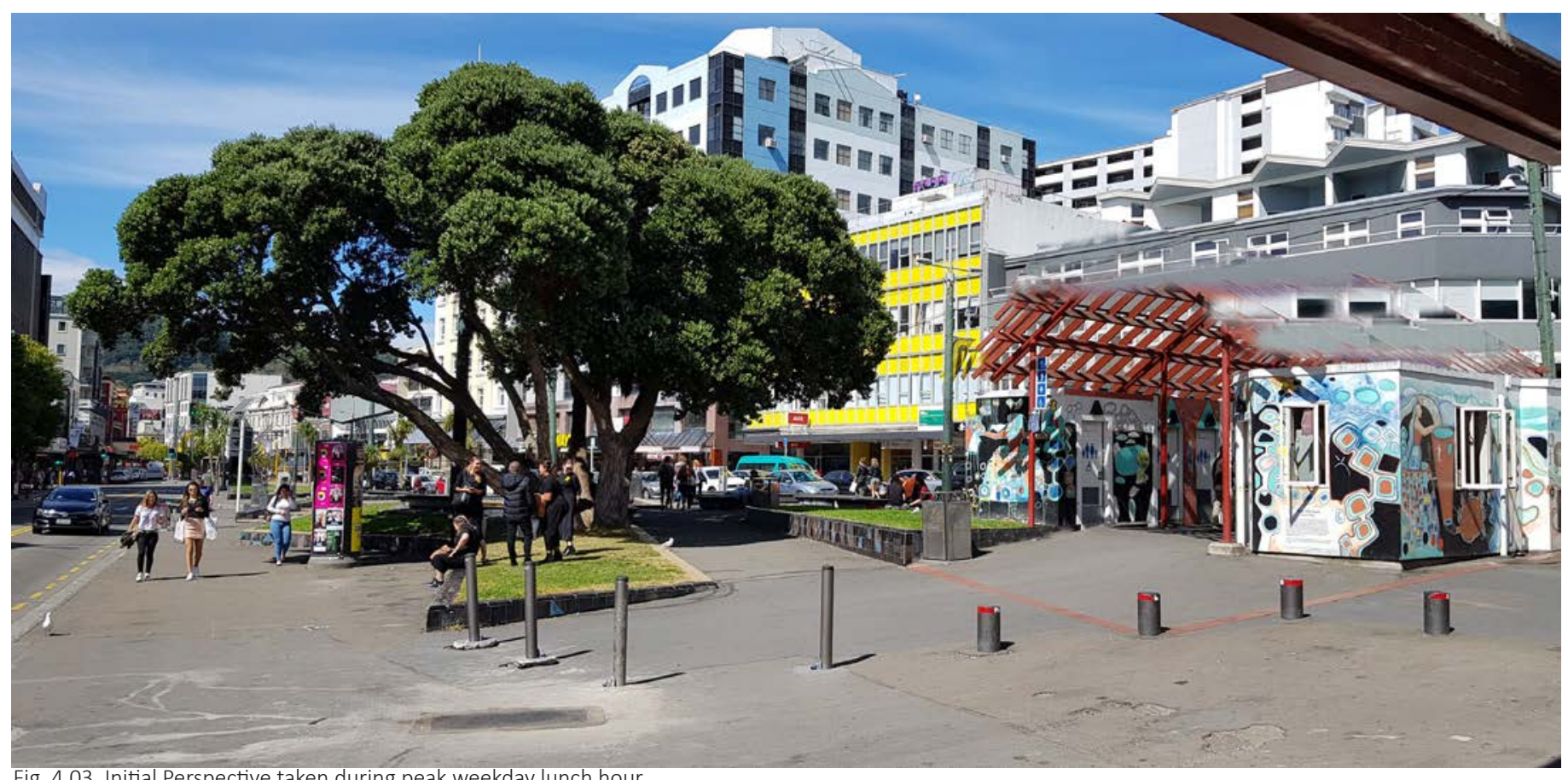

Fig. 4.03. Initial Perspective taken during peak weekday lunch hour.

Attempting to re imagine the scene without the existing

Public Convenience. 


\subsection{Introduction}

As before i found that the Public Convenience was primarily an obstruction to movement and connection both physically and visually across the site.

This is where i formed my initial criteria for testing in the space.

1. Clear sightliness between the Eva Street and Manners Street.

2. A Public Convenience that is out of the way of traffic and has dignified entry, exit and waiting functionality.

But not only was it an amenity that drew in the Marginalised, it also shielded Memphis Belle and gave a flat vertical surface for a site specific mural, an act of defacement in Stavros Stavrides terms that gives identity to the space, a unique character and reinforces ownership.

From this i began to investigate the Public Convenience as a combination of components.

1. Being a public amenity.

2. Being a physical barrier.

3. Being an opportunity for defacement expression and creation of local identity.

I found that these components could be broken apart and augmented so that it maintained its potential while also meeting the criteria for a site where the Mainstream can move with greater ease through the site.

Therefore the criteria for testing now became

1. Clear sightliness between Eva Street and Manners Street.

2. A public amenity that has dignified entry, exit and waiting functionality.

3. Physical separation of spaces for movement and congregation while maintaining exposure between cohorts and opportunity for 'defacement'.

This led me to my initial testing investigation. Placement of the Public Convenience. A series of arrangements that critically considered the spatial potentials of the Public Convenience according to movement patterns observed. 


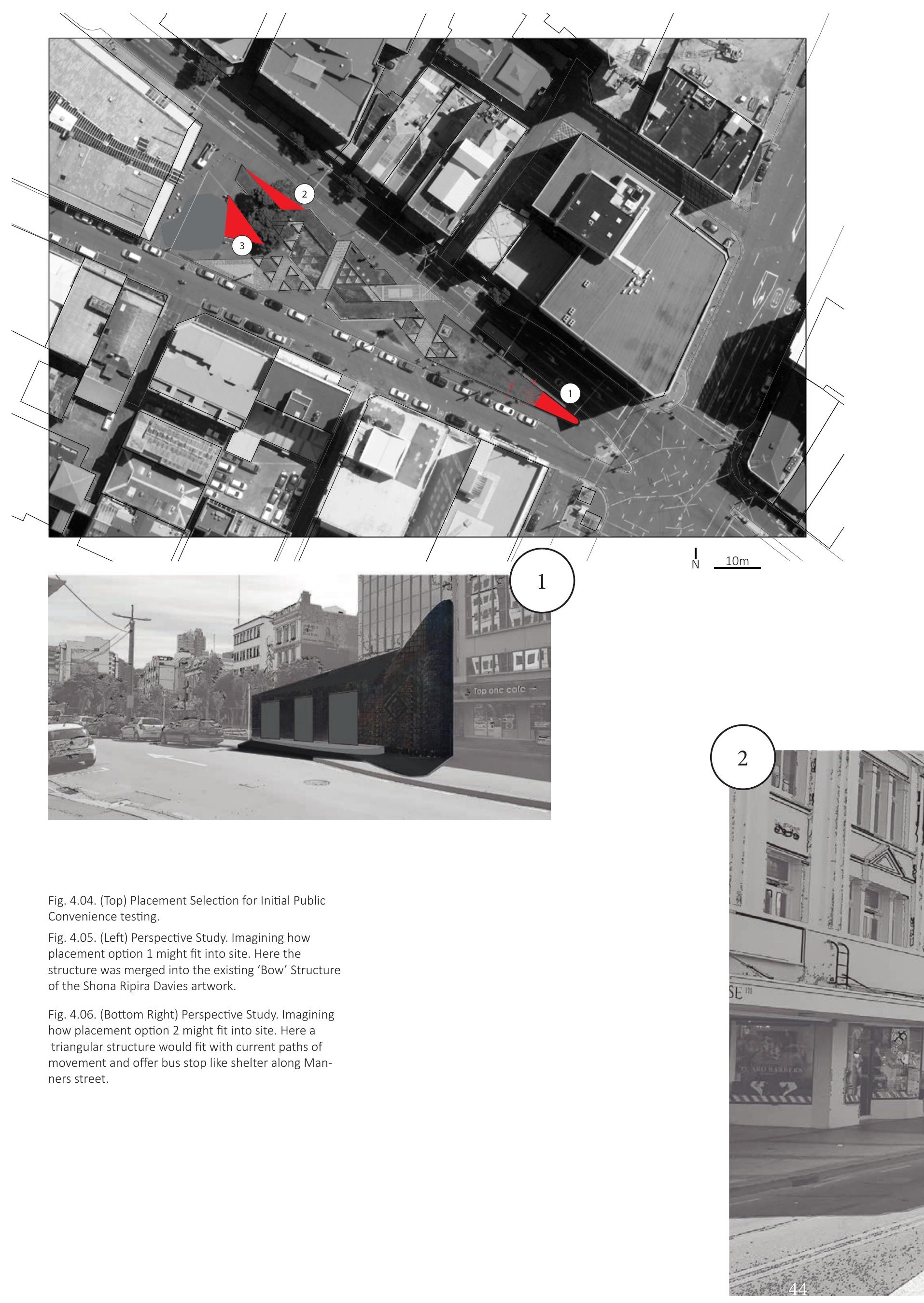




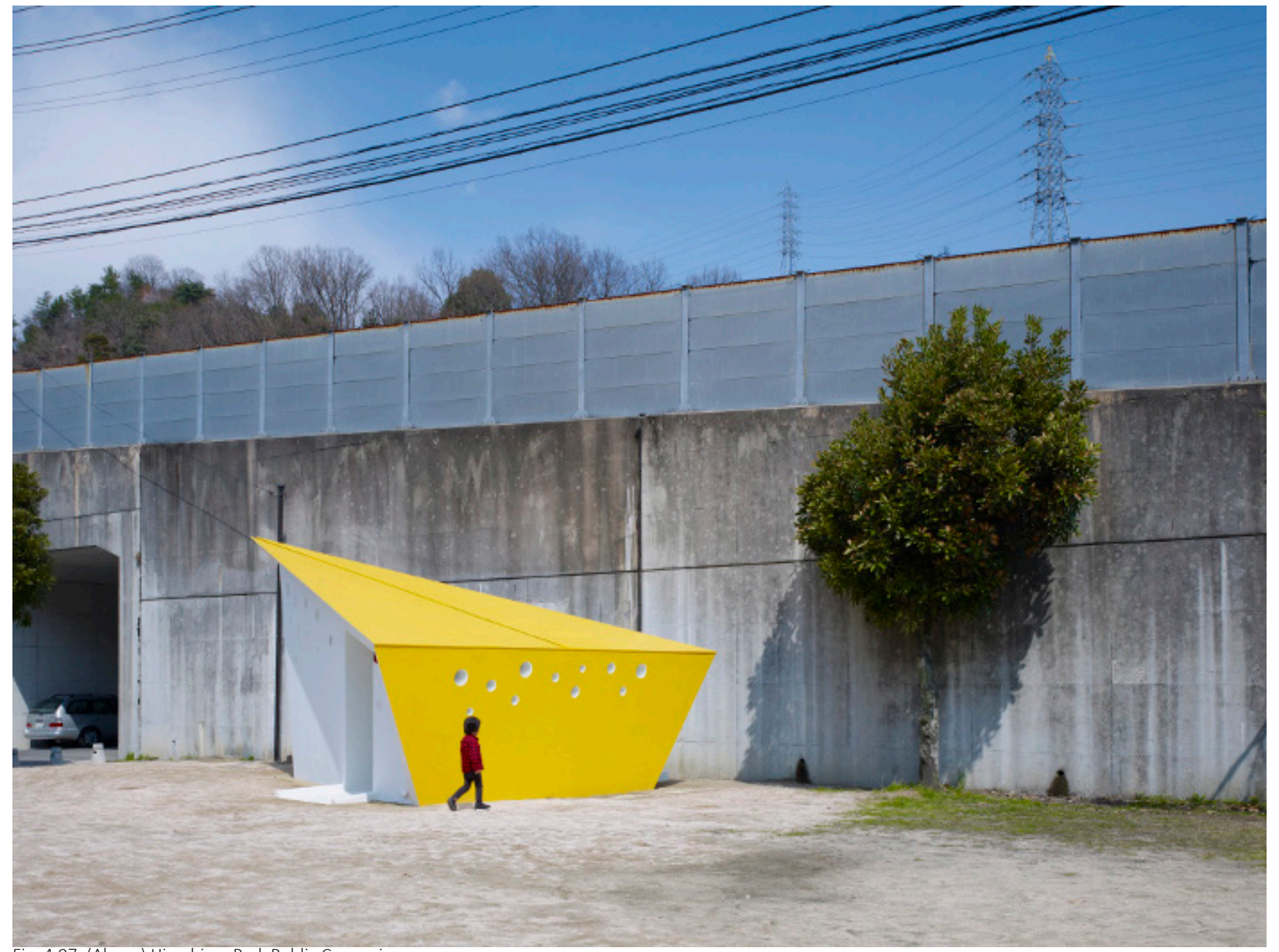

Fig. 4.07. (Above) Hiroshima Park Public Convenience.

Fig. 4.08. (Below) Oriental Bay Changing Sheds.

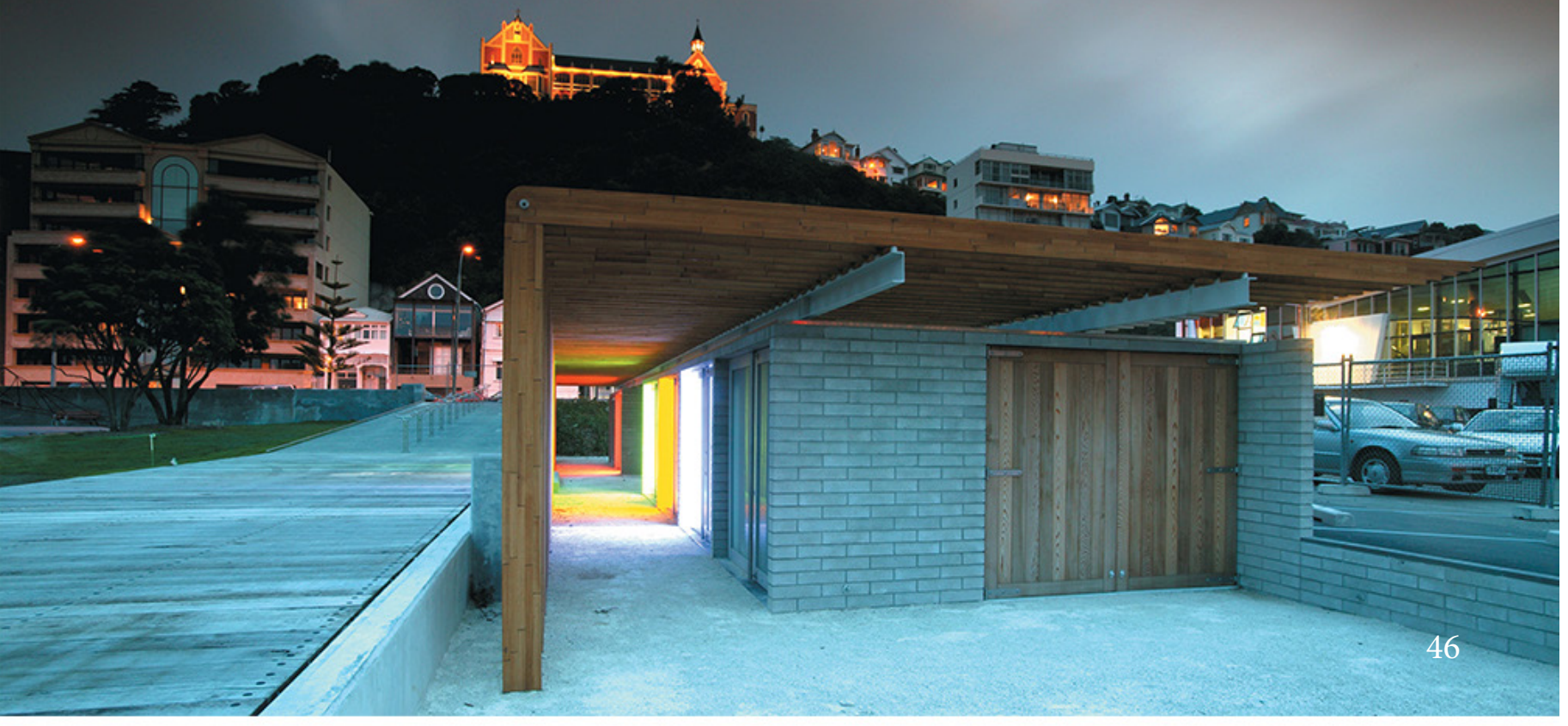


I initiated this public convenience design testing by studying relevant precedents. This triangular bathroom located in Hiroshima Park (see fig 4.07.) seemed like the best fit for a site made up of triangular geometry aesthetically. When orienting the test in plan I also found the form of a triangle like this could give the opportunity for defacement as well as clear lines of site depending on its orientation.

While I was looking for bathrooms to use as precedents I also found that the changing sheds/ bathrooms next to the Frey burg Pool (see, fig 4.08.) took into consideration sidelines. Dropped down several feet below the boardwalk it allows for users to get a better view of the harbour.

This brought me back to my level testing and I discovered I could achieve the first criteria of improving sightliness by lowering the bathroom and augmenting the topography to keep the users above the bathroom until they had cleared the site (see fig 4.09 and 4.10).

This also sparked interest in the value of the otherwise overlooked micro topography of the site.

Fig. 4.09. (Right) Basic Plan for Function of traffic flow and defacement opportunity for Placement option 3.

Fig. 4.10. (Bottom) Perspective Study design iteration cutting away all but the basic form of the site to re imagine one of several public conveniences in site. Informed but Hiroshima park public bathroom.3.

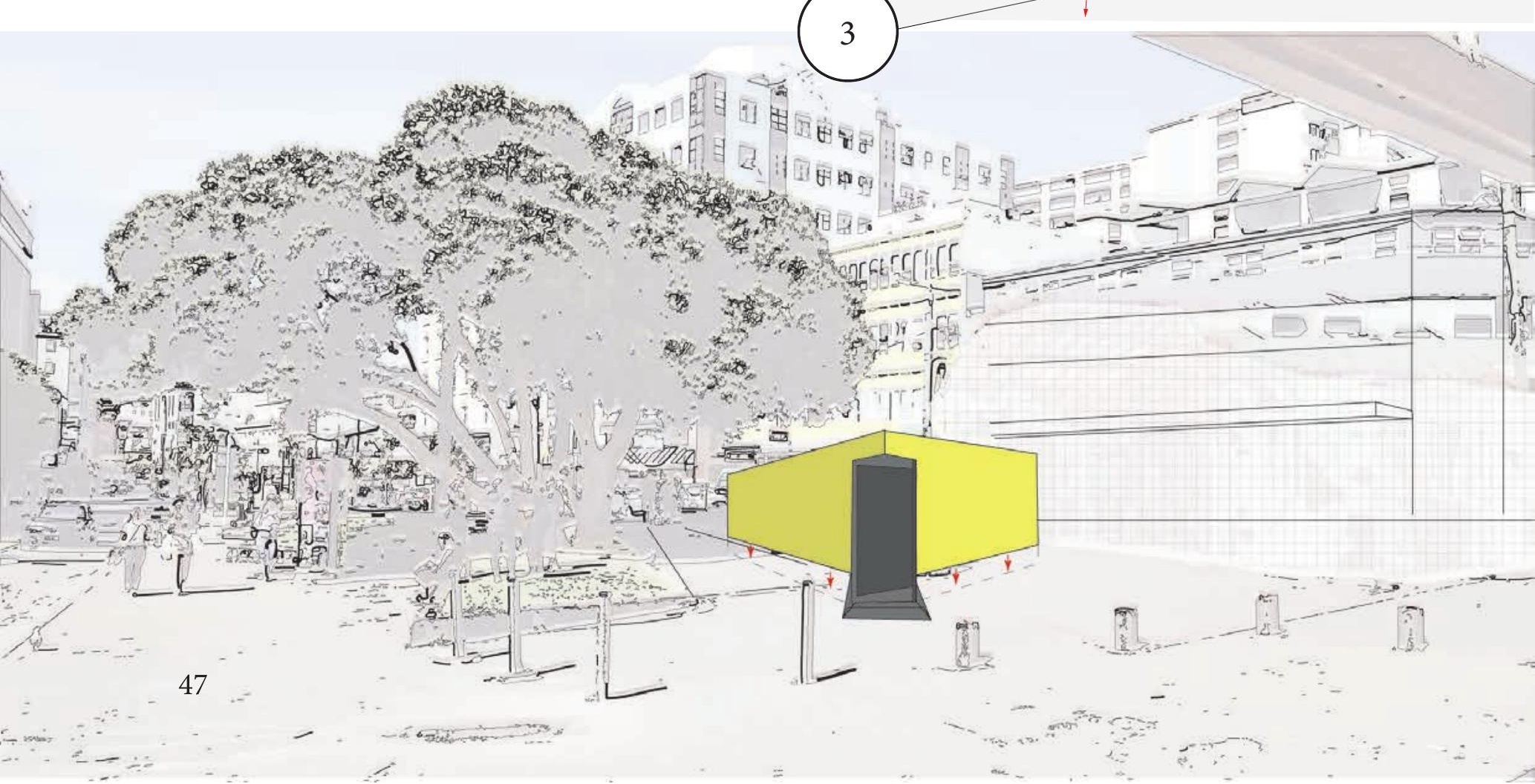




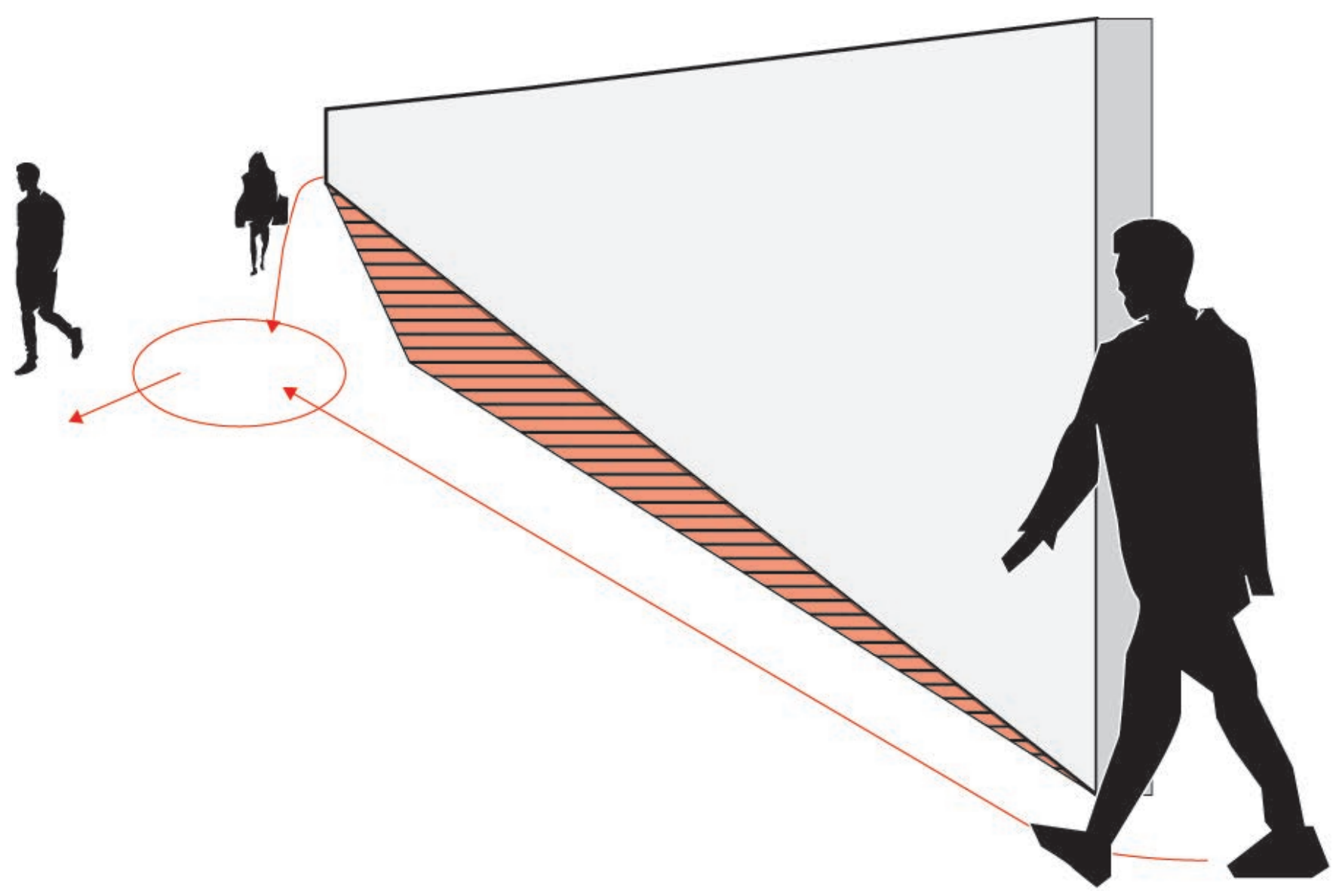

Fig. 4.11. (Above) Movement around higher wall and the areas out of traffic that it may create.

Fig. 4.12. (Right) Movement around Lower wall and the areas out of traffic that it may create as well as leaning Affordance.

48 


\subsection{Replacing the Wall}

I placed a wall that extended 1 metre above the maximum height of the Memphis Belle elevation and 2 metres above the lower channel running Between Dixon and Manner Street. This came from the original requirement for the wall which was to replace the facade of the original public convenience design facing Memphis Belle. Limited testing occurred and the wall at this stage was a result of the allowances of the topographic testing (see fig. 4.11 and 4.12)..
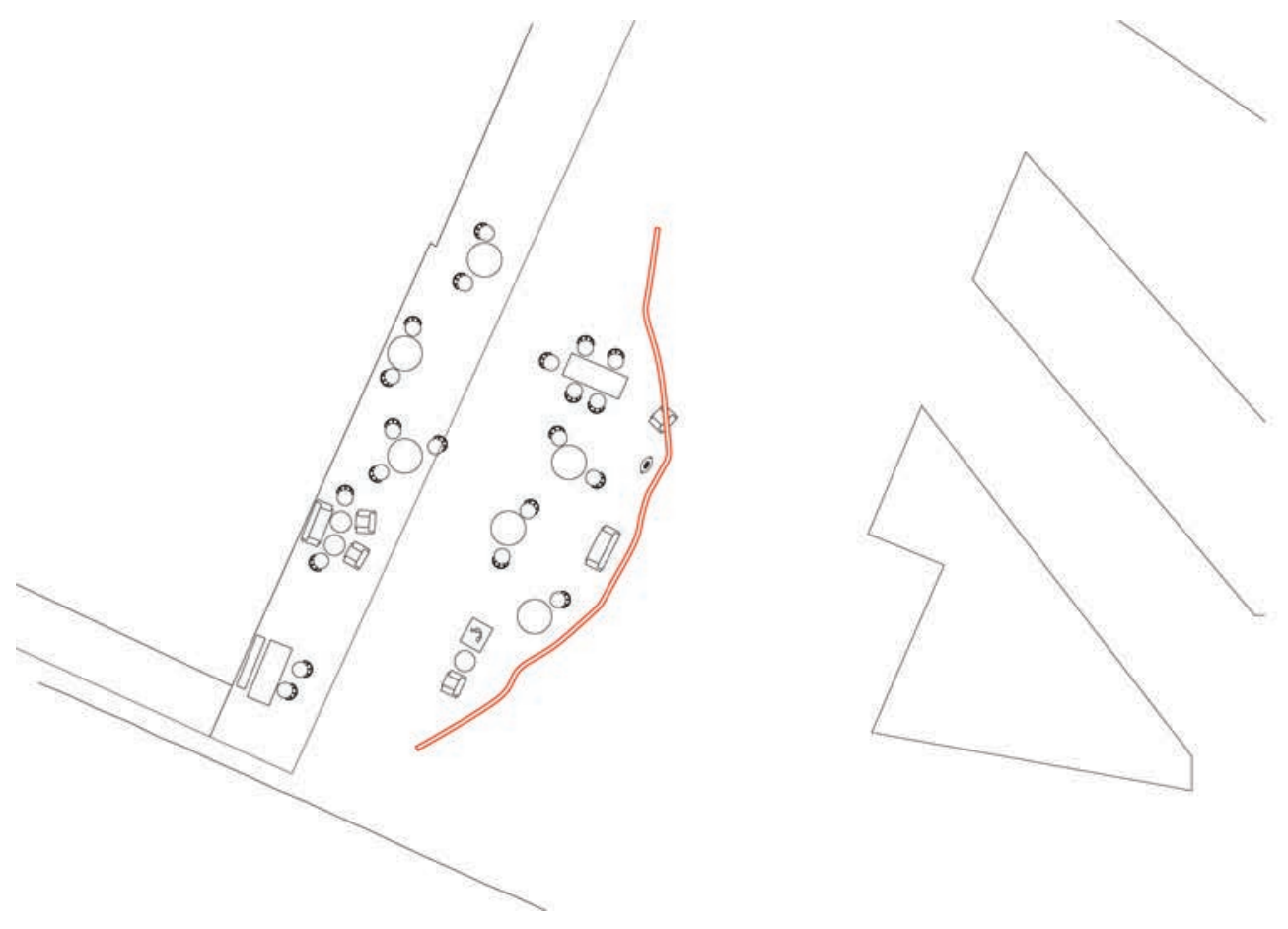

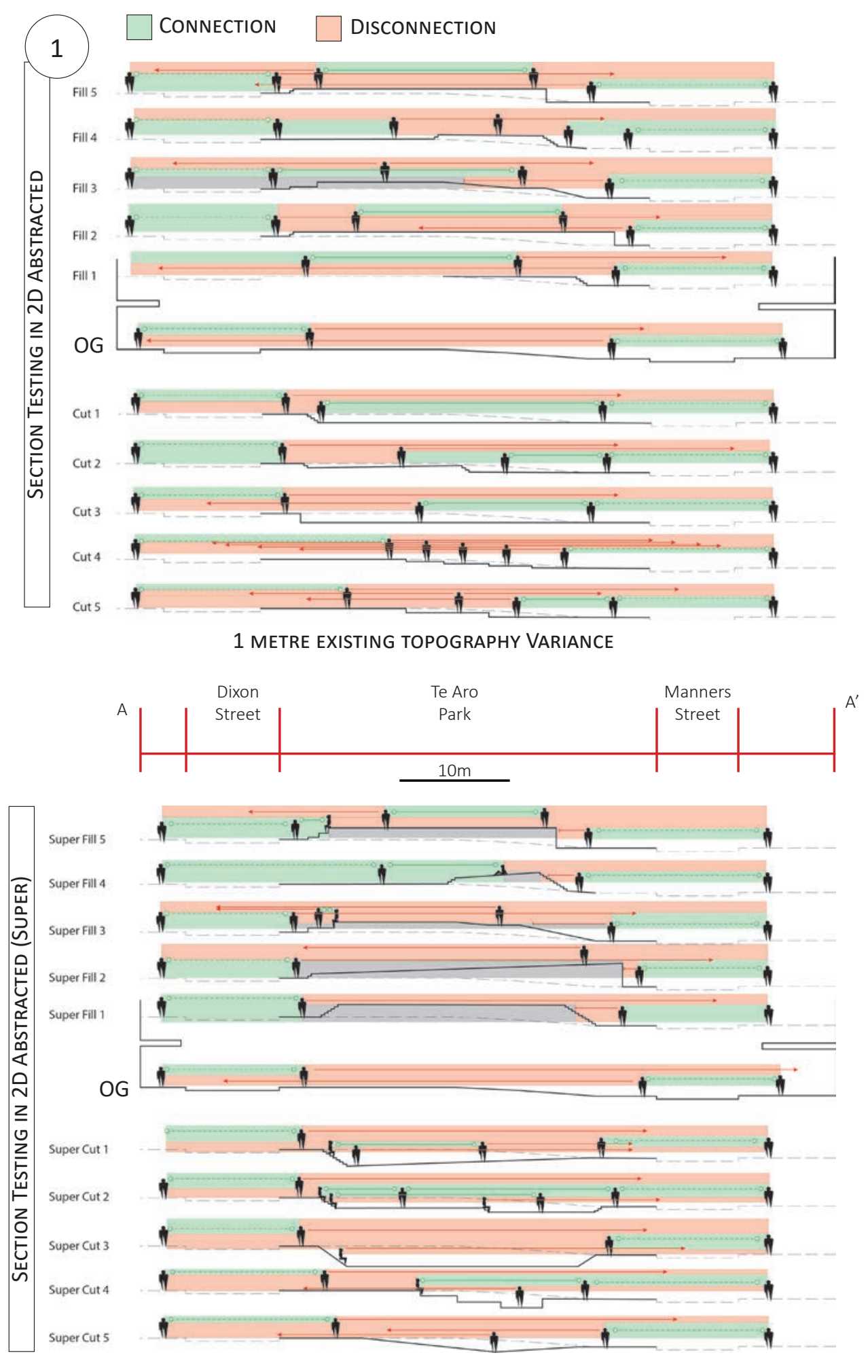

2 METRE TOPOGRAPHY VARIANCE

Fig. 4.13. (Top) Intial Topographic Augmentation. Using the 1 metre variance in elevation to cut and fill. An attempt to create different visual and therefore social connections across site

Fig. 4.14. (Bottom) Intial Topographic Augmentation. Using the 1 metre variance in elevation then exaggerating that elevation to 2 metres of either cut or fill. An attempt to create different visual and therefore social connections across site as well as understand how a 1 metre difference in elevation might compare to a larger variance. 


\subsection{Initial Topographic Testing}

In parallel with wall testing I was testing opportunities that may be created for separation of space using the natural 1 metre change in topography within the site between Manners and Dixon.

Here in $2 \mathrm{D}$ section i analysed the site as it currently sits with visual connection between users over different levels (see fig 4.13).

Basing the testing on visual connection was in accordance with the objective to create physical separation of spaces for movement and congregation while maintaining exposure between cohorts as well as unobstructed sightliness between Dixon and Manners Street.

As the site sits currently there is a greater connection across Dixon Street and separately across Manners Street, than there is over the crossing of the park.

I set up a series of simple level tests where the criteria for success was the greatest level connection over the site between Dixon and Manners Street (across the park) (see fig 4.15). The intention here was to create continuity within the zone of conflict in the $Y$ (NE-SW) direction and fluctuation in the $X$ direction (SE-NW)

I then exaggerated the distance for cut and fill to 2 metres and proceeded with iterations with the same criteria to fill (see fig 4.14).

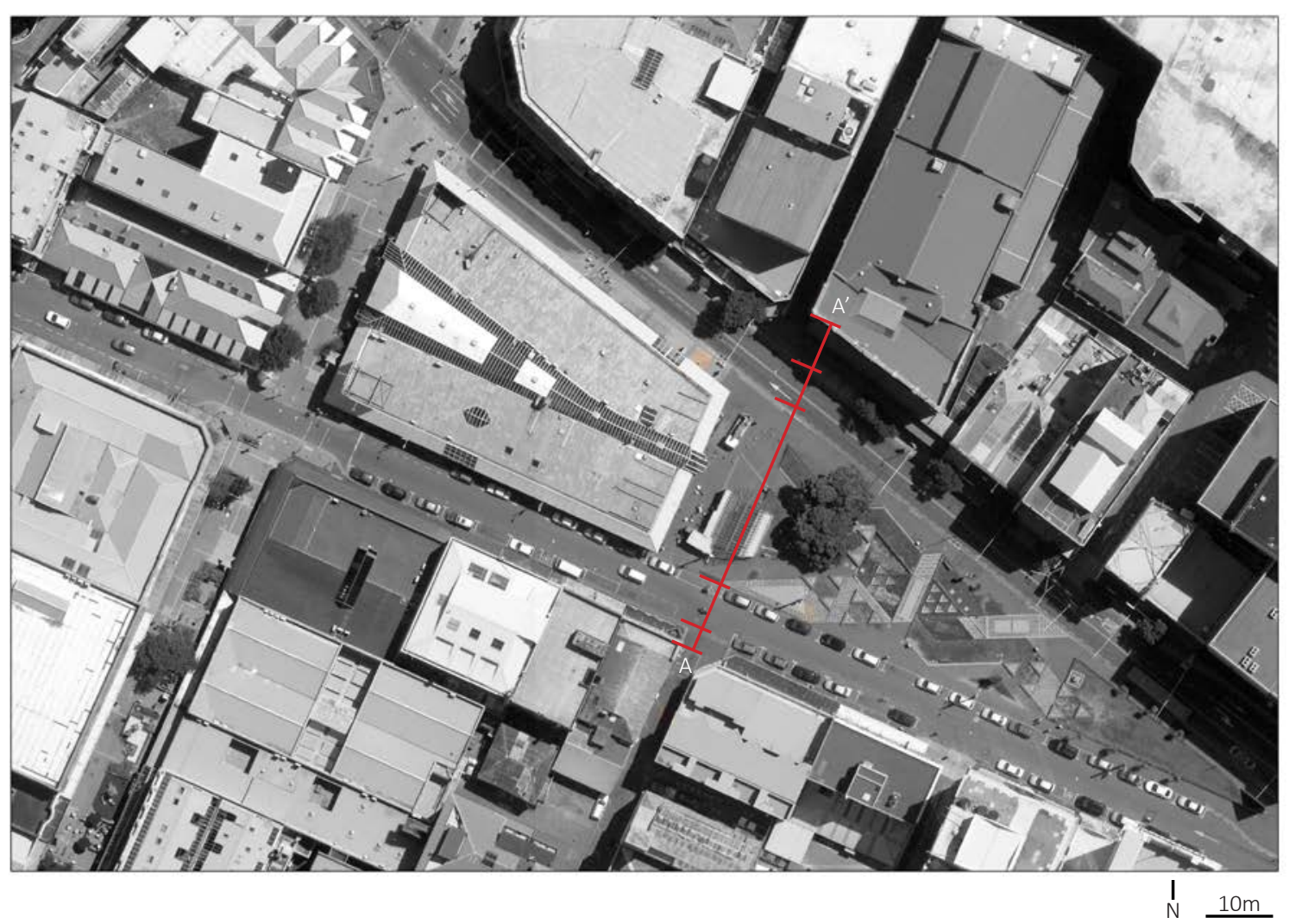




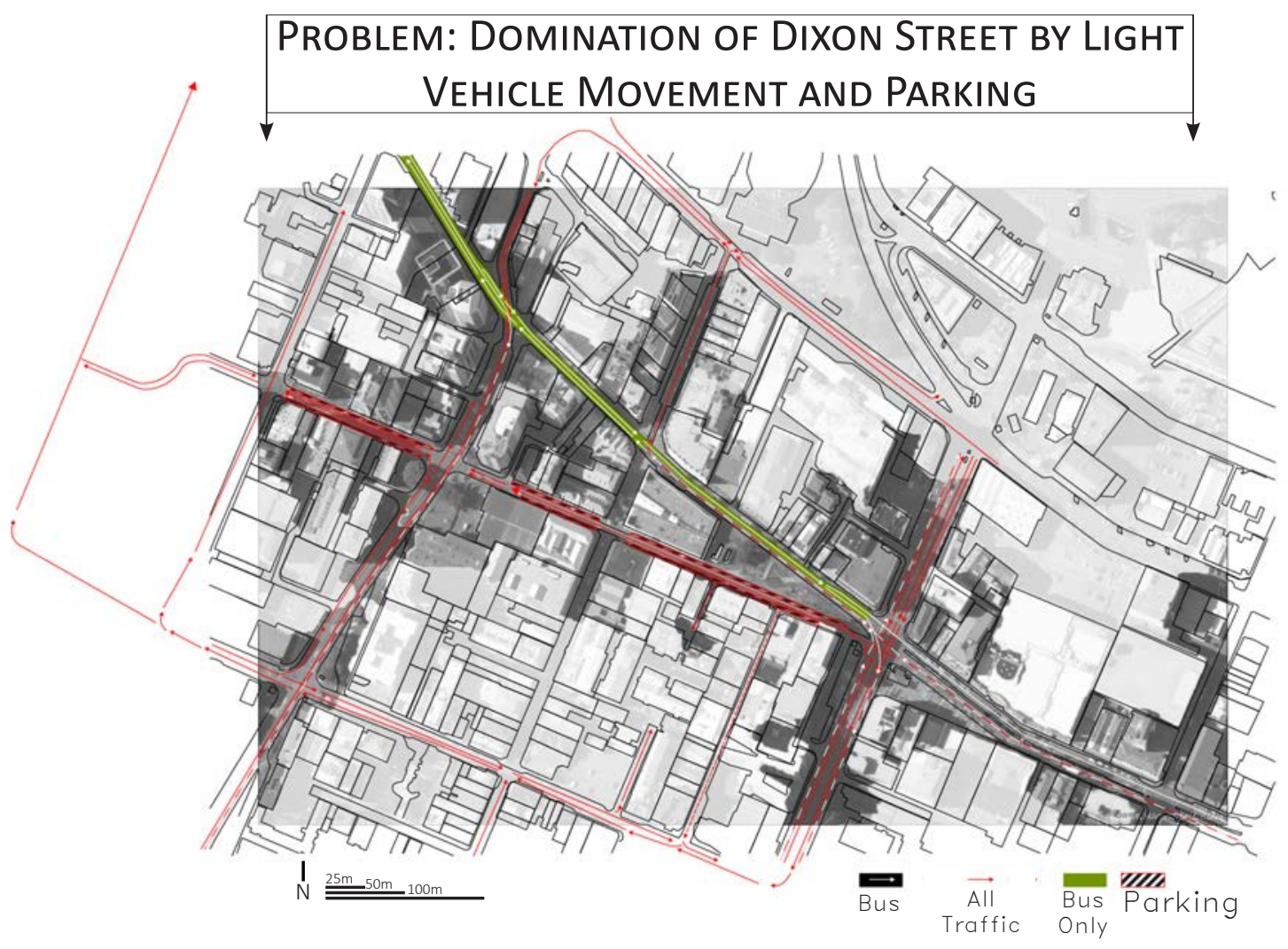

OUTCOME: REMOVAL OF PARKING ON DIXON STREET

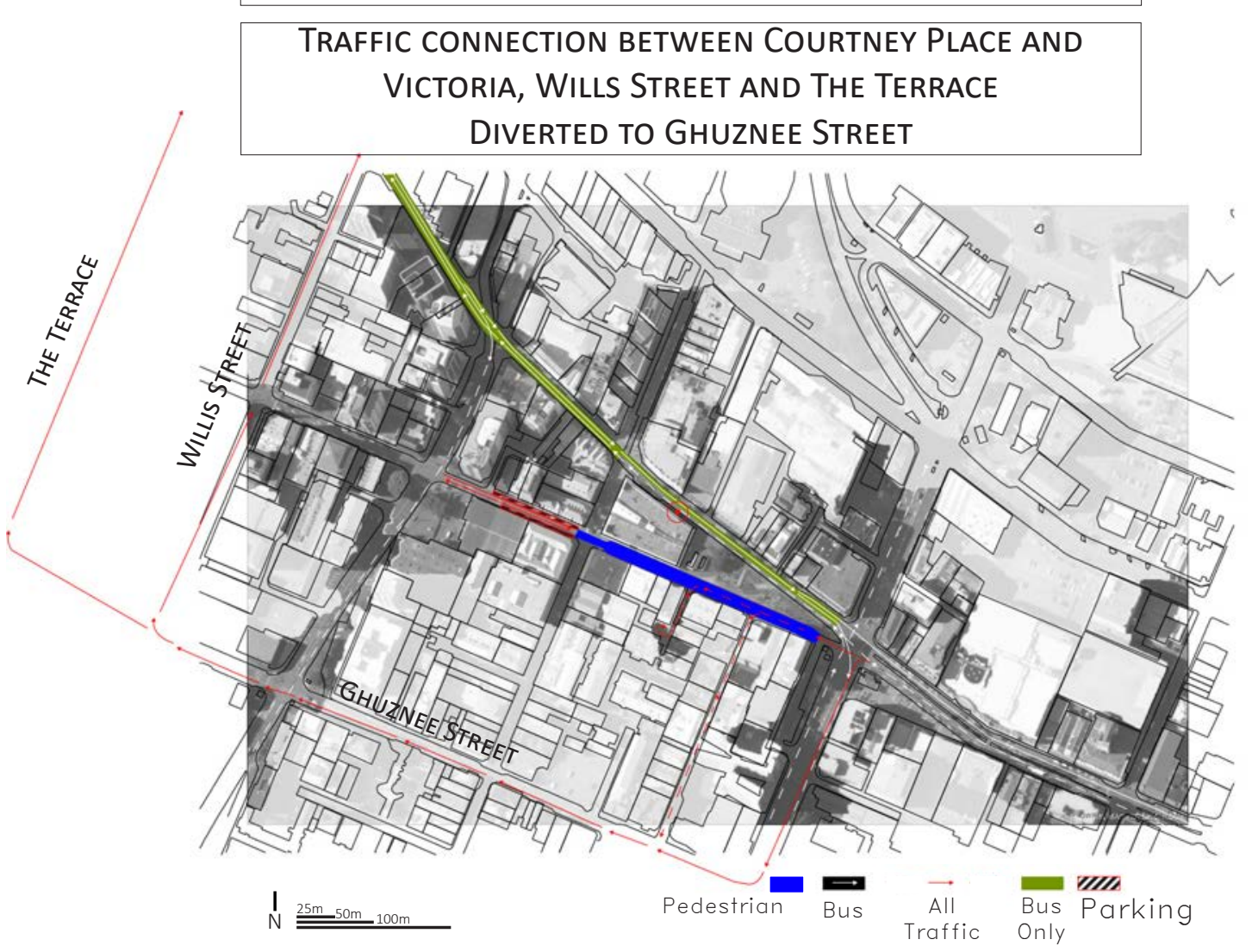




\subsection{Diluting the Threshold}

Despite the parking spaces being unrelated to the Mainstream users moving through or the Marginalised occupying the park, they create a significant physical boundary for those crossing the road to enter the park. Dixon Street as a road however is heavily used by vehicles and is a key connection for vehicle traffic between Courtney Place and The Terrace. The parking space on the northern edge of Dixon Street if removed would open up a significant amount of real estate to test on as well as removing a large physical and visual boundary (see fig 4.16).

I tested several degrees of re purposing the Dixon Street configuration. On a suburb scale I mapped routes that could act as traffic alternatives to allow lower Dixon the become a shared space (see fig 4.17). I tested shared space as well as different degrees of car park removal while maintaining the roadway. Although alternative routes were possible this line of testing was moving outside of the scope of my investigation. Car park removal was still within the scope but at a smaller scale in the interest of maintaining the restrained approach I originally envisioned.

Fig. 4.16. (Top Left) Mapping current vehicle movement proximal to site. Through Dixon and Manners Street. Highlighting alternative options for necessary connections. Diluting the Threshold of the harsh road boundary.

Fig. 4.17. (Bottom Left) Mapping possible alterations to arterial routes. Turning Dixon Street into a shared space. How utility lanes will be maintained. 


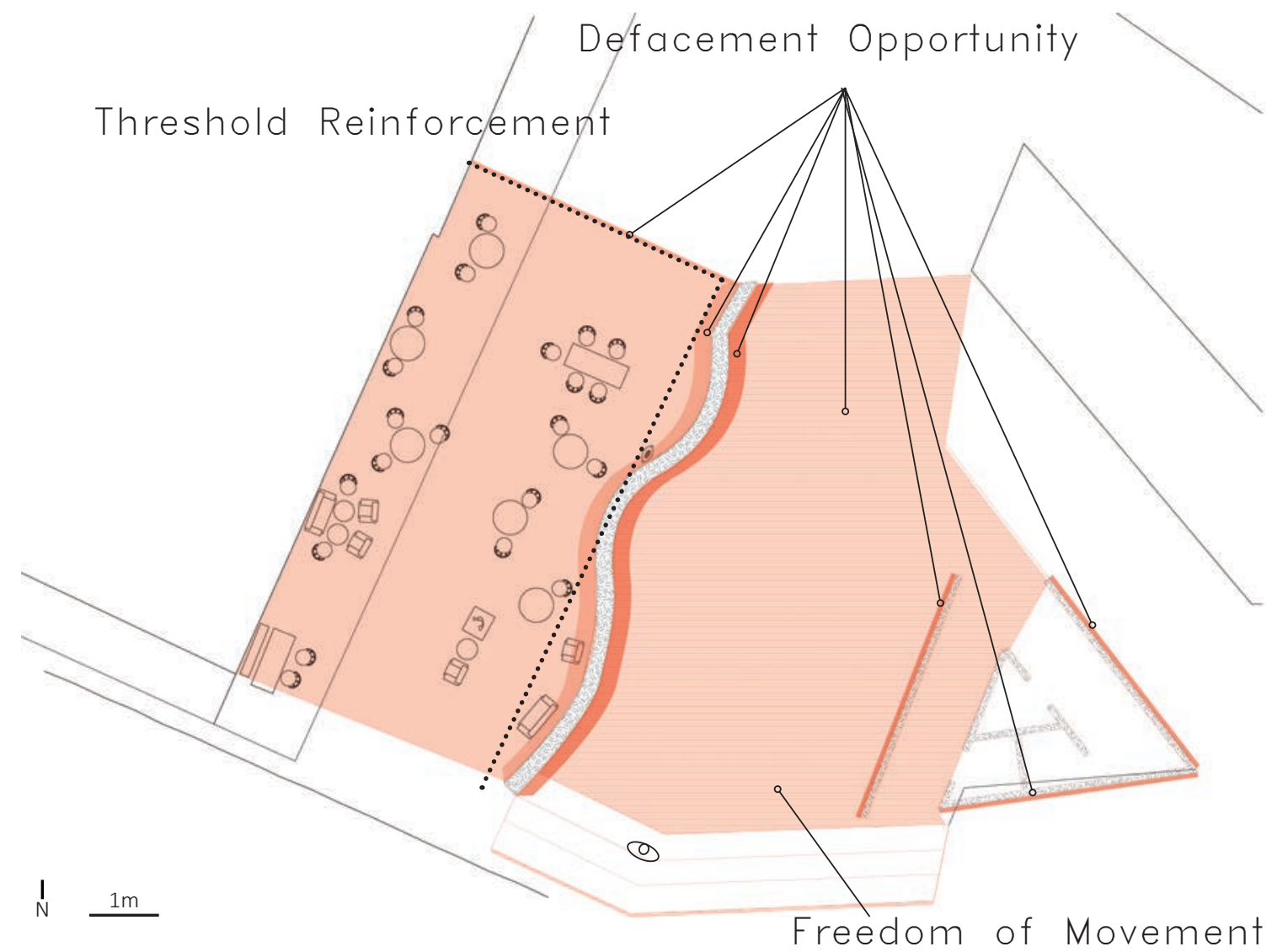

Fig. 4.18. (Above) Basic Layout of Site for initial Concept. 


\subsection{Concept and Reflection}

I put these components into a revised concept for the site with the public convenience as the central feature that everything else would be arranged around. I chose to have the level change focused close to Dixon Street with stairs dropping 1 metre, the outdoor area adjacent to Memphis Belle would be at 1 metre ending in a straight drop and the bathrooms would have their entry facing into the channel but with a facade/wall similar to that in Oriental Bay Changing Sheds that gives discrete entry and exit.

The Concept brought a result that through speculative mapping could increase the freedom of movement by the Mainstream through the space (see fig 4.18 and 4.20), however the exposure between the Marginalised and the Mainstream here was too limited (see fig 4.19). This was mainly due to the separation of the lower elevation the Mainstream would move on in contrast to the tall toilet block to the South East and the wall to the North West occluding visual contact between the two users. Additionally the Toilet block, wall and level configuration under speculative mapping would cut the Marginalised territory in two, diluting the power of their presence and forcefully rearranging the hierarchy in the space. A move that should be avoided if commoning/self organisation of hierarchy is to be established.

It became evident through this series of testing that there needed to be more weighting on topography and a further exploration of wall configurations if the concept was to be successful.

Fig. 4.20. (Below) Concept Perspective of Revised Augmentation and function of components including possible defacement. Viewed from Manners.

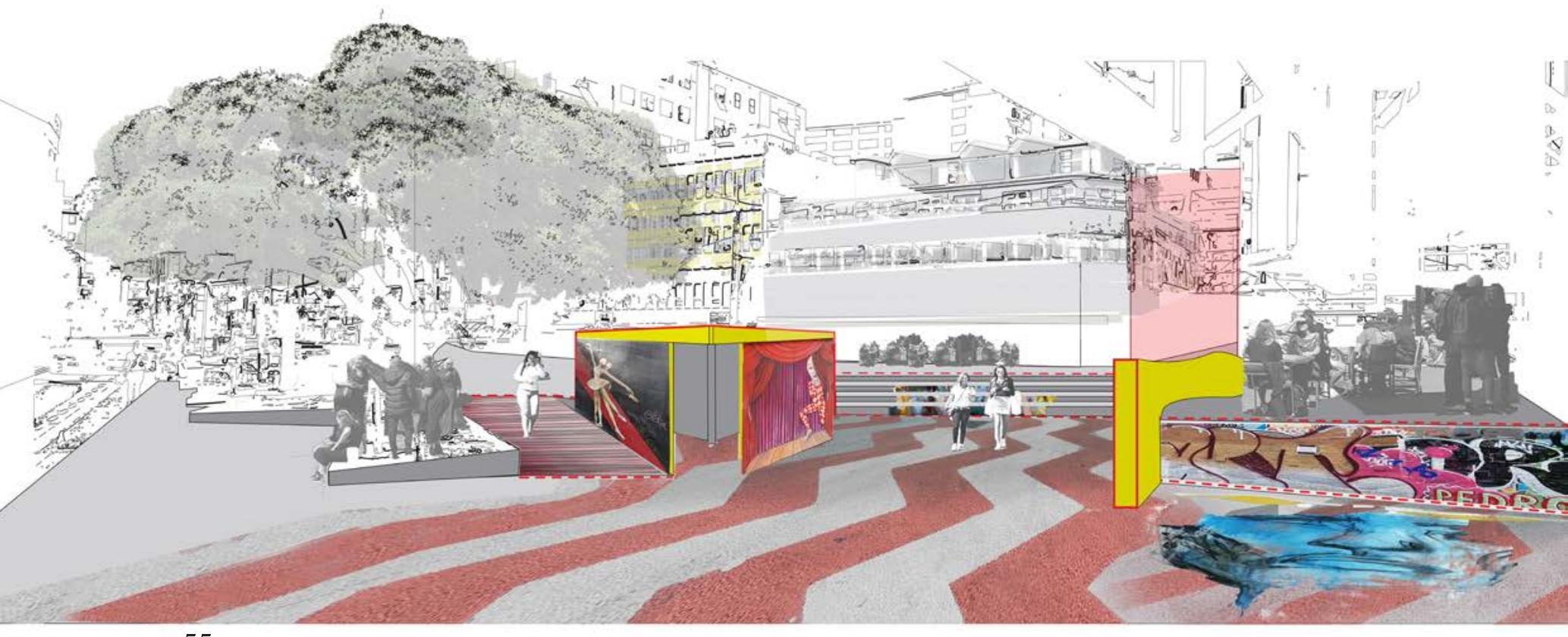




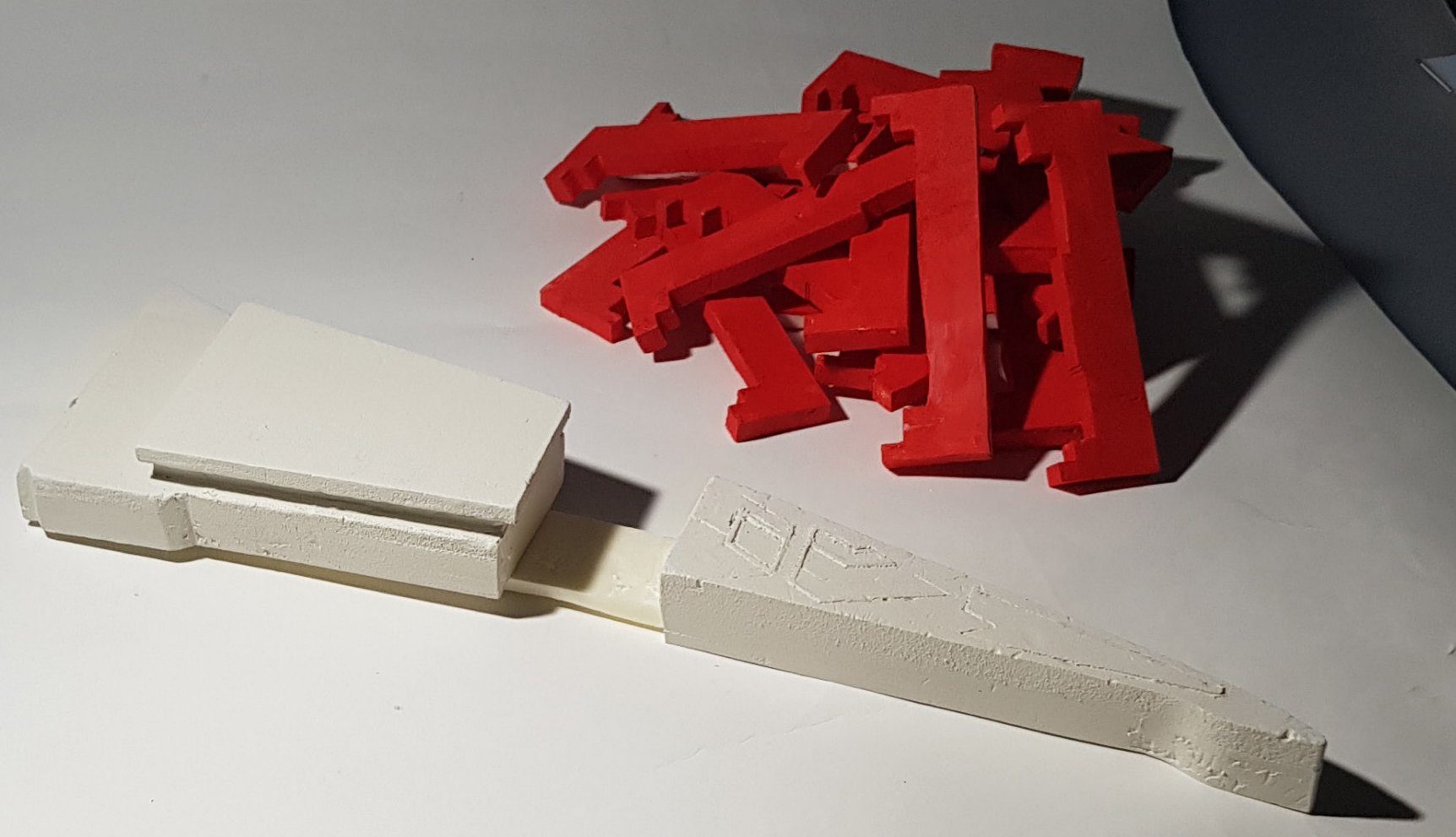

\section{Chapter 5}

\section{Topographic Augmentation Lead Design}




\subsection{Introduction}

As level testing produced an ineffective result in my initial concept, appearing to be of greater importance than initially anticipated, I decided to lead the next phase of testing with a more rigorous series of topography augmentation.

While site lines across the park where one of the objectives of my testing, exposure between the Mainstream user moving through and the Marginalised occupier was equally as important and had not been achieved in previous tests. This exposure would come in the form of a connection perpendicular to the main direction of movement rather than just a fluctuation.

In order to improve topographic testing I needed to speculate on the effect of topographic augmentation on both the $X$ and $Y$ access of the site.

I believed that the 2 dimensional sections didn't give me enough of an understanding on the contrast between levels side by side and i was curious to see how I could follow a chosen level combination with the public convenience. 


\subsection{Topography in Abstract}

I needed to test movement within the topography augmentation tests perpendicular to the movement through site. I tested this in abstract with perspective sections (see fig 5.03).

I discovered that this could give me some indication of movement and connection within the site but each section took time to abstract and there were a large number of combinations of abstracted section that needed to be investigated for speculative success.

Petrescu mapping over time techniques, combined with the photographic study were effective for initial review of the site. This relied upon the fact that the site existed physically allowing for a quick visit to the site with a camera to provide a great deal of information. I needed a way to visualise my topographic testing in three dimensions to rapidly analyse and speculate keeping continuity of reflection with my original site analysis techniques. 

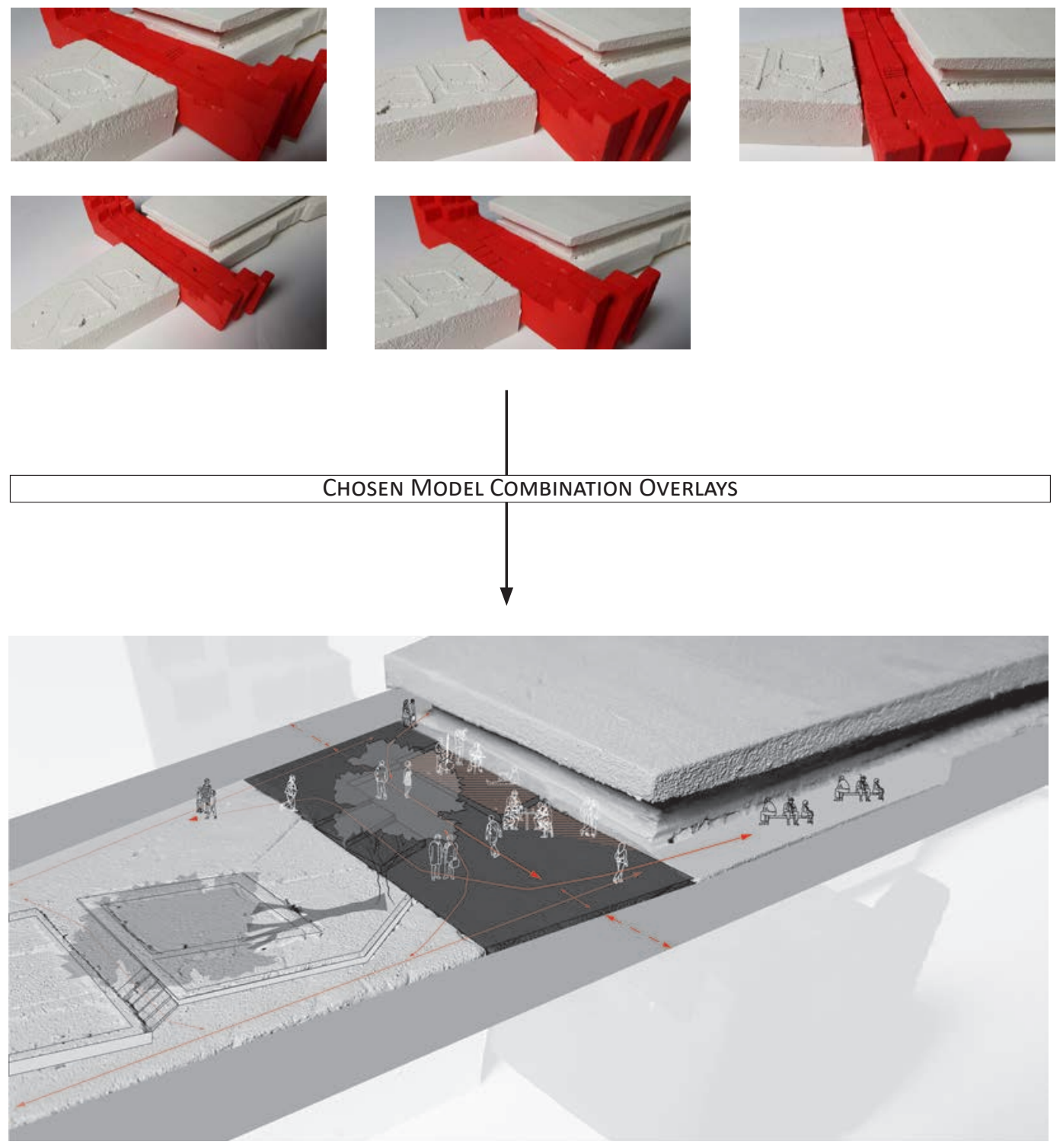

MILD

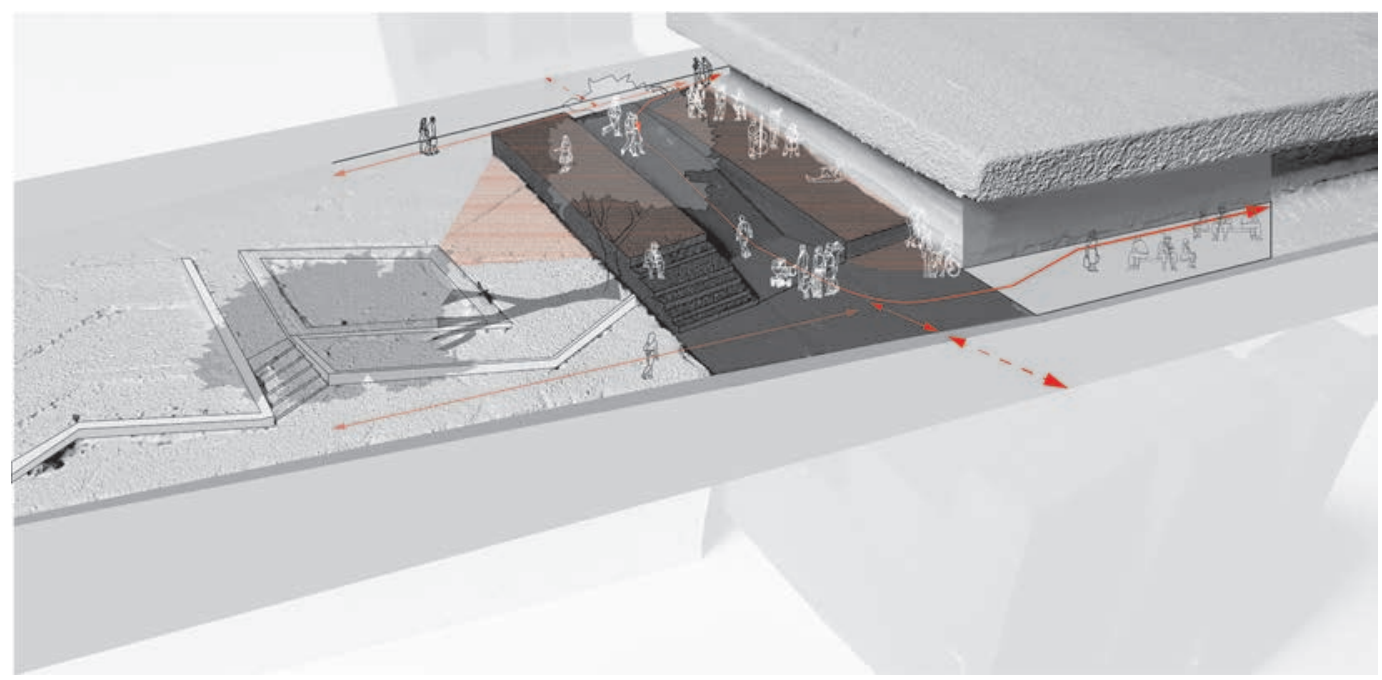

TRENCH 


\subsection{Modeling Topographic Combinations}

The limitations of abstract testing of topographic augmentation led me to creating a digital drafting model that went onto become a scale model made from gold foam. The site and 17 sections to combine and test in the zone of conflict (see fig 5.01 and 5.04).

After many combinations I narrowed down a select few that fit the criteria of a movement connection along the $\mathrm{Y}$ axis and an exposure connection on the $\mathrm{X}$ access. I used photographs in an attempt to set up for diagrammatic overlay and analysis of combinations in a similar fashion to my original analyses (see fig 5.05, 5.06 and 5.07).

Fig. 5.04. (Top) Photographic Study of level iterations combined in sets of three within site model.

Fig. 5.05. (Middle) A sample diagrammatic overlay of a combination of level tests that were gentle both in level change as well as contrast between the three sets. Here there would be little difference between the visual connection between the Mainstream moving through the middle and the Marginalised occupying the periphery.

Fig. 5.06. (Bottom) A sample diagrammatic overlay of a combination of level tests that created a trench for the thoroughfare for Mainstream users movement. Here the Marginalised occupying the periphery would be able to observe the Mainstream while the Mainstream would have limited visual connection to anything other than the path and direction of movement they were on. 


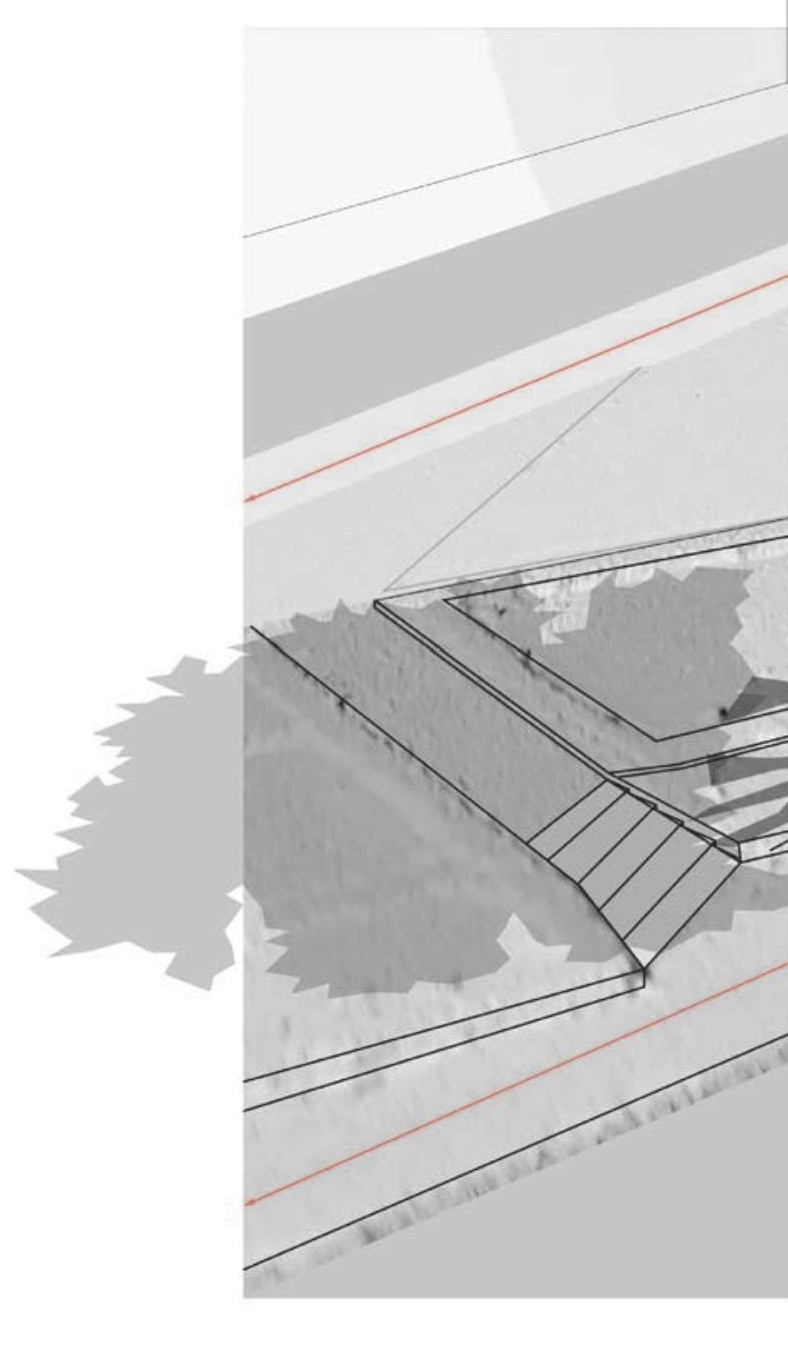


The model gave me a better understanding of how the site falls away and how different level combinations might affect the users in site. Photography followed by diagrammatic analysis gave me a temporal aspect to analyse and was consistent with my initial analysis of the site.

Using these techniques to build upon Petrescu's tracing over time techniques i believe i was able to gain further insight into my level augmentations.

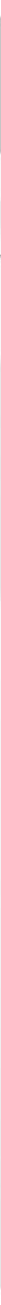

\section{CAUSEWAY}

Fig. 5.07. Diagrammatic overlay of a combination of level tests that created a Causeway for The Mainstream user moving through the sight. The Marginalised occupation here exists to the periphery. Protected and obscured from the Mainstream dominated outside world. A higher level for the Mainstream outsider means they are exposed to the full site as well as the Marginalised. 

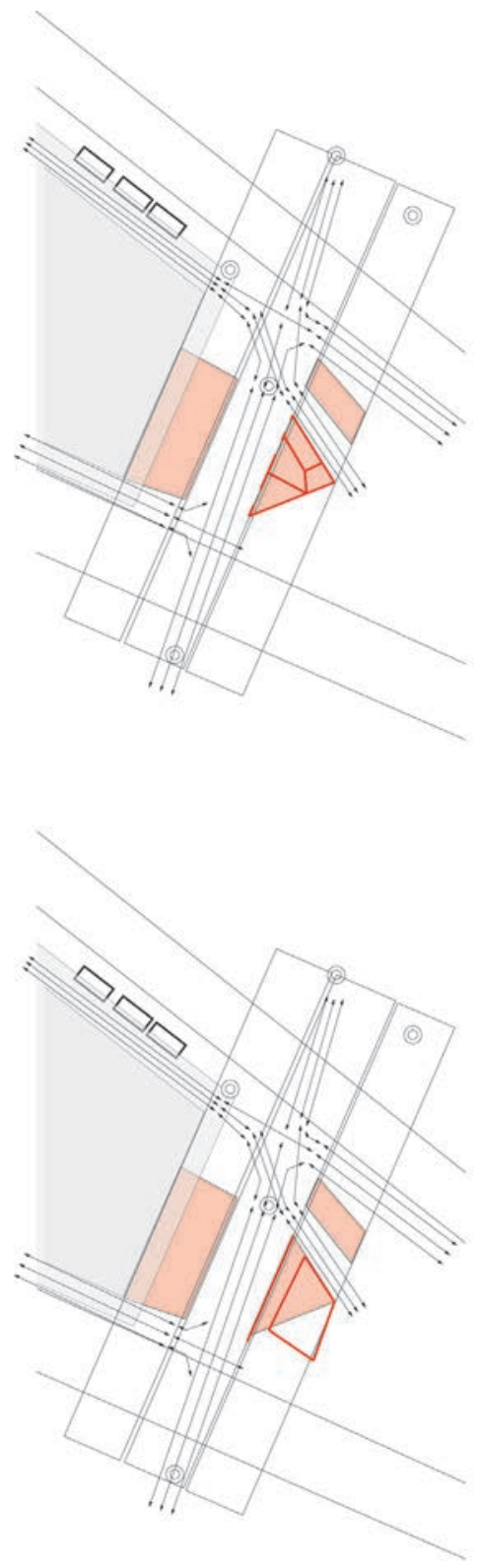
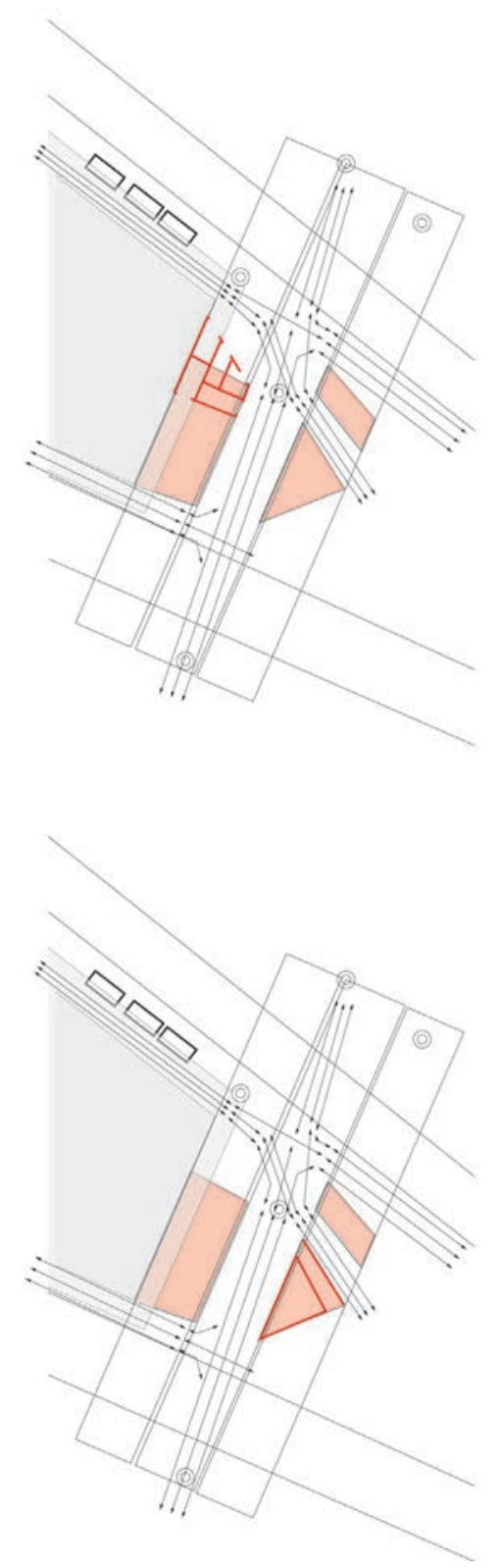

Fig. 5.08. (Above) Diagrammatic Plan. Iterations of possible positions and fit for the Public Convenience. Arrows indicate Mainstream user vectors. Pink zones represent Marginalised

occupation according to both existing occupation patterns as well as reinforced occupation through level testing
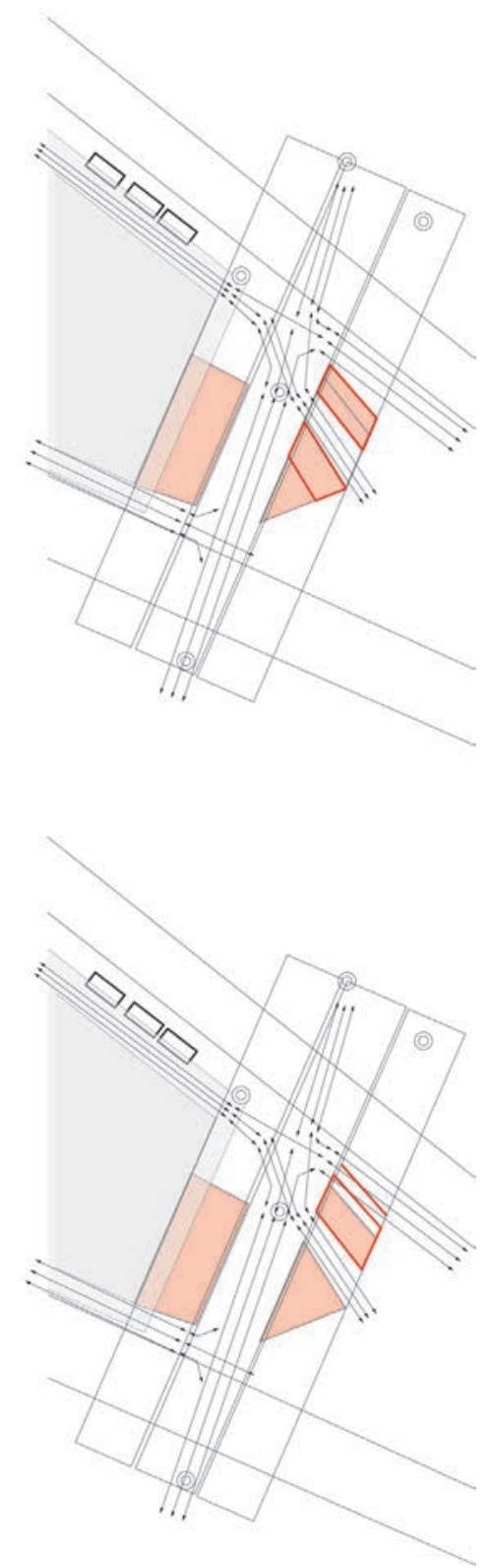

Fig. 5.09. (Right) Diagrammatic Perspective. Overlay of Model Photographic level test. Addition of selected Public Convenience and how it may fit into site along with wall systems.

Fig. 5.10. (Below) Perspective looking out of the Memphis Belle window across the park, before and after restrained design augmentation of the Public Convenience
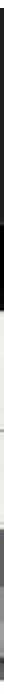


\subsection{Re Introducing the Public Convenience}

Using the same triangular geometry for the public conveniences as initially tested I was able to insert the unisex facilities discreetly into the plan. Discreet in this instance refers to maximisation of visual clearance across the park for the Mainstream user. I oriented the triangular structure in a way that allowed for the preservation of a wheelchair ramp/divergent pathway that in the site scale would cater to those walkers moving from Courtney Place through to the Golden Mile on Manners Street.

With the diagrammatic overlays used in the photographic study of the scale model $i$ was able to test sightliness and movement/congregation of users in a perspective study (5.09) as well as the 2 dimensional section elevation and plan drawings (see fig 5.08). Again bringing consistency to my speculative analysis of success in design concepts.

Through the original topographic augmentation study, and with the Frey burg changing sheds as inspiration, I was able to once again bring the elevation profile of the public convenience down to the level of Manners Street. Here its 2.5 metre height would only rise 1.5 metres above the Dixon Street level. This not only allowed for a clear line of sight from Eva Street, across Dixon toward the Opera House on Manners, but also allowed for a clear line of site from within Memphis Belle Cafe and the Mainstream walkway down the length of the park, toward Courtney Place.

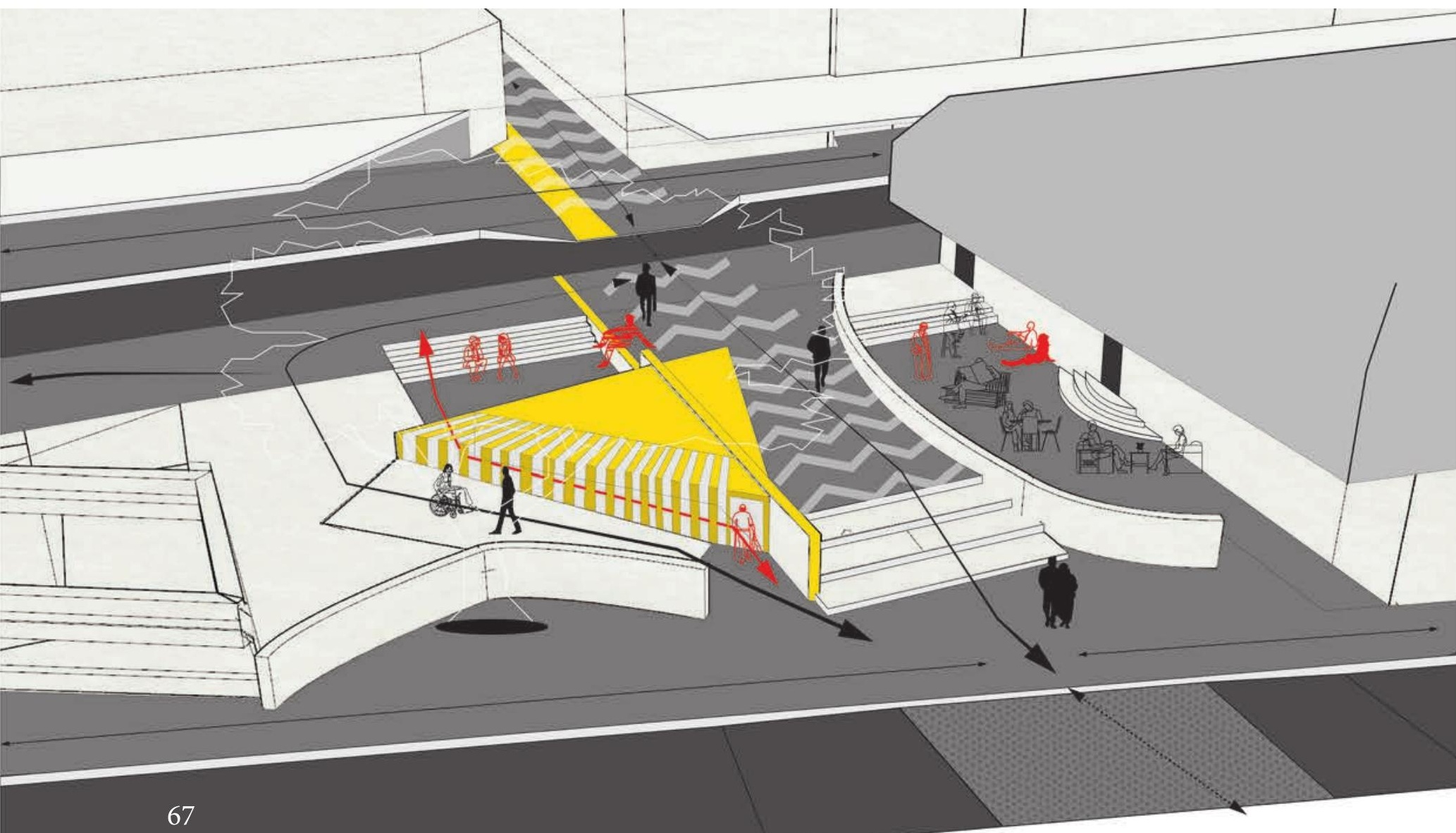




\section{FILTER}
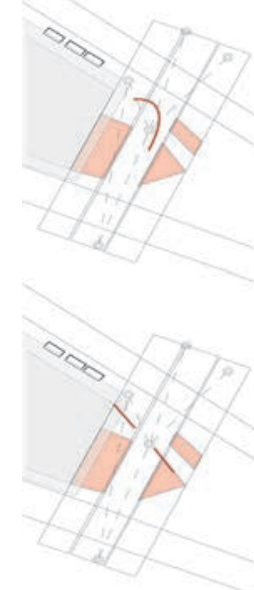

\section{SEgREgate}

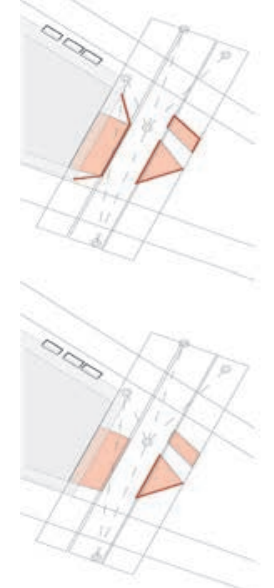

\section{AN AUdiENCE}
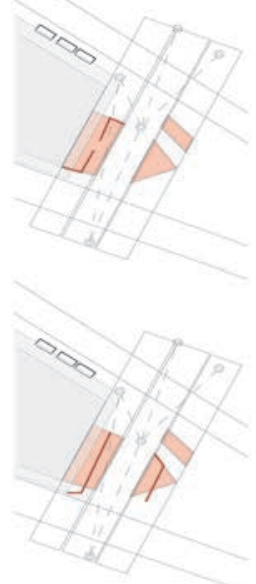

\section{SPLIT}
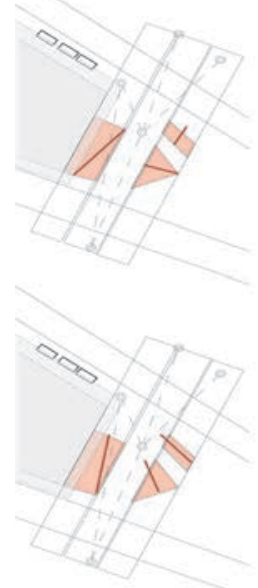
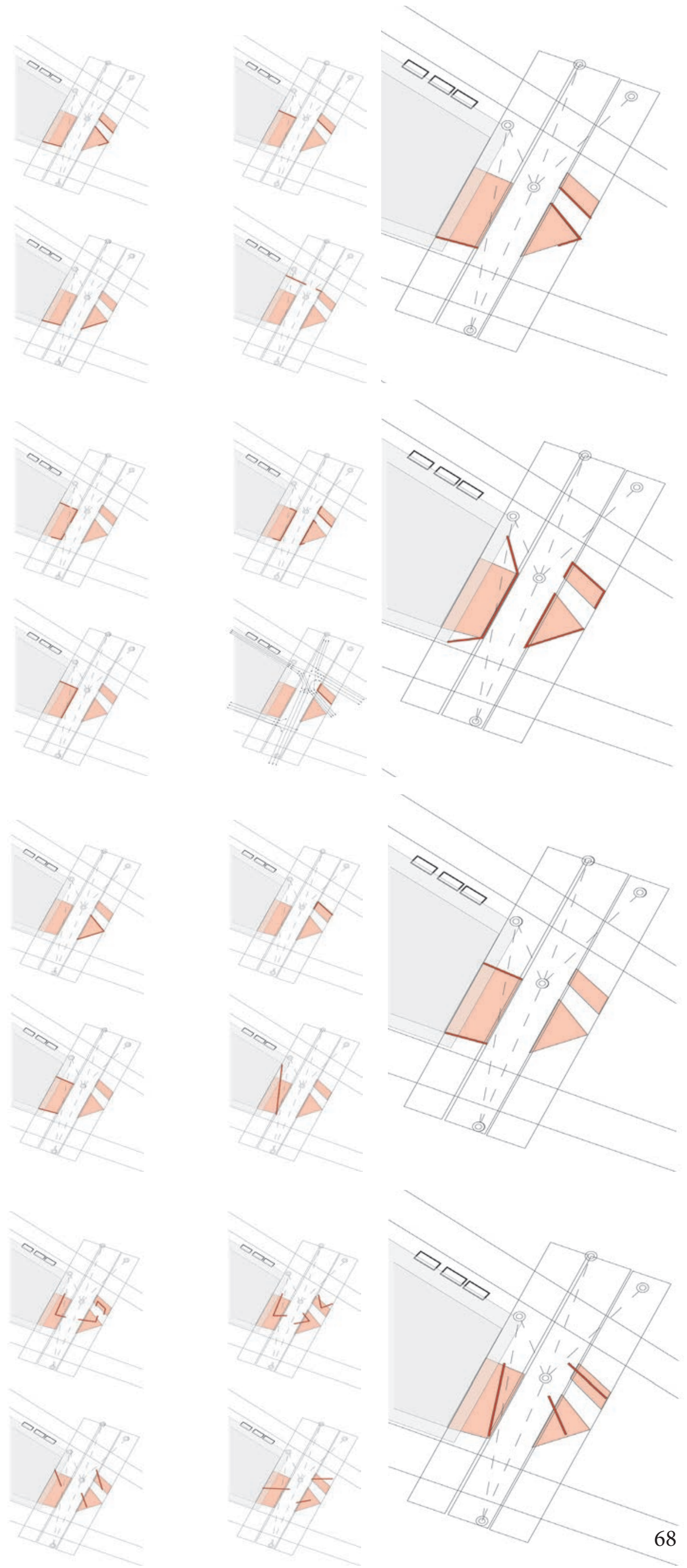


\subsection{The Wall and affect}

My original interest in the wall itself as both a barrier and a blank canvas for defacement ended, in the first concept, in me attempting to simply replace the facade of the existing public convenience. In this series of testing I want to further explore the role of walls in separating and integrating users in a space paying attention to other social outcomes that may result from placement and form of wall(s) within the site.

I began testing multiple iterations in plan grouped into general goals for the sociality on site. Split, Segregate, An Audience and Filter were the categories i chose initially (see fig 5.11). These antonyms were chosen for their description of what $i$ wanted to avoid as well as accomplish on site. I was to complete the iterative process followed by categorization followed by critical review of my categorization and attempting to speculate on alternative potential outcomes for wall iterations that may have been negatively categorized in plan.

Fig. 5.11. Diagrammatic Plan. Iterations of possible positions and fit for the Wall Systems. Circles represent points of important visual connection for users moving into and through the site.

Pink zones represent Marginalised occupation and red lines represent wall systems. Iterations catagorised into their affect under speculation. 

Challenging my initial speculation on iterations in plan was important as it lead me to imagine and test how, for example, iterations that were categorised under segregation (the opposite of what this research aimed to achieve) could become something with potential for achieving objectives by adjusting its qualities in elevation. To carry on the example, exposure between the Marginalised and the Mainstream could be achieved if the walls were low enough, while privacy and dignity for entering and exiting the public facilities could also be achieved if the wall was high enough. There would be and was a height at which I believe an otherwise unsuccessful wall iteration in plan, could be more successful once adjusted in elevation, than wall configurations that were initially identified as successful in plan (see fig 5.12).

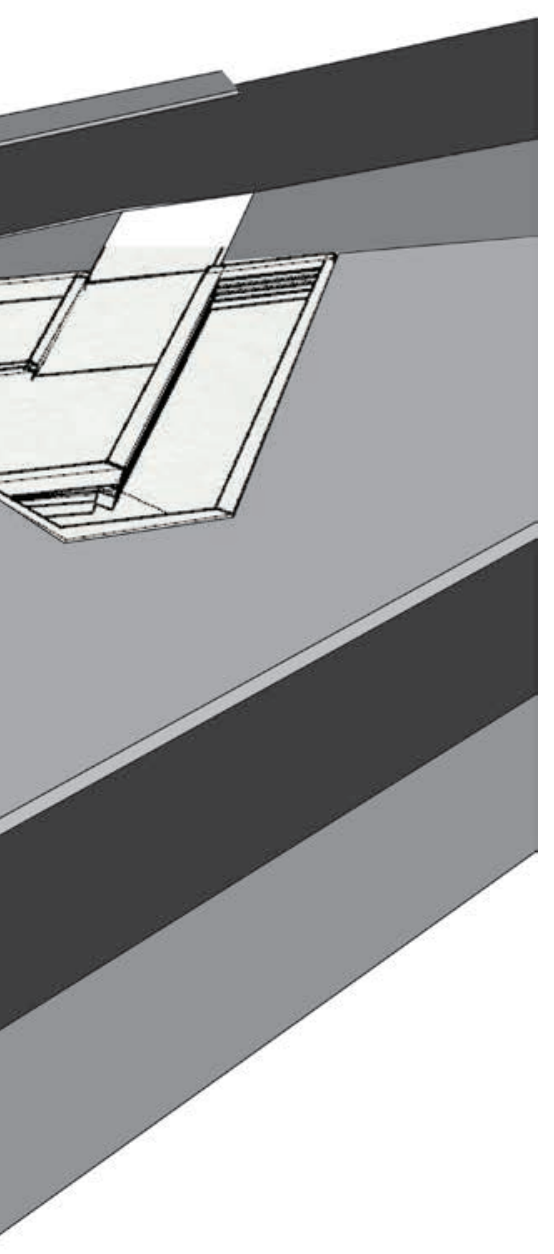

Fig. 5.12. Diagrammmatic Perspective. Overlay of Model Photographic level test. Addition of selected Wall Systems and a study of how they may create zones of separation physically while maintaining visual exposure between the two cohorts. 


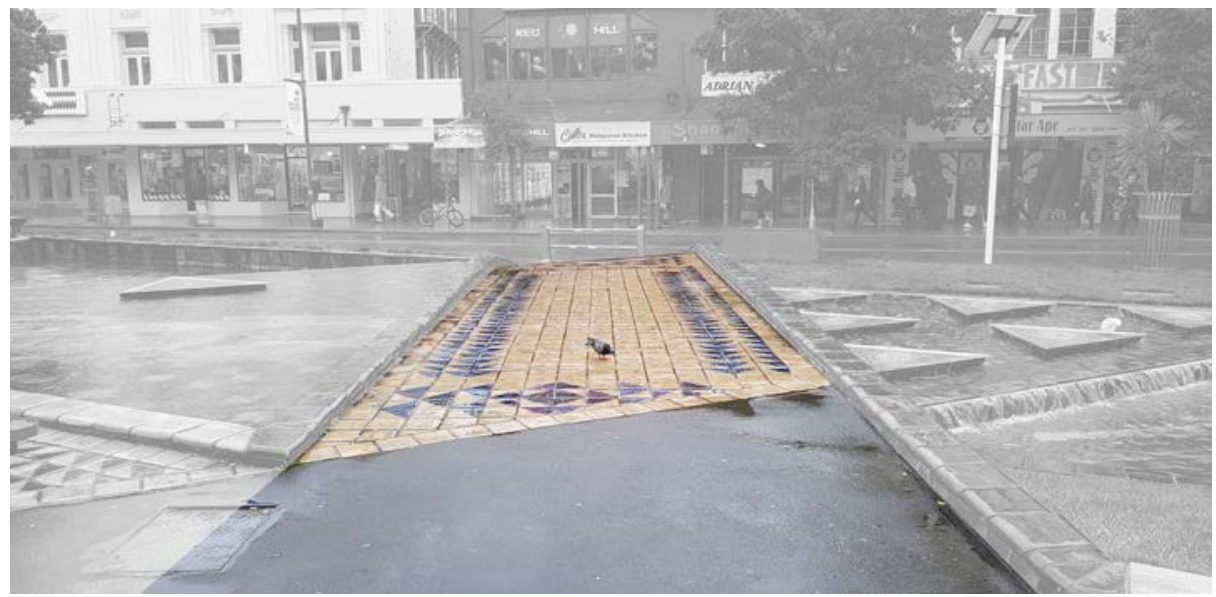

Tiled Ground

patterns arranged orthogonally against asphalt
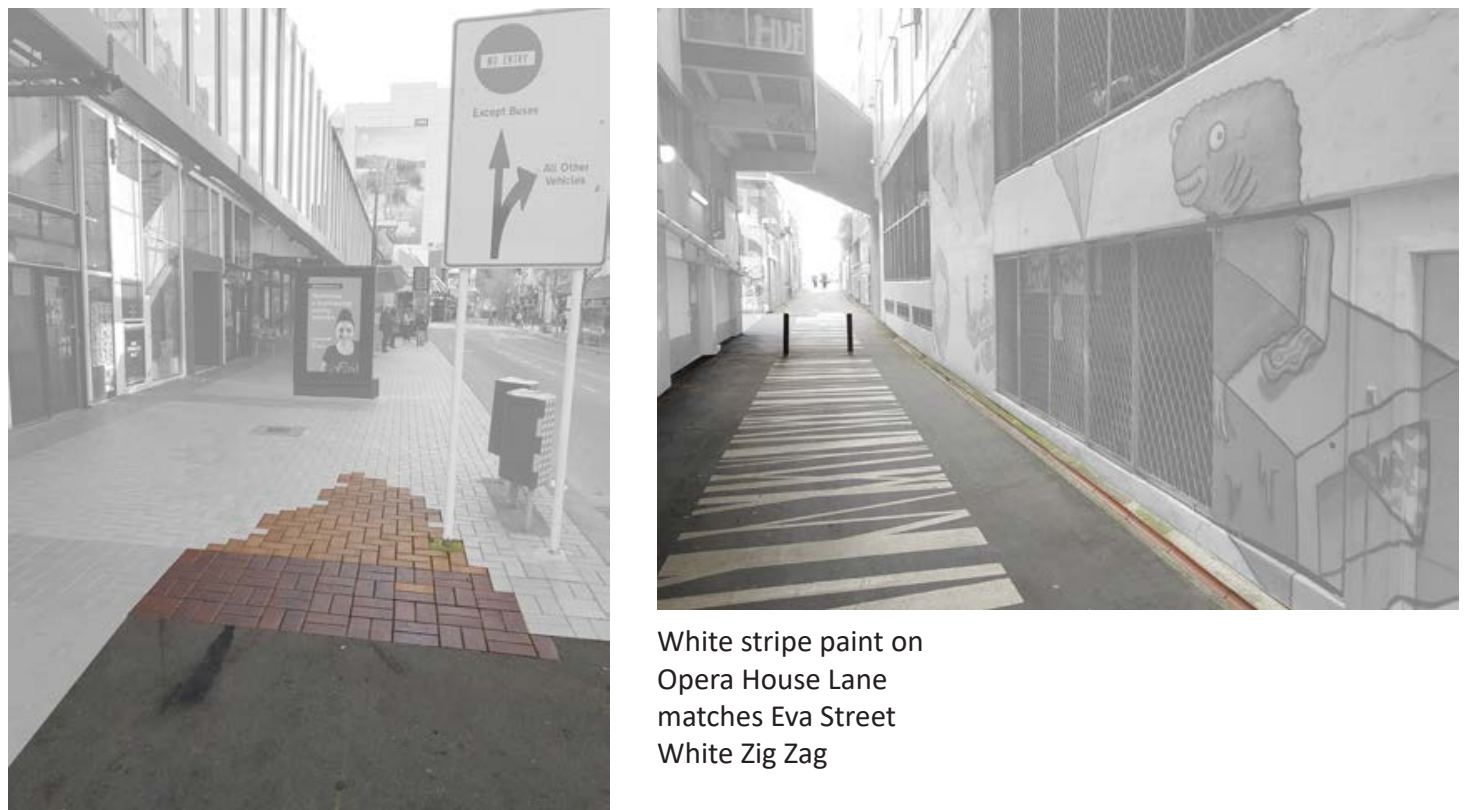

\section{White stripe paint on}

Opera House Lane

matches Eva Street

White Zig Zag

Cuba Street and

Lambton Quay Tiles end

abruptly and do not

integrate with site

Fig. 5.13. (Top) Photographic Isolation of ground Aesthetic. The tiles of Shona Ripira Davies artwork. With a Sheen comes the slippery surface, a richer texture especially when contrasted with its neighbouring material, asphalt.

Fig. 5.14. (Middle Left) Photographic Isolation of ground Aesthetic. The red bricks of Cuba Street bordering the golden bricks of Lambton Quay met by the generic asphalt of our site.

Fig. 5.15. (Middle Right) Photographic Isolation of ground Aesthetic. Clean cut asphalt painted with simple white paint patterns giving the lane way a central focus. 


\subsection{Aesthetic Continuity Testing}

Aesthetic continuity testing was aimed at bleeding the aesthetics of street art, tiling and colour schemes into the park at points where encouraging movement was the intention without diluting the thresholds where congregation and commoning was the intention.

Although Stavrides highlighted the importance of the threshold for a local enclave of commoning, I believed that the thresholds here were not working toward a fluid space of commoning. The barriers to entry like the large public convenience structure, the busy Dixon and Manners Streets as well as the aesthetic separation of the park from the rest of the space made it too inaccessible for outsiders to transition into the space. The initial conundrum here was that I was also was concerned about diluting the thresholds and thereby inhibiting the ability of the local users to separate and identify with the space in contrast with the surrounding area.

Fig. 5.16. (Below) Perspective Collage. Imagining what the new concept for Topographic augmentation, Public Convenience and wall might look like in comparison to the existing site.

\section{After FROM EVA}

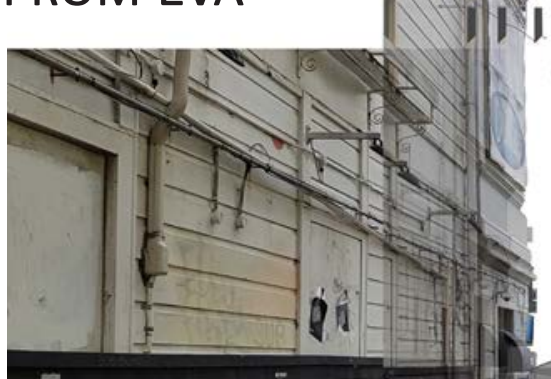

으

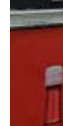

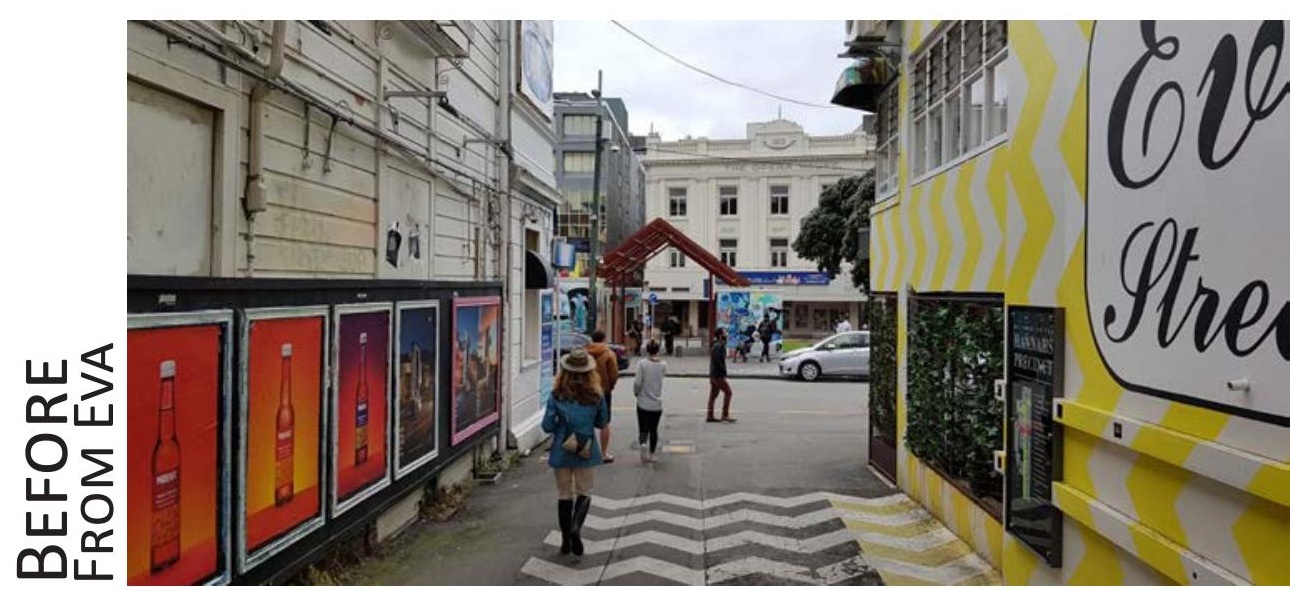




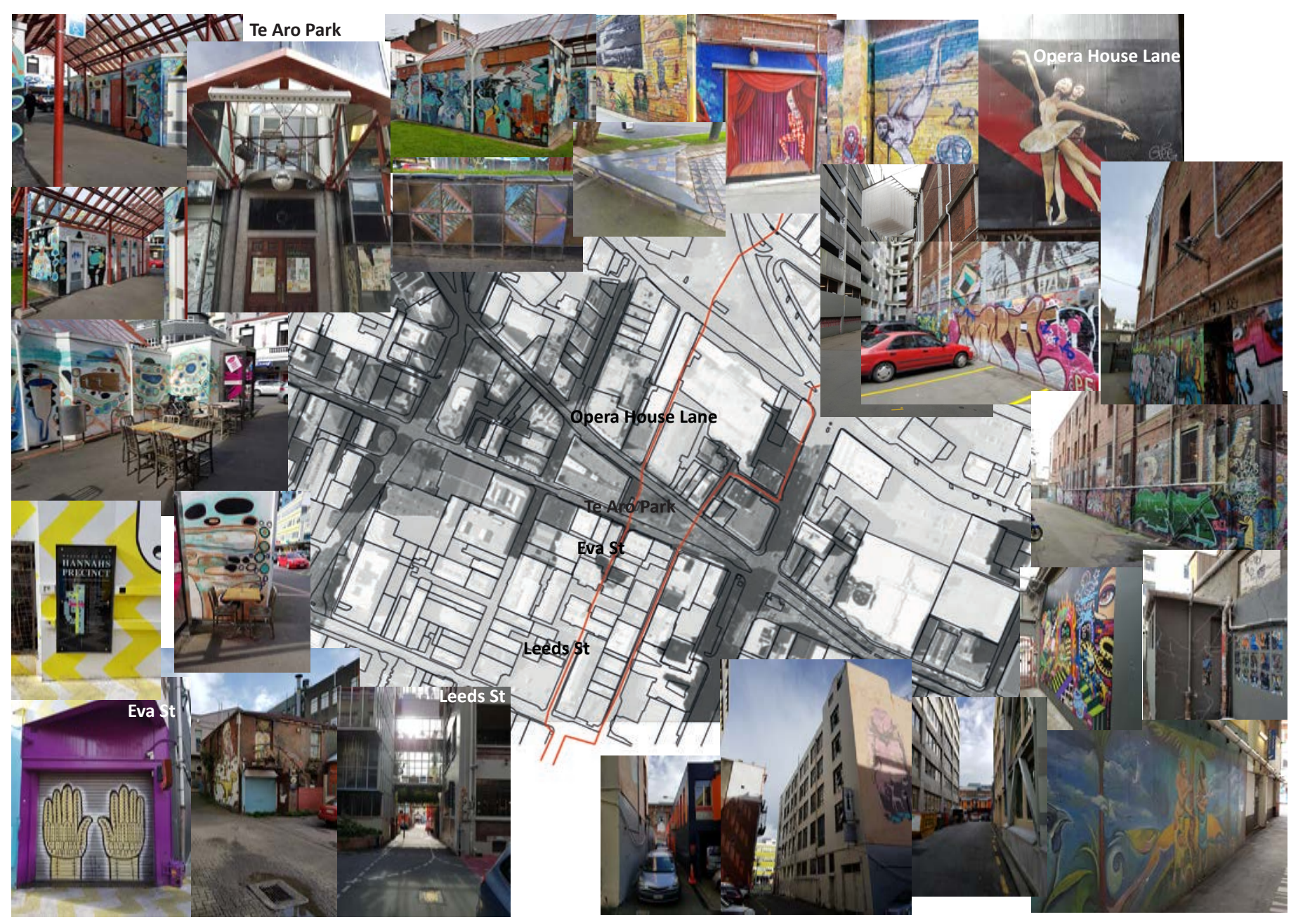

Fig. 5.17. Photographic study of Defacement. The central map shows the two main routes users take while moving through the site. Surrounding this are examples of the colourful and varied artwork both formal and informal. These images of aesthetic will be used to inform continuity of aesthetic moving through the site. 
With a camera i moved through the surrounding lanes and through the site as i had observed Mainstream users doing. I took photos of the various street art and horizontal plane aesthetics as i moved along the journey (see fig 5.13, 5.14, 5.15 and 5.17). I then used these aesthetics to create more gentle thresholds between the spaces. My theory behind this was a gentle visual threshold would encourage movement into and through the space. This tool was a light compliment to the existing concept informed by topographic testing, public convenience placement and form and wall insertion.

From the first concept $\mathrm{i}$ adapted the idea of narrowing the gap across the heavily vehicle dominated Dixon Street. Removing the parking spaces along the southern edge or the park gave an extra 1.8 metres to work with on the horizontal plane within the site. Removing one car park outside of the entrance to Eva Street allowed for a more formal extrusion of the footpath toward the park. With this subtle extrusion and the removal of 10 car parks along the south side of the park the canvas was set to create an aesthetic continuity in street art between Eva Street and the channel of movement through site (see fig 5.16). 


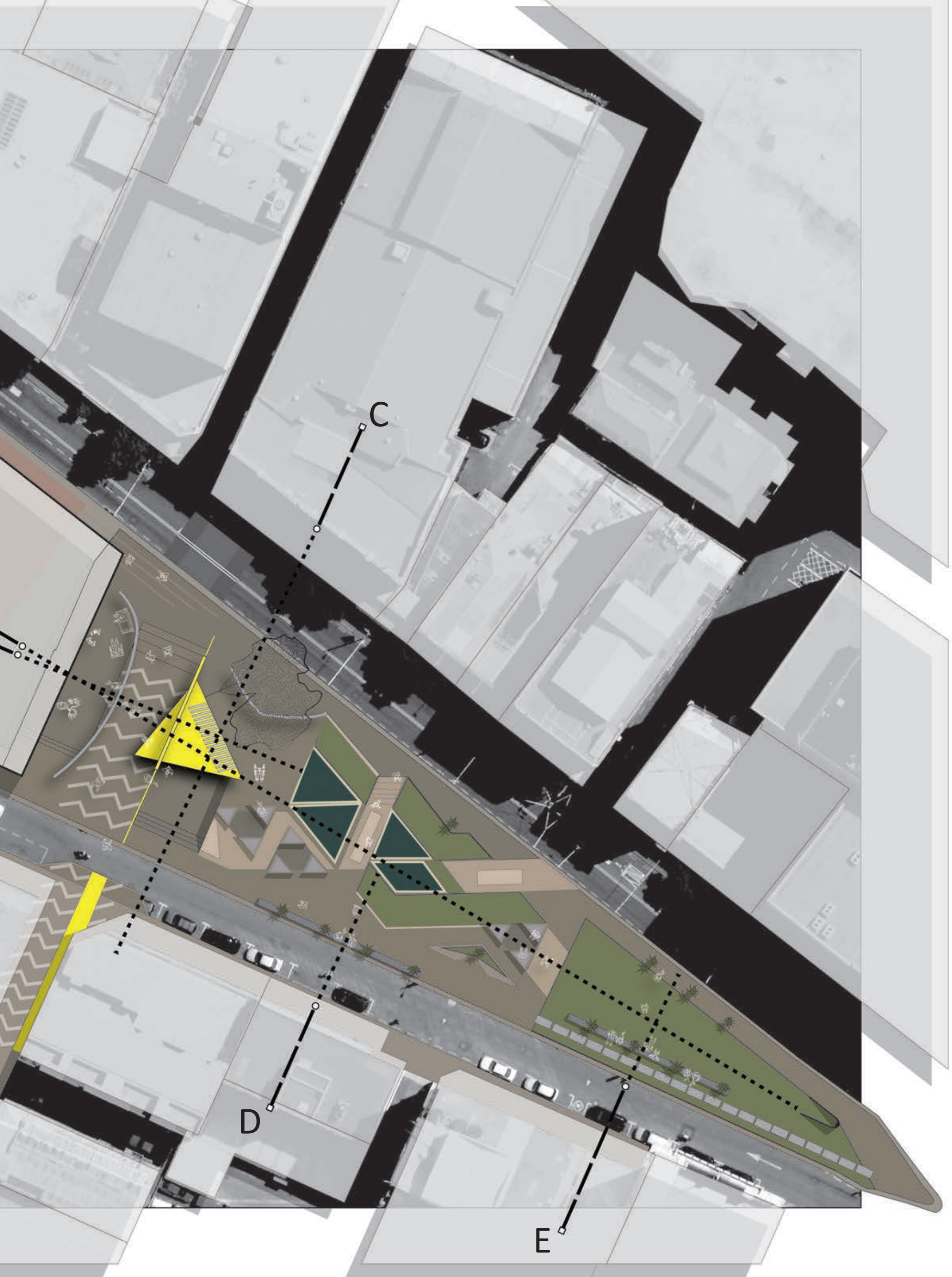




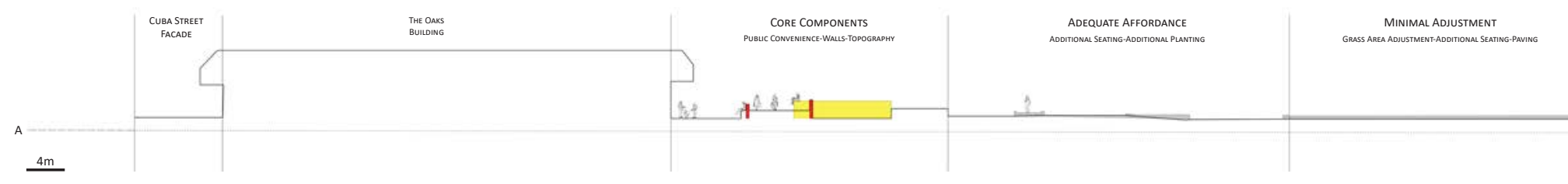

Fig. 5.19. (Above) Section Elevation running the length of the park. In yellow is the public convenience with the walls in red. Descriptions of changes in other zones are also present

Fig. 5.20. (Below) Section Elevation running the length of the Site.

B
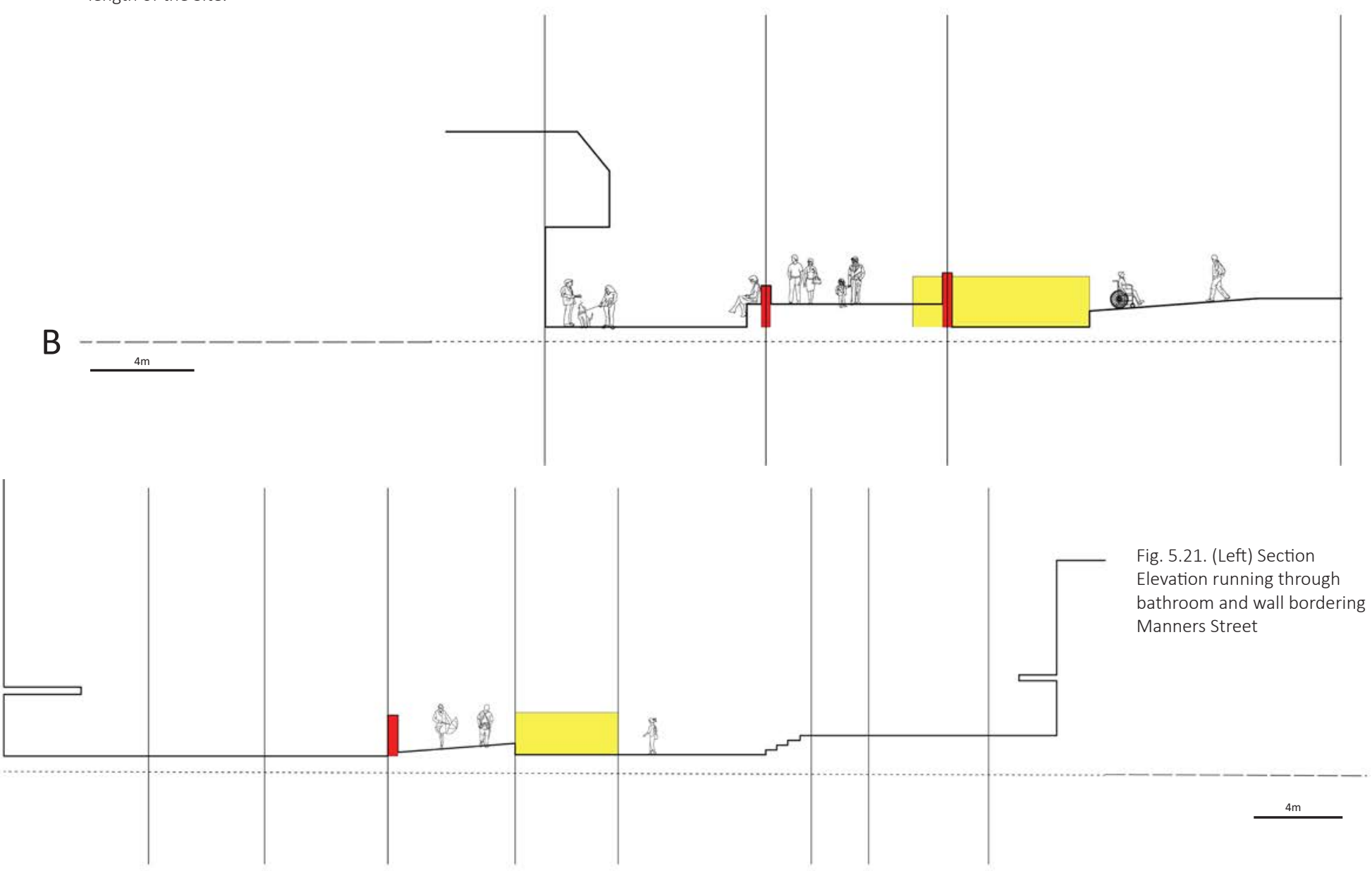

Fig. 5.22. Section Elevation running through Underutilised section of park 1.

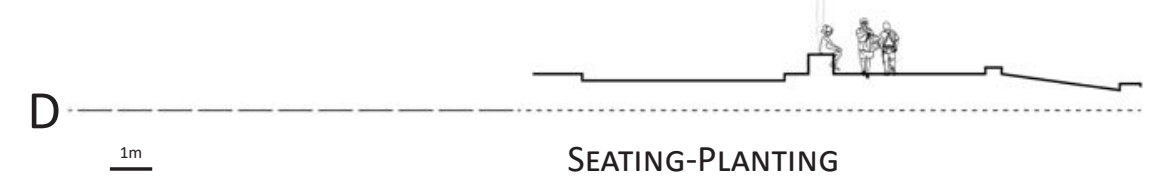

Fig. 5.23. Section Elevation running through Underutilised section of park 2 .

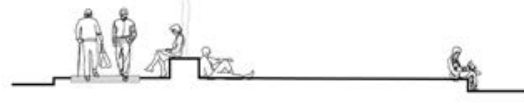

SEATING-PAVING-GRASS EXTENSION 


\subsection{Discovery Through Concept}

In putting together the final concept I started from the ground up. The placement of the bathroom was influenced by the height at which the central path of movement was adjusted to. The height of the 'walkway' accentuated the submersion of the bathroom allowing for at once the walker to see clear over the park and secondly the users of the bathroom to maintain discreet and dignified access to the bathroom well out of the way of traffic. The height difference also provided spaces out of traffic to wait for the bathrooms. The orientation of the bathroom was such that one of its edges allowed for slower traffic flow to gently enter the main flows of traffic. Part of the bathroom merges into the main thoroughfare allowing for a place to sit, lean and observe the happenings across the park. This was an advantage of leading the process with topographic augmentation.

By removing the parking along the north side of Dixon I was presented with an opportunity to add to the now widened footpath running along the southern border of the park. In the underutilised zone identified in site analysis mapping of zones I decided an extension of the grass area and basic concrete slab seating could increase affordance in this sunny space. This in turn could perhaps provide a neutral space for both the Marginalised and Mainstream to spread their commons beyond the original scope of the thoroughfare (see fig 5.22, 5.23 and 5.24).

A point of opportunity for future testing in Te Aro Park.

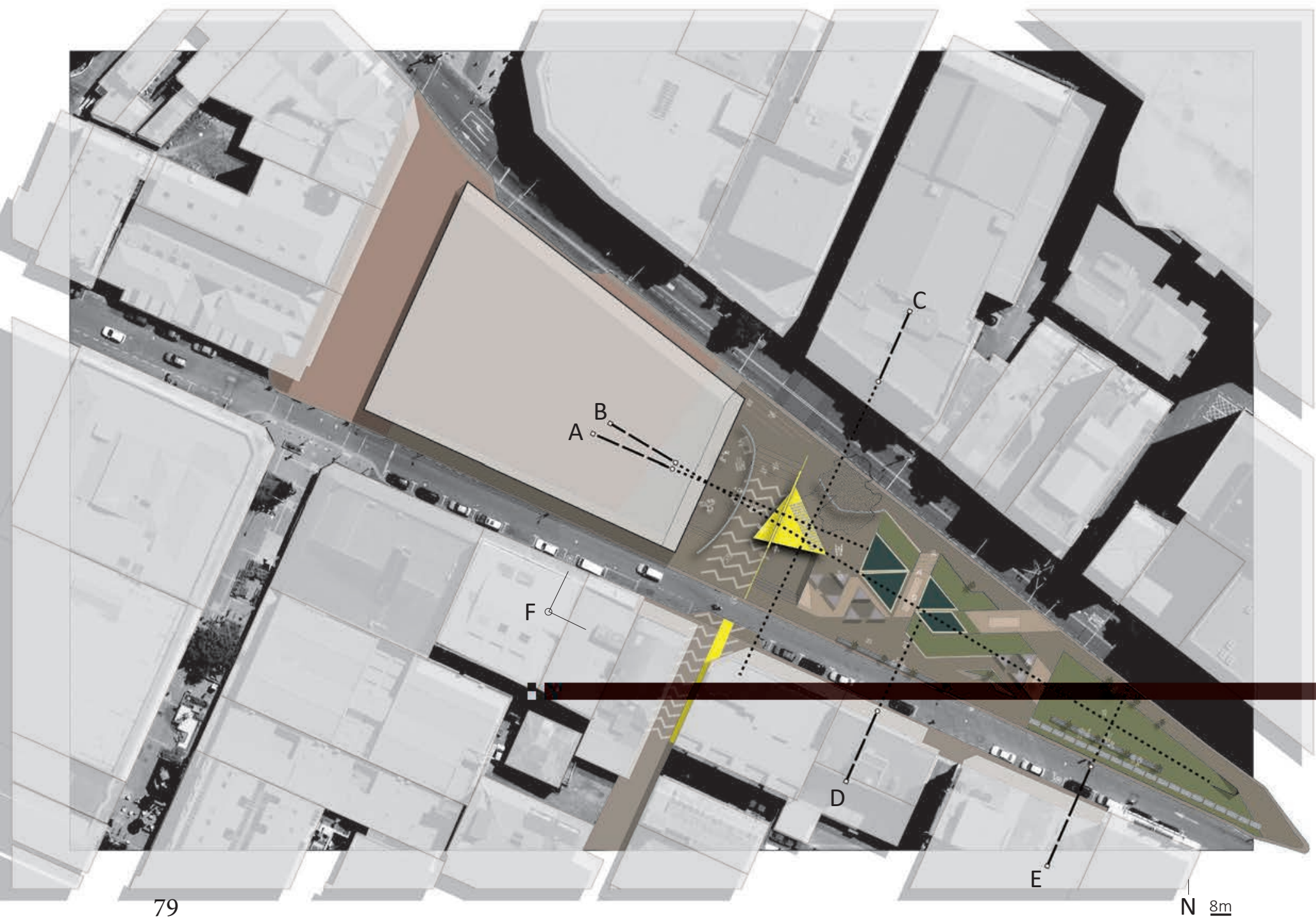



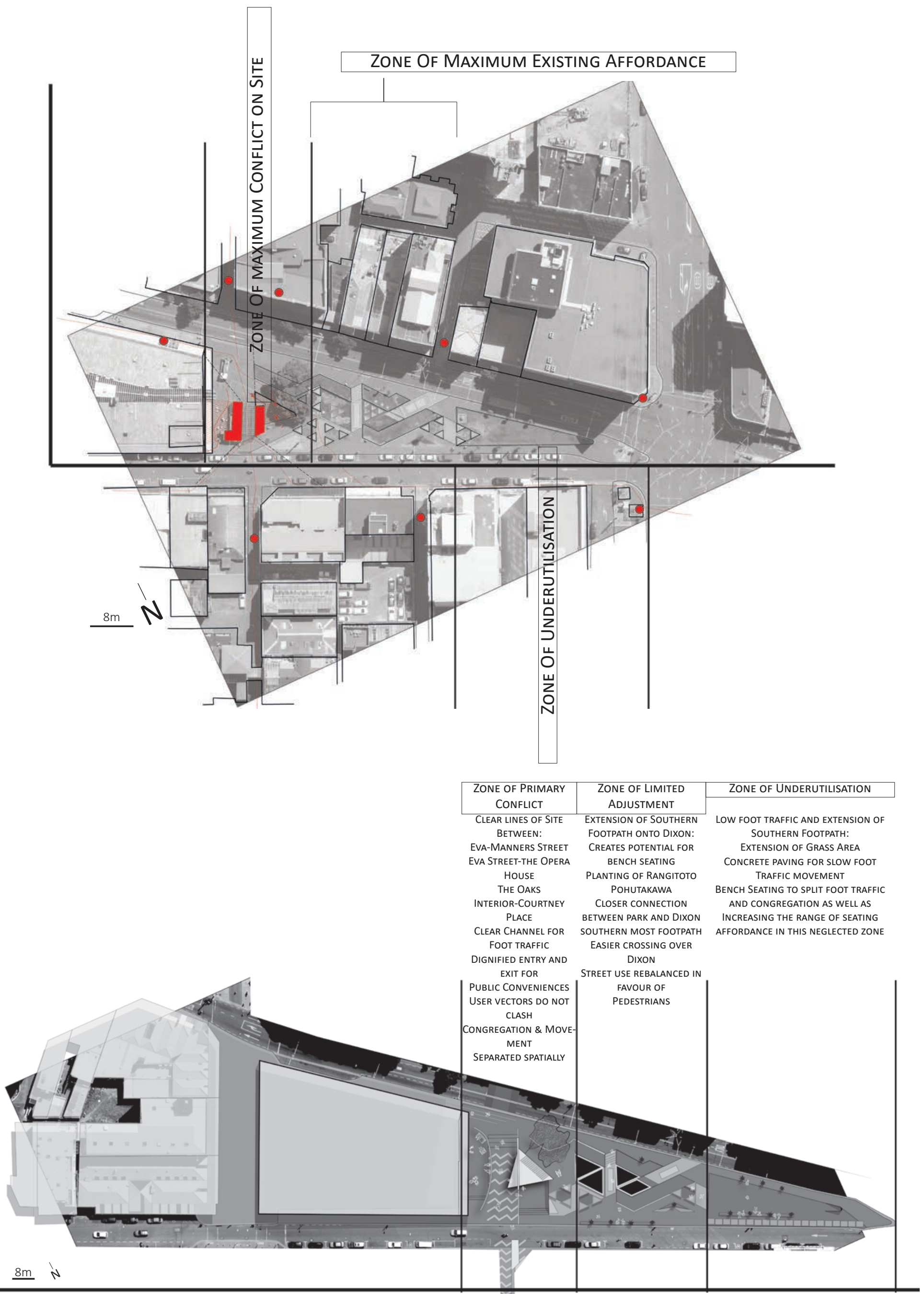


\subsection{Final Concept and Reflection}

Leading the second concept design with topographic augmentation has made all the difference to how the site comes together to both maintain the Marginalised occupation while also adding the Mainstream walker to the site. At first glance elevation of the thoroughfare alone separates the spaces of congregation and movement physically. With the addition of a wall system bordering this channel the physical separation gives a clearer purpose to each space.

The height at which each wall system sits in relation to the elevated channel also allows for visual exposure between the two cohorts while allowing them both to use the site for their purposes, instead of competing for space (see fig 5.19 and 5.20).

The elevation of the walkway and supporting wall systems provides opportunity for both the Mainstream and the Marginalised. The Mainstream who may have been closed off or completely avoided the park have a full view of the happenings in the space with unobstructed sightliness in all directions. This not only exposes them in a non threatening way to the Marginalised, it also presents the entire space and its opportunities.

The difference in elevation means that the walls are higher toward the Marginalised areas of occupation. This provides significant space for defacement and localisation. The thoroughfare for the Mainstream has lower walls letting them see the park as a whole as well as at first observing and then joining the more entrenched Marginalised either side of the thoroughfare.

For the Marginalised the fluctuating elevation in combination with the walls allows them to congregate without the interference of the Mainstream mover while still being visually connected to the wider site. Some visual connection is maintained but is not a priority for the Marginalised occupier who is already familiar with the site and its affordances. While the thresholds for entering the site as a whole have been bled into the surrounding area through continuity testing, the spaces where the Marginalised occupy still maintain a significant threshold of narrow entry and exit points. This means that the Mainstream (uninitiated) user faces a diluted and therefore less intimidating threshold to moving into an area of reversed hierarchy, will be exposed to the happenings of the Marginalised and then have the option of entering the more significant threshold into the Marginalised space. This staggered and leveled intensity of threshold has been discovered as a tool during the concept phase rather than during the individual component testing stage.

The bathroom is in view of the public for safety through passive surveillance yet it does not obstruct sightliness over or within the park. Using a bright colour that is a 'nod' to the colours on Eva Street increases way finding ability for those unfamiliar looking for a restroom. The main functioning (entering/exiting and waiting) of the public convenience is discreet as the entry sits low and out of the way of the main channel. The Public convenience is easy to find, can be monitored passively while being dignified and more private to use.

Fig. 5.25.(Top Left) Original Analysis of Site broken down into zones.

Fig. 5.26.(Bottom Left) Reflection on Final Concept Plan. 


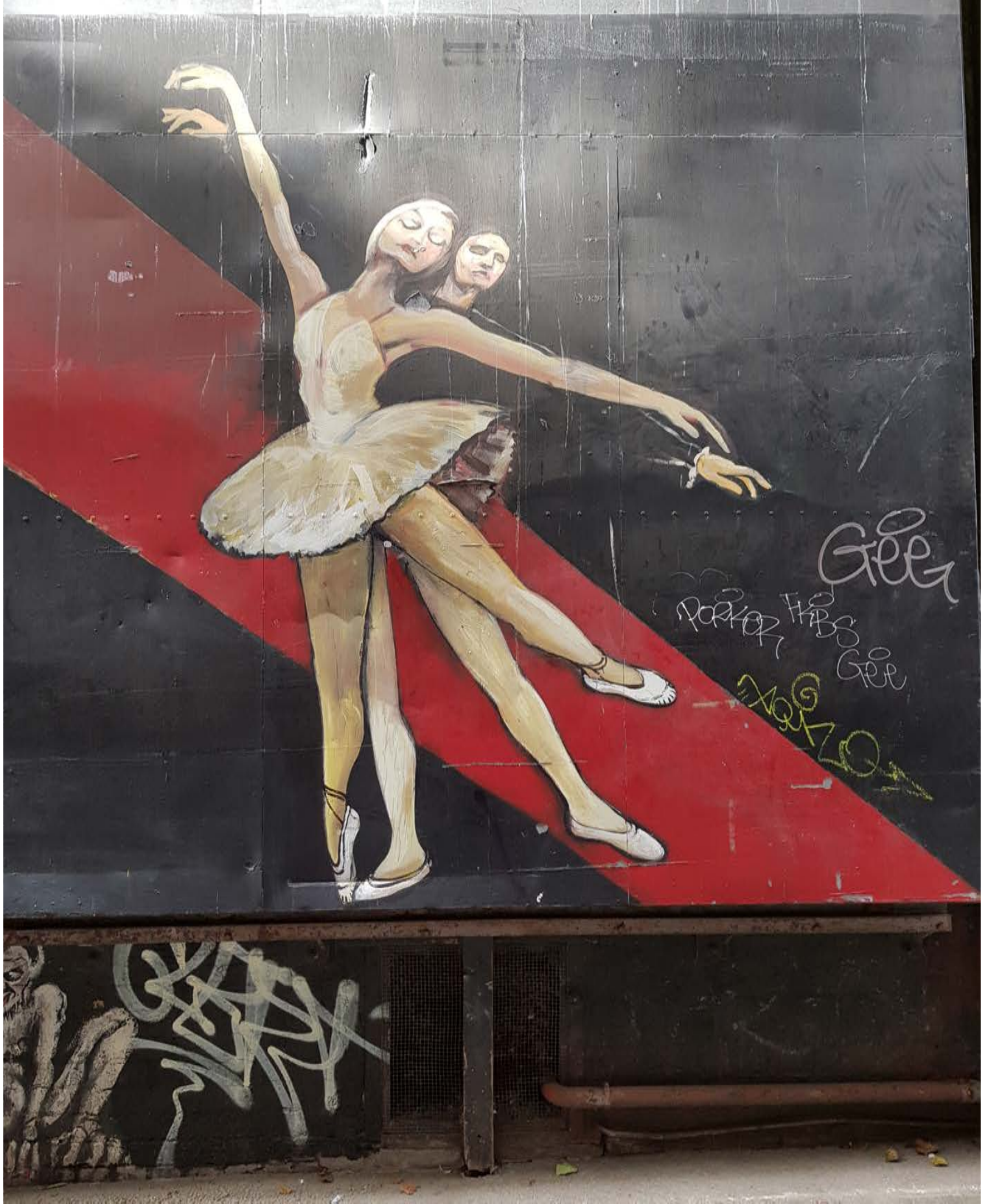

Fig. 6.01. Beautiful defacement within Opera House Lane.

Chapter 6

Critical Reflection and Conclusion 


\subsection{Critical Reflection}

This design-led research suggests that subtle and restrained landscape design augmentations may offer a catalytic solution to this described tension in public space. This suggestion I believe has been verified to an extent. I have shown that through restrained reorganisation and iterative component testing that a space can maintain character and social hierarchies unique to said space while introducing new actors in a way that may catalyse future integration and understanding between Marginalised and Mainstream cohorts. The reorganisation and augmentation of components achieved this through visual exposure between cohorts in combination with threshold breakdown and rebuild.

The extent to which this catalytic solution was achieved may have stopped short of being proven to work as by the very nature of the commoning discourse used. It would require a development of the social and physical site to be forecast accurately. This medium term forecasting was not undertaken in this research and so a significant part of the success of my research outcomes may be left unproven.

In contrast to the limits to proven in the mid to long term, there has been evidence of successful application of restrained design on creating conditions for commoning as a means for reducing social tension. Opportunities for further research have also been presented through this works design testing.

The vital use of Petrescu mapping techniques and the discoveries through the addition of photographic mapping techniques have enabled me to critically assess and respond to my own component augmentation studies. Additionally the usefulness of photographic studies has lead me to create testing conditions in which I can again use photographic exploration and overlays to better and more efficiently understand the potentials in each iteration (physically modeling the topographic study). In this way the tools themselves used for site analysis have lead me to discover the importance of more interactive mediums for testing and reflection. This could have and could be, taken further if variations in other key components were modeled in the same fashion. 
The discovery of threshold variation both welcoming and initiatory was essential for justifying speculative success in my final concept. Without staggering the severity of thresholds in the space I believe there would be a risk of losing the commons that were in existence outside of Memphis Belle and to the immediate east of the thoroughfare. Separating physically without separating visually was one important role of the wall study. Creating specific points of entry into the park and then secondary points into the areas of commoning.

Although the aesthetic continuity study was a complementary design research move to the more fundamental moves I investigated, it was seen as effective to the point where entry into the park could have lost its initiation phase. This risk was balanced with the walls and topographic augmentations. Threshold variation could have been investigated further in and of its own stage. Perhaps this would have been best explored after the wall testing and continuity studies separately. This was another focus that i believe could be investigated further. Limited by time and scope there were many factors within threshold studies that I would have liked to address. One would be the categorisation or hierarchy for threshold typologies directly related to commoning and the effectiveness of establishing/maintaining the commons. A threshold study of this nature could inform further design testing in relation to how far one could alter a space with existing commoning for greater inclusion while maintaining the commons.

The public convenience testing brought an insight into blending public amenities into the site without dominating it. My research through design was limited in terms of function and form. This in itself meant that there was limited ground made on rethinking a public bathroom as a structure in isolation but significant understanding made of how an amenity can maintain its intended use while better fitting with the sites other components. From this I could have applied this same study to other amenities that were initially dominating a landscape but whose function could be better made a component of a site rather than the focal point. This broadly could be applied to a range of public spaces that needed to be re purposed while maintaining important public infrastructure. 


\subsection{Conclusion}

This project has presented a way in which landscape architecture design can be used to critically assess, seek and develop potentials for harmony of urban spaces exhibiting spatial and social conflicts between Marginalised and Mainstream citizens.

It achieved this through investigation of slope as a means to create social spatial transition and congregation space.

It investigated the role of the public convenience and for it, sought alternative relationships in public landscapes.

And a redesign was achieved of the visual and textural aspects of pathways in the public landscape, to improve walk-ability.

To support these moves, Petrescu mapping and the adaptations of this mapping through photographic studies have opened a new way of analysing components and users on sight as well as the speculative success or failure of component combination testing.

Topographic augmentation has been highlighted as an enormously successful tool to lead a concept design and its place in the concept formation process shown to be best serving at the forefront of concept creation. This can been seen with the improvement in component integration in the Final Concept (lead by topographic augmentation) compared to the Initial Concept (lead by public convenience augmentation and placement).

Throughout this research it has been shown that public conveniences can maintain their important role in public space and as an essential amenity for the Marginalised while being a less dominant and dignified component of the commons. Through this research it has also been argued in reflection that a range of public amenities could be put through the same design iteration process. This argument however has not been verified through testing on other public amenities important to the Marginalised and therefore is at best a point of interest for future research.

The implications of this research are such that there may be an opportunity to achieve a design outcome that may bring the Mainstream into spaces of Marginalised occupation through less intrusive and destabilising measures compared to gentrification or regulation. 


\section{Works Cited}

Greenaway, P. (2009). Ladies and Gents: Public Toilets and Gender (Gershenson O. \& Penner B., Eds.). PHILADELPHIA: Temple University Press. Retrieved from http://www.jstor.org/stable/j. ctt14btdn9

Hiroshima Park Public Convenience. Future Studios, Hiroshima, 2009. Web http://www.futurestudio.jp/parkrestroom1215_e.htm

Oriental Bay Changing Sheds. Architecture Workshop, Isthmus \& Tonkin and Taylor 2006. Web https://www.nzia.co.nz/explore/image-gallery\#Oriental\%20Bay\%20Enhancement

Petrescu, D. (2007). The indeterminate mapping of the common. Field: A Free Journal of Architecture, 1(1), 88.

Stavrides, S. (2016). Common space : The city as commons / Stavros Stavrides. (In common (London, England)). 


\section{Figure List}

NOTE: All figures not attributed are author's own.

Figure. 2.02. Hiroshima Park Public Convenience. Future Studios, Hiroshima, 2009. Web http:// www.futurestudio.jp/parkrestroom1215_e.htm

Fig. 2.03. Oriental Bay Changing Sheds. Architecture Workshop, Isthmus \& Tonkin and Taylor 2006. Web https://www.nzia.co.nz/explore/image-gallery\#Oriental\%20Bay\%20Enhancement

Figure. 4.07. Hiroshima Park Public Convenience. Future Studios, Hiroshima, 2009. Web http:// www.futurestudio.jp/parkrestroom1215_e.htm

Figure. 4.08. Oriental Bay Changing Sheds. Architecture Workshop, Isthmus \& Tonkin and Taylor 2006. Web https://www.nzia.co.nz/explore/image-gallery\#Oriental\%20Bay\%20Enhancement 


\section{Bibliography}

Anderson, B. (2006) Becoming and being hopeful: towards a theory of affect. Environment and Planning D: Society and Space, 24, 733-752.

Colette (2014). Shipwrecked on a traffic island : and other previously untranslated gems. Retrieved from https://ebookcentral.proquest.com

Dudding, M. (2011). Making Porridge Pancakes. Retrieved from http://architecture.org. nz/2011/06/24/making-porridge-pancakes-te-aro-park-2/

July, 2018

Ewing, R., \& Handy, S. (2009). Measuring the unmeasurable: Urban design qualities related to walkability. Journal of Urban design, 14(1), 65-84.

Greed, C. (2003). Inclusive urban design : Public toilets / Clara Greed. Boston, MA: Architectural Press.

Greenaway, P. (2009). Ladies and Gents: Public Toilets and Gender (Gershenson O. \& Penner B., Eds.). PHILADELPHIA: Temple University Press. Retrieved from http://www.jstor.org/stable/j. ctt14btdn9

Hans, L., \& Stefan, B. (2003). Opening Spaces: Design as Landscape Architecture.

Hiroshima Park Public Convenience. Future Studios, Hiroshima, 2009. Web http://www.futurestudio.jp/parkrestroom1215_e.htm

Menzies, E. (2007) Retrieved from http://www.nzta.govt.nz/assets/projects/wicb/resources/pdf/ Te-Aro-History.pdf June, 2018

Molotch, H., \& Norén, L. (Eds.). (2010). Toilet: Public Restrooms and the Politics of Sharing. NYU Press. Retrieved from http://www.jstor.org/stable/j.ctt9qfpkj

Oles, T. (2015). Walls: enclosure and ethics in the modern landscape. University of Chicago Press.

Oriental Bay Changing Sheds. Architecture Workshop, Isthmus \& Tonkin and Taylor 2006. Web https://www.nzia.co.nz/explore/image-gallery\#Oriental\%20Bay\%20Enhancement

Petrescu, D. (2007). The indeterminate mapping of the common. Field: A Free Journal of Architecture, $1(1), 88$.

Robinson, D. A. (1997). Eliminating Architecture: The Public Toilet in Wellington:[submitted as Partial Fulfilment of a Bachelor of Architecture Degree, Victoria University of Wellington] (Doctoral dissertation, Victoria University of Wellington).

Rudder, C. (2014). Dataclysm: Who we are (when we think no one's looking). Random House Canada.

Stamps III, A. E. (2005). Enclosure and safety in urbanscapes. Environment and Behavior, 37(1), 102-133.

Stavrides, S. (2016). Common space : The city as commons / Stavros Stavrides. (In common (London, England)). 